\title{
THE POTENTIAL OF RAMAN SPECTROSCOPY AS A MONITORING TOOL FOR THERMAL THERAPY
}

\author{
by \\ Matthew Rodrigues \\ B.Sc. (Hons.), Laurentian University, Sudbury, ON, Canada, 2006
}

\author{
A thesis \\ presented to Ryerson University \\ in partial fulfillment of the \\ requirements for the degree of \\ Master of Science \\ in the Program of \\ Biomedical Physics \\ Toronto, Ontario, Canada 2008 \\ (C) Matthew Rodrigues 2008
}




\section{Author's Declaration}

I hereby declare that I am the sole author of this thesis. I authorize Ryerson University to lend this thesis to other institutions of individuals for the purpose of scholarly research.

\section{MATTHEW RODRIGUES}

I further authorized Ryerson University to reproduce this thesis by photocopying or by other means, in total or in part, at the request of other institutions or individuals for the purposes of scholarly research.

\section{MATTHEW RODRIGUES}




\title{
The Potential of Raman Spectroscopy as a Monitoring Tool for Thermal Therapy
}

\author{
Matthew Rodrigues \\ B.Sc. (Hons) \\ M.Sc. Biomedical Physics, Department of Physics, Ryerson University, 2008
}

\begin{abstract}
Laser Interstitial Thermal Therapy (LITT) is a minimally invasive technique for treating localized solid tumors through heating with light. LITT is not routinely employed in a clinical setting due to difficulties in real-time monitoring of tissue heating. This work investigates the feasibility of Raman Spectroscopy (RS) to monitor thermal therapies. RS has the ability to detect changes in the secondary structure of proteins, and may prove useful as an indicator of tissue coagulation in real-time during thermal therapy. Tissue equivalent albumen phantoms were heated in a water bath and bovine muscle samples were heated in a water bath and through laser photocoagulation. Raman spectra were acquired after heating and increases in the overall Raman intensity and shifts in major band locations were observed after heating. Correlations between Raman intensity and thermal dose were also observed. These results indicate that RS may be employable as a real-time monitoring tool for LITT.
\end{abstract}




\section{Acknowledgements}

Special thanks to my supervisor Dr. William Whelan. Despite being in Prince Edward Island through most of my thesis, our conversations over the phone and internet were always insightful and gave me the motivation to keep going and to keep everything in life in perspective. Thank you for your constant mentorship, words of wisdom, encouragement and praise.

To my co-supervisor, Dr. Robert Weersink (Princess Margaret Hospital). I always enjoyed our discussions on Raman and research in general. Your suggestions, words of advice and willingness to lend a hand with problems kept me positive and motivated.

I would like to thank Dr. Vladislav Toronov for being a member of my supervisory committee, our chair Dr. Pedro Goldman for his encouragement and support, and all of the other staff and faculty in the department. Thanks to George Netchev (Princess Margaret Hospital) for showing me how to use the Raman system, and for putting up with all my questions. Thanks also to Dr. Eduardo Galiano (Laurentian University) and Dr. Jean-Philippe Pignol (Sunnybrook Health Sciences Center) for their mentorship and support.

Thanks to Robin Castelino and Omar Falou for their help with the Matlab programs used in this thesis and for keeping the lab environment humorous and relaxed. Thanks to Eli Lechtman, Ahmed El Kaffas, Nazanin Nayebi, Rachel Guha and all of the other graduate students for the scientific discussions, Youtube videos and the games of ping-pong when we just couldn't do anymore physics.

Thank you to all of my friends and family members for your continual love and support through the easy times and the difficult times. Thanks mom for everything, especially the soup, lasagna and everything else we took from the house. If dad were here, he'd be proud.

Last but certainly not least, to my wife Tanya. This thesis, and everything else, would never have been possible without your continued love, support and encouragement. I'll never forget your patience and understanding through the tough times. All my love, forever. 


\section{Table of Contents}

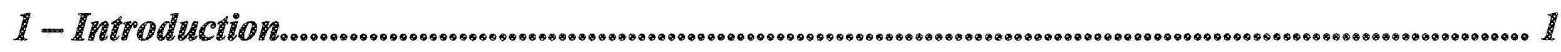

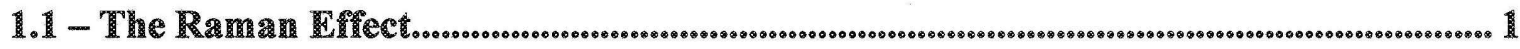

1.2 - Near Infrared (NIR) Raman Spectroscopy............................................................................... 6

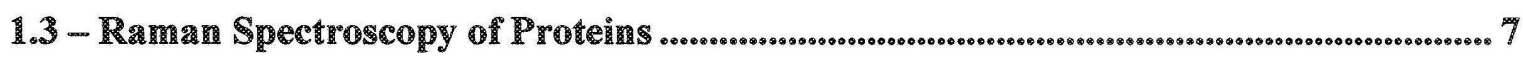

1.3.1 - Albumen Protein ................................................................................................................

1.3.2 - Collagen Protein ......................................................................................................... 10

1.4 - Raman Spectroscopy in Medicine

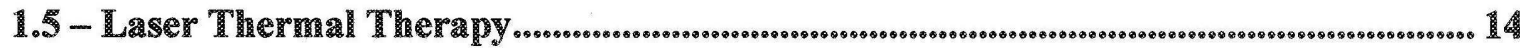

1.6 - Interaction of Laser Light with Tỉssue...............................................s................................ 14

1.7 - Biological Effects of Laser Heating............................................................................... 15

1.8 - Thermal Dose Determination in Thermal Therapy ........................................................ 17

1.9 - Current Monitoring Techniques for LITT ........................................................................ 18

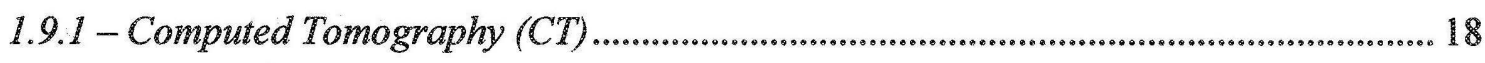

1.9.2 - Magnetic Resonance Imaging (MRI) .................................................................................... 18

1.9 .3 - Ultrasound (US) .............................................................................................................. 19

1.9 .4 - Point Monitoring ..................................................................................................................... 19

1.10 - Experimental and Clinical Applications of LITT ....................................s.................. 21

1.11 - Thesis Organization and Objectives ................................................................................... 23

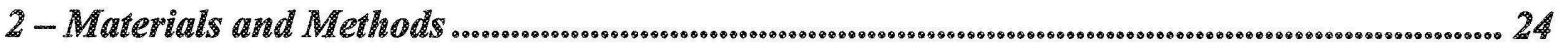

2.1 - The Raman System............................................................................................................. 24

2.1.1-System Overview .................................................................................................... 24

2.1.2 - The Excitation Lasers ............................................................................................................ 25

2.1.3 - Photon Collection and Detection Components ......................................................... 25

2.2 - Raman Spectral Analysis ...................................................................................................... 28

2.2 .1 - Pixel to Wovenumber Conversion ............................................................................. 29

2.2.2 - Detector Responsivity Correction ..................................................................................... 32 


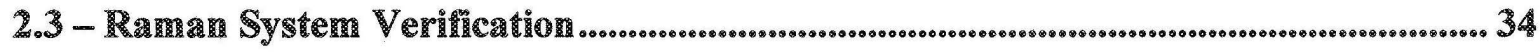

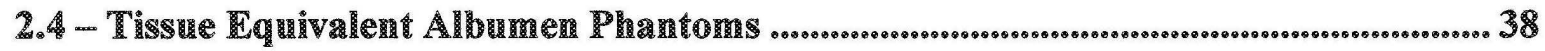

2.5 -Water Bath Heating of Bovine Muscle

2.6- Laser Photocoagulation of Bovine Muscle

2.7-Monte Carlo Simulations of Photon Migration in Tissue.s.........................................42

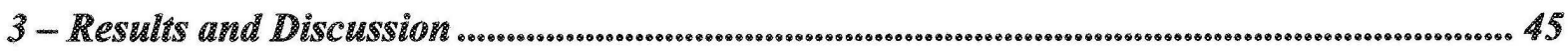

3.1 - Tissue Equi๋

3.2 - Water Bath Heating of Bovine Muscle

3.3 - Laser Photocoagulation of Bovine Muscle ............

3.4-Monte Carlo Simulations of Photon Migration in Tissue.......................................... 68

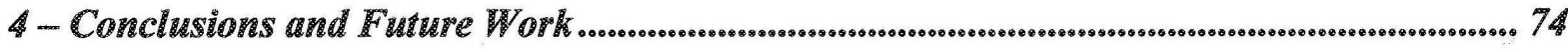

4. 1 - COHCW

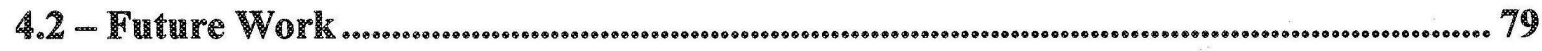

S- Apperd dix .

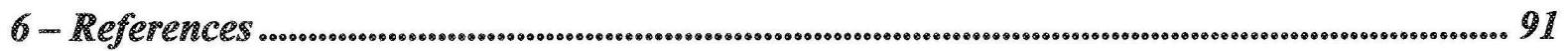




\section{List of Tables}

Table 2-1 - The muscle sample, thermocouple location and maxintum temperature recorded by each thermocouple.

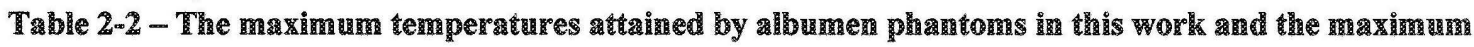
temperat

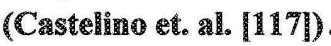

Table 3-1 - The target temperature at which each phantom was removed from the water bath, 嗞axinam temperature attained at the center of the phantom, and the therrinal dose in equivalent min

Table 3-2-Locations of three najor Raman bands arising from the albumen protein. The Dands at $1002 \mathrm{~cm}^{-1}$ and $1463 \mathrm{~cm}^{-1}$ appear unafeeted by heating however, the Amide 1 -helix shifis from $1658 \mathrm{~cm}^{-1}$ to $1663 \mathrm{~cm}^{-1}$ upor heating to $75^{\circ} \mathrm{C}$

Table 3-3-The maximum temperature attained by each phantom and the corresponding thermal dose valnes

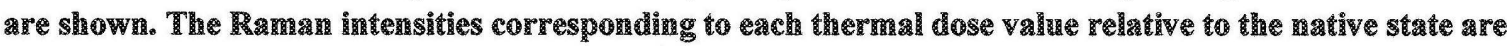
shown for bamds near 1002,1463 and $1663 \mathrm{~cm}^{-1}$. The average Raman intensity at each temperature is also shown

Table 3-4 - The muscle sample, maximum temperature recorded by the thermocouple near the edge of the

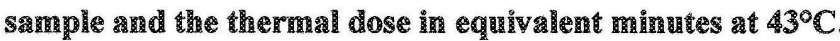

Table 3-5 - Locations of the major Raman bands, specidic to collagen, arising from bovine muscle samples. All

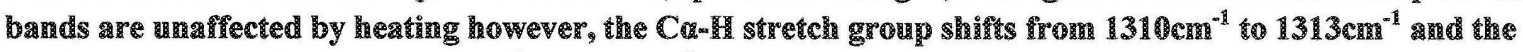
Amide 1 - helix shif

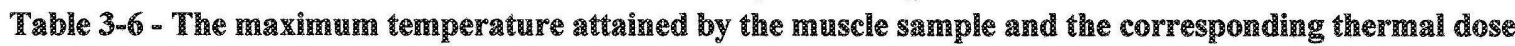
Values are show. The Raman intensities corresponding state (norkalized to 1) are shown for bands near 1000,1446 and $1655 \mathrm{~cm}^{-1}$

Table 3-7 - The therrinocounle location, maxing thermal dose in equivalent minutes at $43^{\circ} \mathrm{C}$

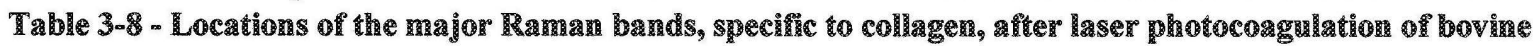
muscle. Shifting in a mumber of bamds is moted apon heating the tissue to $90^{\circ} \mathrm{C}$

Table 3-9 - The maximum temperature recorded by exch therrinocouple and the corresponding thermal dose values are shown. The Raman intensities corresponding to each thermal dose valne relative to the zative state (normalized to 1) are shown for bands near $1000,1317,1448$ and $1655 \mathrm{cmi}^{-1}$

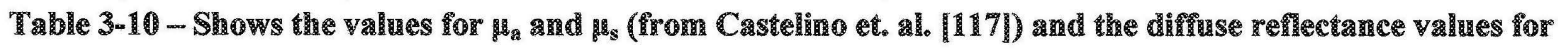
each sinuulation rusp using the Monte Carlo Maplet.

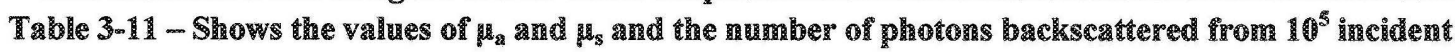
photons 


\section{List of Figures}

Figure 1-1 - Rayleigh and Raman scattering processes. With Stokes scattering, the wavelength of the scattered light is shifted towards longer wavelengths and with anti-Stokes scattering the scattered light is shifted towards shorter waveleagths.

Figure 1-2 - Plot of the relative intensities of the (i) Stokes, (ii) Rayleigh and (iii) anti-Stokes scattering processes for an arbitrary vibrational mode frequency. .3

Figure 1-3 - Spring and ball models of the three possible vibrational modes of a $\mathrm{H}_{2} \mathrm{O}$ molecule[ [5]. ..................5

Figure 1-4 - (a) Raman spectrum of unheated albumen protein, (b) Raman spectrum of albumen protein kheated to $90^{\circ} \mathrm{C}$ ior 30 minutes [17].

Figure 1-5 - Raman spectra of collagen and lamina propria adapted from De Jong et. al. [19].

Figure 1-6 - Raman spectra of collagen I fiber (A) at $80^{\circ} \mathrm{C}$, (B) at $20^{\circ} \mathrm{C}$ and (C) at $-100^{\circ} \mathrm{C}$. Adapted from Dong et. 2l. [23].

Figure 1-7 - Cross section of a typical circular thermal lesion indicating the different regions of observable thermal damage

Figure 2-1 - Overview of the Raman System. ..................................................................................................................24

Figure 2-2 - The spectrograph utilizes a holographic grating, notch filter, and NIR anti-reflective coated leases to produce high optical transmission [10]. . .27

Figure 2-4 - Raman spectrum of a tooth sample [98]. Peaks due to cosmic ray interference are shown by asterisks.

Figure 2-5 - Raman spectrum of Tylenol(3) used for calibration. The peak-finding portion of the program is rased to identify peak locations.

Figure 2-6 - (a) Pixel values and wavenumbers for Tylenol (B) (b) Plot of wavenumbers versus pixel values and the quadratic equation of the line of best fit.

Figure 2-7 - (a) Collected Raman spectrum of sulfur indicating the two major bands resolvable by the system.

(b) Raman spectrum of sulfur from Pasteris et. al. [110].

Figure 2-8 - (a) Collected Raman spectrum of polystyrene indicating the major bands. (b) Raman spectrum of polystyrene from McCreery et. al. 1111 .

Figure 2-9- Experimental setup used for water bath heating of bovine muscle samples. One thermocouple is placed near the edge of the sample and another is placed approximately in the center of the sample........... 41

Figure 2-10 - Experimental setup for laser photocoagulation of bovine muscle. Thermocouple temperature sensors were placed at $2 \mathrm{~mm}, 5 \mathrm{~mm}$ and $10 \mathrm{~mm}$ from the laser fiber .42

Figure 3-1 - Time-temperature histories for albumen phantoms heated to target temperatures of $45^{\circ} \mathrm{C}, 5^{\circ}{ }^{\circ} \mathrm{C}$, $65^{\circ} \mathrm{C}$ and $75^{\circ} \mathrm{C}$ in a water bath maintained at $75^{\circ} \mathrm{C}$.

Figure 3-2 - Tissue-mimicking albumen phantoms heated to $45,55,65$ and $75^{\circ} \mathrm{C}$. Each phantom was cut in half and Raman spectra were acquired at the center.

Figure 3-3 - Raman spectra of albumen phantoms at room temperature, and heated in a $75^{\circ} \mathrm{C}$ water bath to $45,55,65$ and $75^{\circ} \mathrm{C}$.

Figure 3-4 - Raman spectra of a phantom without albumen protein. Components include water, bacteriological agar and naphthol green dye.

Figure 3-5 - Relationship between the relative Raman intensity and the logarithm of thermal dose for bands near 1002,1463 and $1663 \mathrm{~cm}^{-1}$.

Figure 3-6- Tovine muscle samples heated to $45^{\circ} \mathrm{C}, 55^{\circ} \mathrm{C}, 65^{\circ} \mathrm{C}$ and $75^{\circ} \mathrm{C}$ in a water bath. .............................52

Figure 3-7 - Time-temperature histories for bovine muscle samples heated to target temperatures of $45^{\circ} \mathrm{C}$, $55^{\circ} \mathrm{C}, 65^{\circ} \mathrm{C}$ and $75^{\circ} \mathrm{C}$.

Figure 3-8 - Raman spectrum of bovine muscle with major bands arising from collagen labeled. 
Figure 3-9 - Raman spectra of bovine muscle heated in a water bath to target temperatures of $45^{\circ} \mathrm{C}, 55^{\circ} \mathrm{C}$,

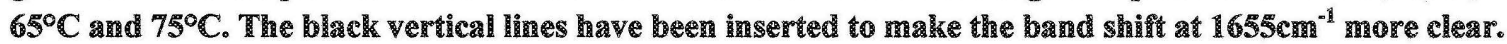

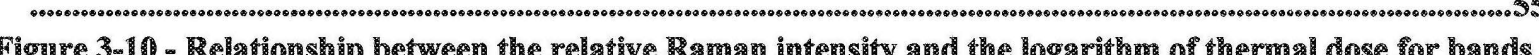

Figure 3-10 - Relationship between the relative Iaman intensity and the logarionthn of thermal dose for band near 1000,1446 and $1655 \mathrm{~cm}^{-1}$.

Figgire 3-11 - Time temperature histories for laser photocoagulation of bovine muscle measured at 10man, 5nm and $2 \mathrm{~mm}$ from the laser

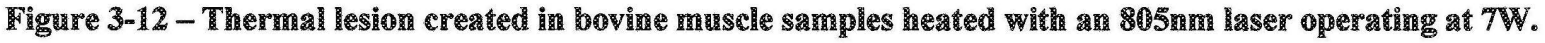
Indentations by the laser fiber and three thermocouples are indicated.

Figure 3-13- Raman spectra of bovine muscle in the native state and heated by laser photocoagulation.

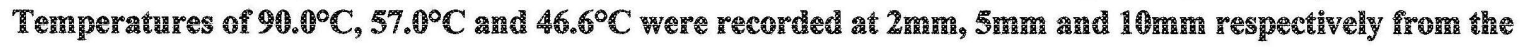
laser fiber. Raman spectra were collected at these locations.

Figure 3-14 - Relationship between the relative Raman intensity and the logarithm of thermal dose for bamds near $1000,1317,1448$ and $1655 \mathrm{~mm}^{-1}$.

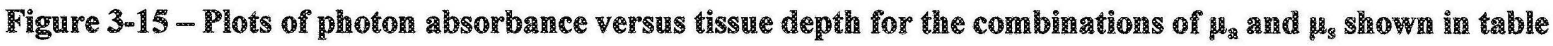
$3-10$.

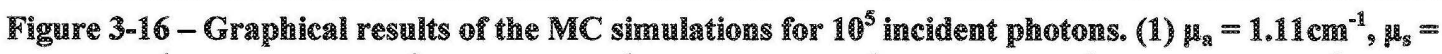
$10.35 \mathrm{~cm}^{-1},(2) \mu_{\mathrm{a}}=1.20 \mathrm{~cm}^{-1}, \mu_{\mathrm{s}}=23.01 \mathrm{~cm}^{-1},(3) \mu_{\mathrm{a}}=1.22 \mathrm{~cm}^{-1}, \mu_{\mathrm{s}}=40.44 \mathrm{~cm}^{-1},(4) \mu_{\mathrm{B}}=1.36 \mathrm{~cm}^{-1}, \mu_{8}=126.0 \mathrm{~cm}^{-1}$ atd (5) $\mathrm{gs}_{\mathrm{s}}=1.60 \mathrm{~cm}^{-1}, \mathrm{~ms}_{\mathrm{s}}=170.77 \mathrm{~cm}^{-1}$. 


\section{1 - Introduction}

\section{1-The Raman Effect}

Scattering of photons by atoms or molecules occurs through either elastic or inelastic scattering. During elastic scattering, the incident energy of a photon remains the same; a process known as Rayleigh scattering (Figure 1-1). Conversely, during inelastic scattering the energy and therefore wavelength of the incident photon changes; a process known as Raman Scattering. Raman scattering is an inherently weak process, occurring once in approximately $10^{7}$ photon interactions [1]. When incident photons interact with a molecule, the electron cloud around the nucleus becomes polarized and forms a "virtual state". This is an unstable, short-lived state so the incident photon is almost immediately re-irradiated. For a particular vibration in the Raman effect, one of two possible scattering events can take place; Stokes scattering or anti-Stokes scattering [2]. Stokes scattering occurs when an incident photon interacting with a molecule in a low energy state transfers some of its energy to the molecule leaving the molecule in an excited vibrational state $n$ of higher energy as seen in figure 1-1. On the other hand, some molecules may already be in an excited energy state due to thermal energy. A photon interacting with such a molecule will gain energy, leaving the molecule in a lower energy state as shown in figure 1-1. This process is known as anti-Stokes scattering [2]. 


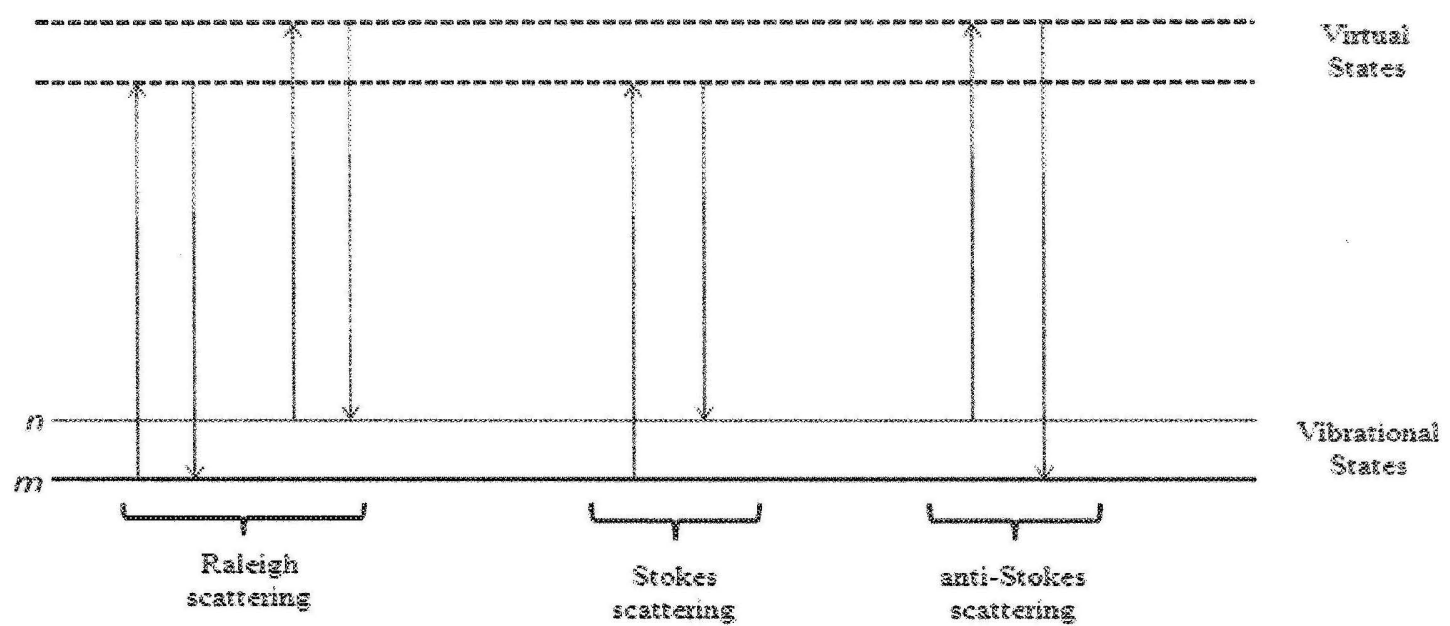

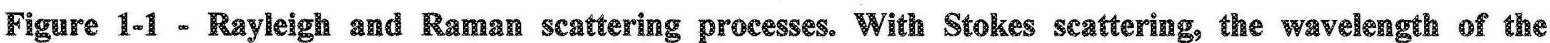

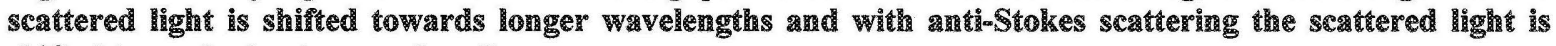

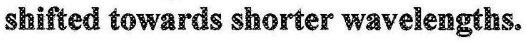

Usually, at room temperature, most molecules are found in the ground state which makes the anti-Stokes scattering weak in comparison to Stokes scattering. Also, as the frequency of vibration of the molecules increases, the population of the excited state decreases and the antiStokes scattering becomes even weaker. However, as the temperature of a sample increases, the probability of finding molecules in an excited vibrational state increases, and thus the anti-Stokes scattering becomes stronger as seen in figure 1-2. Rayleigh scattering is approximately 3 to 9 orders of magnitude more intense than Stokes scattering and 6 to 12 orders of magnitude more intense than anti-Stokes scattering [3]. 


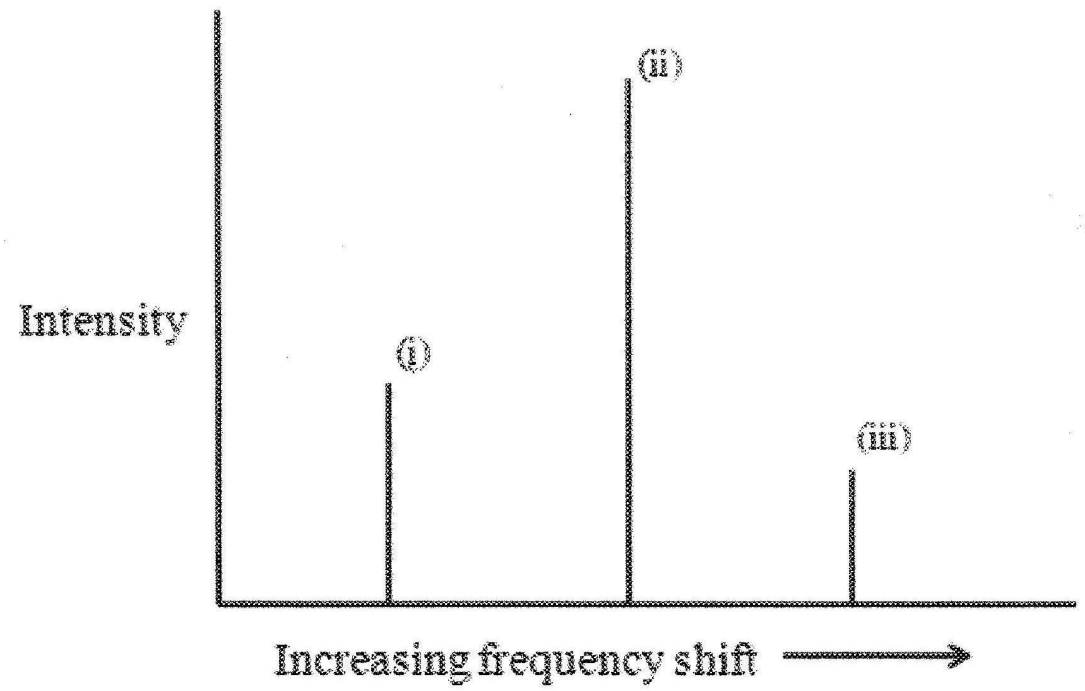

Figure 1-2 - Tlot of the relative intensities of hihe (i) Stokes, (ii) Rayleigh and (iii) anti-Stokes scattering processes for an arbittrary vibrational mode requency.

In order to describe the Raman effect, classical electromagnetic (EM) theory must be discussed. The electric field of the incident light is given by

$$
\vec{E}=\vec{E}_{o} \cos (2 \pi v t)
$$

which induces a dipole moment in a molecule that is proportional to the electric field.

$$
\vec{P}=\alpha \vec{E}
$$

$\alpha$ is the polarizability of the molecule, which is a measure of the ease of distorting the electron cloud surrounding the molecule and varies as a function of the distance between the nucleus and the electron cloud [4]. As previously discussed, Raman scattering occurs due to a change in the polarizability of the molecule which can be described by the polarizability derivative $\frac{\partial \alpha}{\partial Q}$ where $Q$ is the molecular vibrational mode given by 


$$
Q=Q_{o} \cos \left(2 \pi v_{v} t\right)
$$

Here, $Q_{o}$ represents the maximum vibrational amplitude and $v_{v}$ representing a particular vibrational frequency. If 1.3 equals zero, there will be no Raman event since the intensity of the Raman scattering is proportional to the square of the polarizability differential;

$$
I \alpha\left(\frac{\partial \alpha}{\partial Q}\right)^{2}
$$

Thus, the intensity of the Raman scattering depends directly on the polarizability of the molecule. In order for a molecule to exhibit Raman activity, there must be a change in the polarizability of the molecule resulting from a change in the shape of the electron cloud surrounding each bond. These changes are referred to as selection rules [2]. The translation and rotation of the molecule can be described by the vibrational degrees of freedom (D.O.F.); 3 for translation and 3 for rotation. For a linear molecule, the number of D.O.F. are given by $3 \mathrm{~N}-5$ and for all other molecules by $3 \mathrm{~N}-6$, where $\mathrm{N}$ is the number of atoms in the molecule. For example, if one examines gaseous Oxygen $(\mathrm{O}-\mathrm{O})$, when a simple stretch of the molecule occurs altering the polarizability, a band will appear in the Raman spectrum as a result. For a triatomic molecule with 3 degrees of freedom such as water $\left(\mathrm{H}_{2} \mathrm{O}\right)$, there is now the possibility for three modes of vibration; symmetrical stretch, asymmetrical stretch and bending (deformation). Figure 1-3 illustrates these different modes of vibration using the spring and ball model for $\mathrm{H}_{2} \mathrm{O}$ [2].

The observed Raman shift resulting from these events is the difference between the energies of the incident photons and scattered photons calculated using equation 1.5 


$$
\bar{v}=\frac{1}{\lambda_{\text {incident }}}-\frac{1}{\lambda_{\text {scautered }}}
$$

where $\bar{F}$ is the Raman shift measured in units of inverse length, usually $\mathrm{cm}^{-1}, \lambda_{\text {incident }}$ is the wavelength of the incident photon and $\lambda_{\text {scattered }}$ is the wavelength of the scattered photon. When dealing with triatomic molecules, a symmetrical stretch causes large Raman scattering due to large polarization changes, but causes a very subtle and therefore weak change in the dipole moment that exists between the molecules. The bending vibration does cause a substantial change in the dipole moment, but causes little change in the polarization which results in very weak Raman scattering [2].

Symmetric Stretch
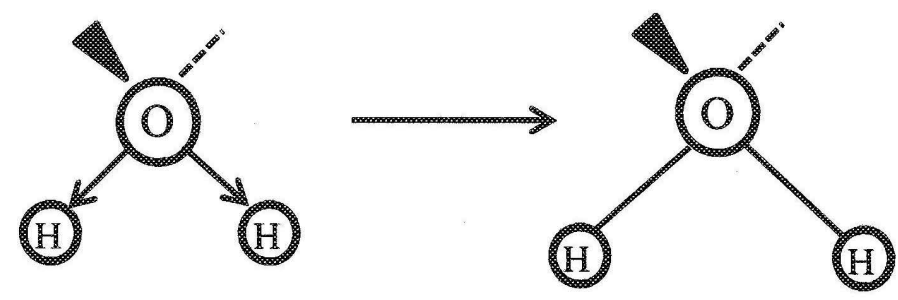

Asymmetric Stretch
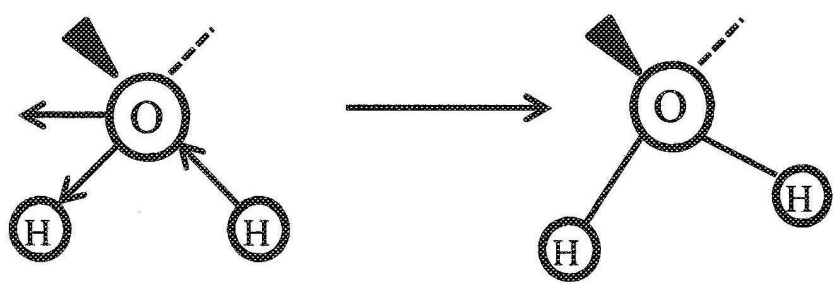

Bending
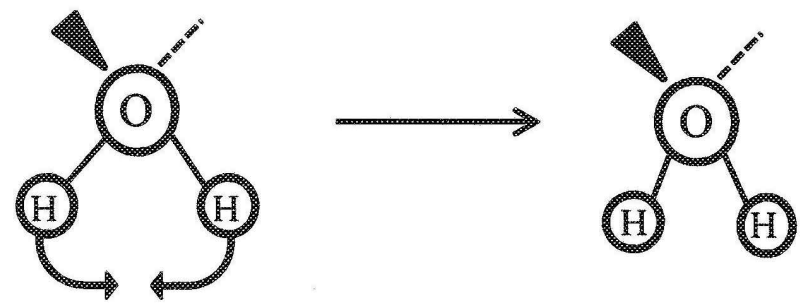

Figure 1-3 - Spring and ball models of the three possible vibrational modes of a $\mathrm{H}_{2} \mathrm{O}$ molecule[5]. 


\section{2 - Near Infrared (NIR) Raman Spectroscopy}

The first reported Raman spectrum of any biological material using a laser as the excitation source was published by Lord and Yu in 1970 at the MIT Spectroscopy Laboratory [6]. Employing a He-Ne gas laser operating at $633 \mathrm{~nm}$ as the excitation source, the first interpretable Raman spectrum was obtained from lysozome. Since then, the use of near-infrared light has prevailed as the method of choice for interrogating samples due to the advantage of deeper tissue penetration and the reduction of autofluorescence.

The early 1980's saw the introduction of Fourier-Transform Raman Spectroscopy (FTRS) and the use of Neodymium-doped Yttrium Aluminum Garnet (Nd:YAG) lasers operating at $1064 \mathrm{~nm}$ as and excitation source. Indium gallium arsenide (InGaAs) or Germanium (Ge) detectors were used with a wavelength of $1064 \mathrm{~nm}$ due to their high spectral range above $1000 \mathrm{~nm}$. The main advantage of the use of a $1064 \mathrm{~nm}$ excitation wavelength is the reduction of background fluorescence from the sample. Using this technology, Hirschfeld and Chase [7] showed that Raman spectra could be obtained from certain materials previously overpowered by fluorescence. However, while many InGaAs detectors have been shown to produce acceptable signal-to-noise ratios (SNR's), they do exhibit enough noise to degrade the quality of the Raman spectrum. Thus, unfavourably long collection times must be employed to compensate for this loss [8].

The most commonly used Raman systems now couple a diode laser as the excitation source (operating between $750-850 \mathrm{~nm}$ ) to a liquid nitrogen cooled charge coupled device (CCD) for detection. The development of these systems was seen as a major breakthrough in RS, resulting in a number of clinical applications [9]. Typically, the excitation laser light is passed through a holographic bandpass filter to remove unwanted fluorescence from the laser source, 
and then delivered through fiber optics into the sample [10]. In some cases, the delivery fiber can be surrounded by a ring of collection fibers in a hexagonal or octagonal arrangement, depending on the application [10-12]. The collected light is then passed through a spectrograph usually equipped with a notch filter to remove any collected photons at the excitation wavelength. The spectrograph collimates and focuses the collected light sometimes using curved mirrors as in the Czemzy-Turner design [10] and sometimes using converging lenses [9]. The collected light is then detected using liquid nitrogen cooled $\mathrm{CCD}$. If the $\mathrm{CCD}$ is not cooled to $\sim 90^{\circ} \mathrm{C}$, the collection efficiency of the $\mathrm{CCD}$ is compromised due to an increase in dark noise which results in a low SNR. Using a CCD detector and two turnkey diode lasers operating at $782 \mathrm{~nm}$ and $830 \mathrm{~nm}$, Wang and McCreery [13] were able to obtain Raman spectra with high SNR for samples such as nylon and Rhodamine-6G which are by their nature, highly fluorescent. RS at $785 \mathrm{~nm}$ is ideal since background fluorescence can be largely avoided but the Raman signal is still significant enough to be detected with a $\mathrm{CCD}$. However, this was not possible until recently, due to the lack of availability of equipment necessary for Raman applications. The Invictus NIR laser operating at $785 \mathrm{~nm}$ was developed by Kaiser specifically for fiber based RS [14]. Since then, a number of lasers from many different companies have been developed and RS at $785 \mathrm{~nm}$ is now possible in many laboratories.

\section{3 - Raman Spectroscopy of Proteins}

Proteins are a sequence of amino acids (AA's) linked together in a linear fashion, joined by peptide bonds between the amino $(\mathrm{N})$ and carboxyl $(\mathrm{C})$ terminals of adjacent $\mathrm{AA}$ residues [15]. All proteins have four levels of structural organization: primary $\left(1^{\circ}\right)$, secondary $\left(2^{\circ}\right)$, tertiary $\left(3^{\circ}\right)$ and quatemary $\left(4^{\circ}\right) .1^{\circ}$ structure refers to the linear order of AA residues along the 
polypeptide chain arising from covalent linkage of $\mathrm{AA}$ 's through peptide bonds between the $\mathrm{C}$ and $\mathrm{N}$ terminals. This $1^{\circ}$ structure leads to $2^{\circ}$ structure, which is the local conformation of the AA's that are close together in the $1^{\circ}$ sequence. Three basic types of $2^{\circ}$ structure exist, namely the $\alpha$-helix, $\beta$-strand and turns from which all other variations are generated [15]. RS can be employed to determine the type of $2^{\circ}$ structures present within a particular protein [5]. The $3^{\circ}$ structure of a protein refers to a folded polypeptide chain. This folding arises from the linkage of secondary structures forming a compact globular molecule. In particular, disulphide bridges form strong covalent links between cysteine side chains. Disulphide bridges are very stable and are only broken as a result of extremely high temperatures, acidic $\mathrm{pH}$ or in the presence of reducing agents in reduction-oxidation chemical reactions. $4^{\circ}$ structure refers to the link between polypeptide chains through disulphide bridges and hydrogen bonding among others, forming a subunit $[5,15]$. Protein denaturation is defined as a conformational change in the $2^{\circ}$ and $3^{\circ}$ structures of the native protein without cleavage of peptide bonds within the amino acid sequence. Depending on conditions, partial or complete, as well as reversible or irreversible denaturation can be observed due to factors such as temperature, $\mathrm{pH}$ changes and pressure [15].

The Amide I and III $\alpha$-helix $2^{\circ}$ structures can be easily identified through RS. The Amide I band $\left(\sim 1645-1660 \mathrm{~cm}^{-1}\right)$ typically arises from $\mathrm{C}=\mathrm{O}$ stretching vibrations of the peptide group with a small contribution from the N-H in-plane bending. The amide III band $\left(-1260-1310 \mathrm{~cm}^{-1}\right)$ arises from a combination of $\mathrm{N}-\mathrm{H}$ bending and $\mathrm{C}-\mathrm{N}$ stretching of the peptide group. Vibrations from AA's can be classified into two groups: those originating from $\mathrm{CH}_{2} / \mathrm{CH}_{3}$ groups $(\sim 1440$ $\left.1455 \mathrm{~cm}^{-1}\right)$ and those originating from the aromatic ring structures such as phenylalanine $(\sim 1000$ $\left.1004 \mathrm{~cm}^{-1}\right)[5]$. The Amide I and III $\alpha$-helicies, $\mathrm{CH}_{2} / \mathrm{CH}_{3}$ and phenylalanine groups are 
responsible for major Raman bands in the albumen group of proteins and collagen, the two major proteins studied in this work.

\subsection{1-Albsmen Protein}

Raman spectra of albumen protein have been presented by a number of authors including Nagarize et. al. $[16,17]$. They reported Raman spectra of albumen protein dissolved in $\mathrm{D}_{2} \mathrm{O}$ unheated and heated to $90^{\circ} \mathrm{C}$ for 30 minutes as shown in figure $1-4$.
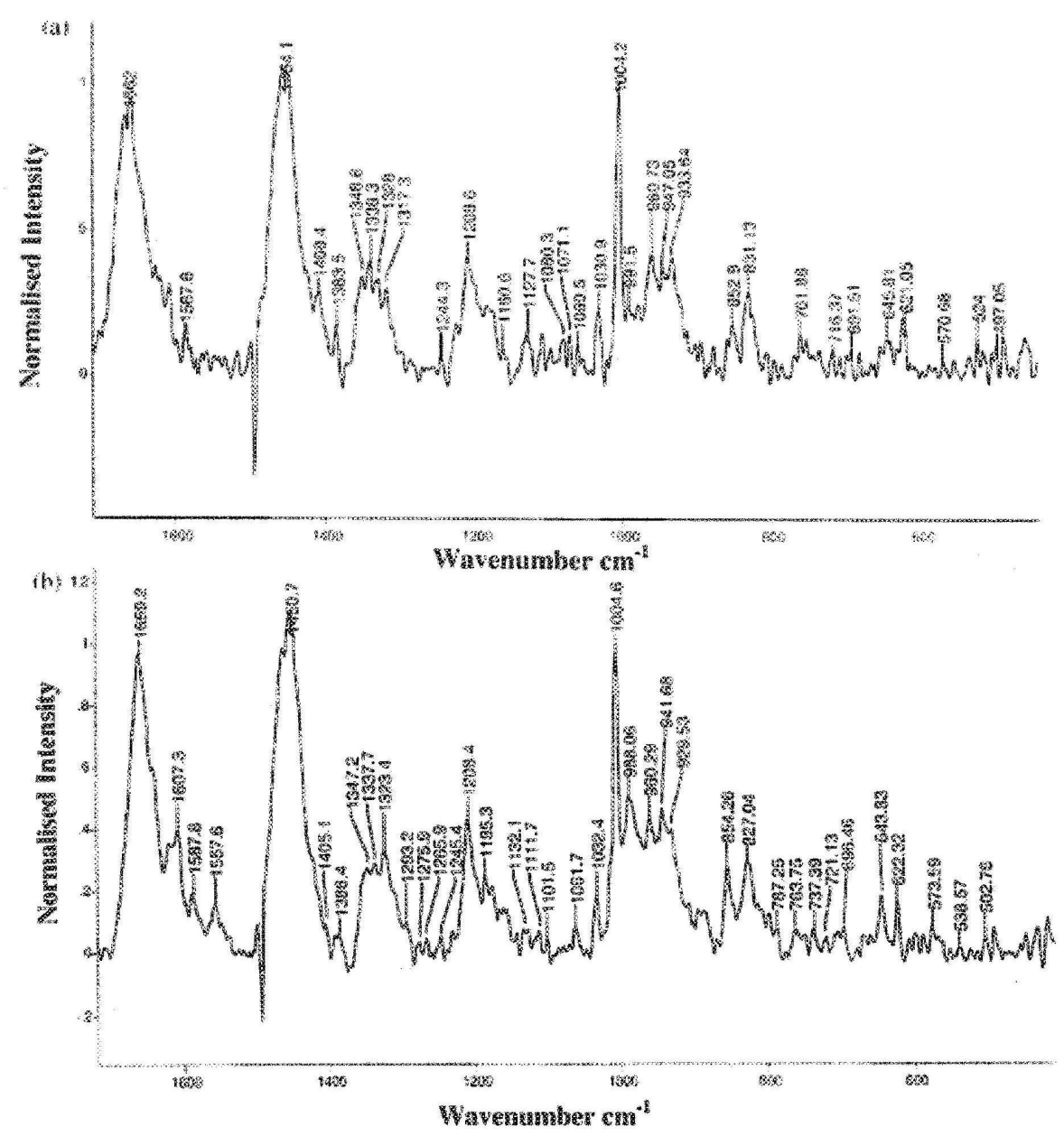

Figure 1-4 - (a) Raman spectrum of anheated albumen protein, (b) Raman spectrum of albumen protein heated 10 $90^{\circ} \mathrm{C}$ 10r 30 minutes[17]. 
The denaturation temperatures of ovalbumin and conalbumin, the two major constituents in albumen (54\% and $13 \%$ respectively) have been determined to be $84.5^{\circ} \mathrm{C}$ and $61.0^{\circ} \mathrm{C}$ respectively [18]. Upon heating albumen to $90^{\circ} \mathrm{C}$ for 30 minutes, Nagarize et. al. noted that the major Raman band from phenylalanine remained constant, shifting only from $1004.2 \mathrm{~cm}^{-1}$ to $1004.6 \mathrm{~cm}^{-1}$. However, a band shift from $1454.1 \mathrm{~cm}^{-1}$ to $1450.7 \mathrm{~cm}^{-1}$ in the $\mathrm{CH}_{2} / \mathrm{CH}_{3}$ group and a shift from $1662 \mathrm{~cm}^{-1}$ to $1659.2 \mathrm{~cm}^{-1}$ in the Amide I $a$-helix were observed. A slight intensity increase in these major bands between the native and heated states was also noted [17]. These band shifts are believed to be due to changes in the $2^{\circ}$ and $3^{\circ}$ structure of the albumen protein constituents as a result of thermal denaturation.

\subsection{2- Collogen Protein}

Collagen, specifically collagen 1 , is the most abundant protein in the human body comprising $25 \%$ of the whole-body protein content. It is a major component of skin, tendons, ligaments and tissues found in organs such as the breasts and bladder [15]. Its structure is that of a triple helix in which three similarly sized polypeptide chains $(\sim 1000 \mathrm{AA}$ 's in length $)$ twist around each other [15]. Raman spectra of collagen have been presented by a number of authors. De Jong et. al. [19] have illustrated the similarities between collagen and the lamina propria (figure 1-5), a constituent of the mucous membranes which line various tubes in the body such as those in the respiratory and gastrointestinal tract [20]. Similar to the Raman spectra of albumen, the major Raman bands in the collagen spectrum occur at $\sim 1000 \mathrm{~cm}^{-1}$ (phenylalanine), $\sim 1445 \mathrm{~cm}^{-1}$ $\left(\mathrm{CH}_{2} / \mathrm{CH}_{3}\right.$ group) and $\sim 1660 \mathrm{~cm}^{-1}$ (Amide I $\alpha$-helix). 


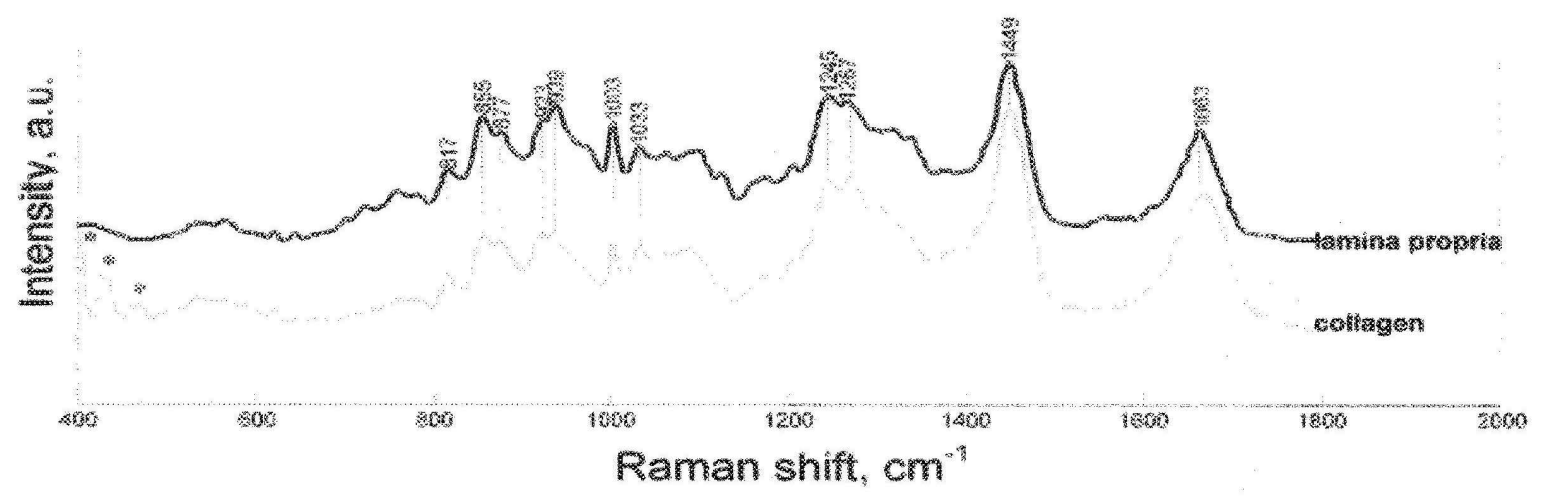

Figure 1-5 - Raman spectra of collagen and lamina propria adapted from De Jong et. al. [19].

Thermal denaturation causes the collagen fibrils to shrink resulting from a loss of water during the heating process. A number studies have attempted to determine the thermal denaturation temperature of collagen, and have estimated it to be somewhere in the range between $62.4^{\circ} \mathrm{C}$ and $67.0^{\circ} \mathrm{C}$ [21]. A recent study by Vyazovkin et. al. using a mixture of $10 \%$ by weight collagen I fiber and $90 \%$ by weight deionized water $(\mathrm{pH} \sim 7)$ determined that the irreversible denaturation temperature of collagen I fiber occurs as $\sim 63.0^{\circ} \mathrm{C}[22]$.

Raman spectra of collagen I fiber were acquired by Dong et. al. at $-100^{\circ} \mathrm{C}, 20^{\circ} \mathrm{C}$ and $80^{\circ} \mathrm{C}$ [23]. The phenylalanine band was located at $1003 \mathrm{~cm}^{-1}$ for temperatures of $-100^{\circ} \mathrm{C}$ and $20^{\circ} \mathrm{C}$, but shifted to $1002 \mathrm{~cm}^{-1}$ upon heating to $80^{\circ} \mathrm{C}$. The band arising from the $\mathrm{CH}_{2} / \mathrm{CH}_{3}$ group was located at $1447 \mathrm{~cm}^{-1}$ at $-100^{\circ} \mathrm{C}$, shifted to $1443 \mathrm{~cm}^{-1}$ at $20^{\circ} \mathrm{C}$ and shifted again to $1441 \mathrm{~cm}^{-1}$ upon heating to $80^{\circ} \mathrm{C}$. Also, the Raman band arising from the Amide I $\alpha$-helix shifted from $1660 \mathrm{~cm}^{-1}$ at $-100^{\circ} \mathrm{C}$, to $1655 \mathrm{~cm}^{-1}$ at $20^{\circ} \mathrm{C}$ and finally to $1652 \mathrm{~cm}^{-1}$ at $80^{\circ} \mathrm{C}$. 


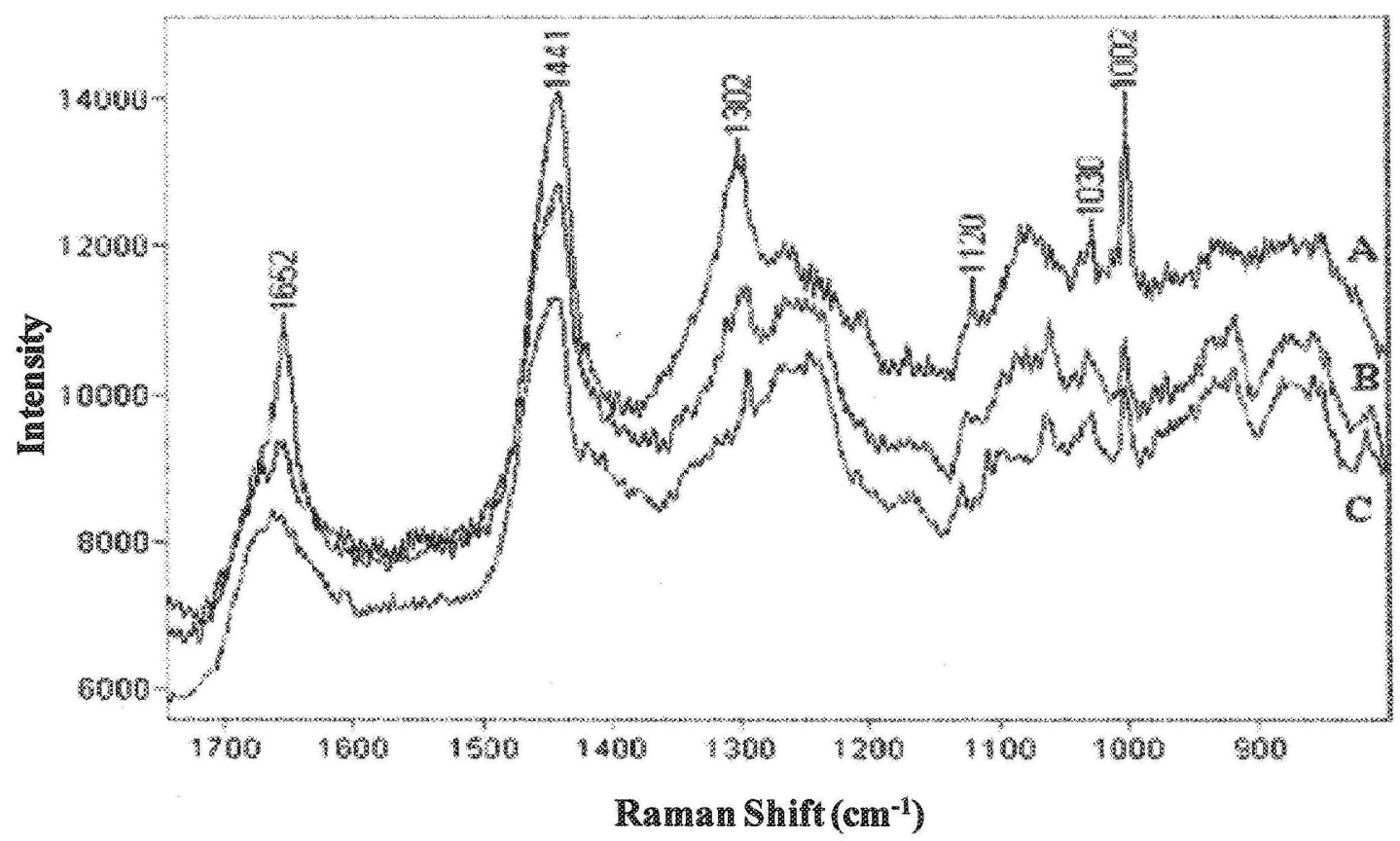

Figure 1-6-Raman spectra of collagen I fiber (A) at $80^{\circ} \mathrm{C}$, (B) at $20^{\circ} \mathrm{C}$ and $(\mathrm{C})$ at $-100^{\circ} \mathrm{C}$. Adapted from Dorgeg et. al[ [23].

As with the albumen group and many other proteins, the overall intensity changes and shifts seen in the Raman bands of collagen I are believed to be due to changes in the $2^{\circ} \mathrm{AA}$ conformation and the $3^{\circ}$ folding structure of the protein constituents as a result of denaturation caused by heating.

\section{4-Raman Spectroscopy in Medicine}

Over the last few decades, a number of investigators have used RS to evaluate many biomedical tissues with medical applications. Nie and collaborators used RS to investigate ocular lenses and calcified tissues. Using Raman spectra obtained from animal and human lenses, they were able to study a number of pathological processed such as protein glycation and cataract 
formation $[24,25]$. A number of studies on aortic tissues and human arteries to diagnose atherosclerosis have been published in the literature. Baraga and co-workers developed a method to quantitatively analyze the histochemical composition of human arterial and aortic tissues [2628]. Raman spectra have been reported for collagen fibers under strain [29], for use in identifying bladder wall layers which have different tissue construction [19] and characterization of living and dead lung epithelial cells [30]. A wide variety of Raman spectra have been obtained by Keller and collaborators to investigate the ability of RS to provide a component analysis for tissue identification. They also noted pathological changes in a number of human tissues, indicating that RS may be very useful as a diagnostic tool [31].

A number of studies have been published on the potential of using RS as a tool for diagnosing cancers. Raman spectra have been obtained to analyze lesions of human skin and stratum corneum [32-37]. Liu and collaborators used RS to distinguish between normal, benign and cancerous gynecological tract samples [38]. The possibility of diagnosing breast cancers in humans and animals by differentiating between normal, benign and malignant tissue has been investigated by a number of authors [9, 39-42]. RS has also been applied to the problem of diagnosing brain cancers $[31,43]$ and lung cancers $[44,45]$ by attempting to exploit the spectral differences between normal and cancerous human tissues. The issue of cancerous gastrointestinal polyps has been investigated by RS. Shim and Wilson developed an in vivo Raman spectroscopic system [10] which allowed them to acquire Raman spectra of human gastrointestinal tissues measured during routine clinical endoscopy [46]. Also, the diagnostic potential of RS in the colon was assessed by evaluating its ability to distinguish between adenomatous and hyperplastic polyps [47]. Finally, Feld and collaborators have published a 
number of studies in RS including work investigating breast cancer [48], atherosclerosis [49] and blood glucose measurements in vivo for the assessment of diabetes [50].

\section{5-Laser Thermal Therapy}

Laser interstitial thermal therapy (LITT) techniques have developed significantly over the last few decades, and it has been shown that interstitial laser heating can be used to effectively treat small, solid, isolated tumour masses. The main advantage of LITT is the ability to target tumour tissue while leaving surrounding viable tissue relatively undamaged. The first significant advancement for this application was outlined by Bown in 1983. He described a technique in which laser light was delivered through fibers which were placed into lesions of solid organs under image guidance [51]. To date, the most established clinical application of LITT is in the treatment of small, isolated hepatic tumours which are unsuitable for surgery [52].

Early in its history, LITT procedures were subject to many technical difficulties including the complexity of operating appropriate lasers for treatment and challenges in delivering the laser beam accurately to the desired area in the body. Although still considered experimental after two decades of advancement, LITT continues to show increasing promise and potential for clinical implementation.

\section{6-Interaction of Laser Light with Tissue}

In order to quantify the interaction between laser light and tissue, one must understand the characteristics of the incident laser light and the optical properties of the tissue sample being 
irradiated. Reflection, transmission, scattering and absorption all play a role in dictating how light will react when it enters a tissue sample. The two most important processes in laser therapy are scattering, which produces a fairly uniform distribution of energy within the tissue, and absorption, which produces the biological effects of laser therapy. The most important event in laser thermal therapy is the conversion of electromagnetic energy (light) into thermal energy (heat), which is dependent on the properties of the tissue and blood perfusion [53]. The choice of wavelength for LITT is highly dependent on the compromise between sufficient penetration depth of the laser light and sufficient absorption by the tissue. Therefore, the optimal wavelengths preferred for LITT are in the infrared range. For example, $805 \mathrm{~nm}$ produced by a semi-conductor diode laser or 1064nm from a Nd:YAG laser are two common wavelengths [54].

\section{7-Biological Effects of Laser Heating}

As the laser energy increases, the tissue being treated goes through a number of different stages which can be identified by their temperatures as well as microscopic pathologic alterations [55]. Hyperthermia occurs when the tissue reaches temperatures of approximately $43^{\circ} \mathrm{C}$ to $45^{\circ} \mathrm{C}$, and is maintained for a substantial period of time (30 to 60 minutes) $[56,57]$. At $50^{\circ} \mathrm{C}$ a reduction in enzyme activity is apparent. Thermal coagulation and protein denaturation occurs when tissues reach temperatures between approximately $60^{\circ} \mathrm{C}$ and $100^{\circ} \mathrm{C}$ [58-60]. Once tissue temperatures exceed $100^{\circ} \mathrm{C}$, tissue vaporization can occur [53]. Typical treatment times are on the order of a few minutes, since tissue temperatures can reach $100^{\circ} \mathrm{C}$ relatively quickly. The type of therapy chosen to treat a particular target is normally dependent on the intended outcome of the treatment. A cross section of a typical thermally induced lesion is shown in figure 1-4. 


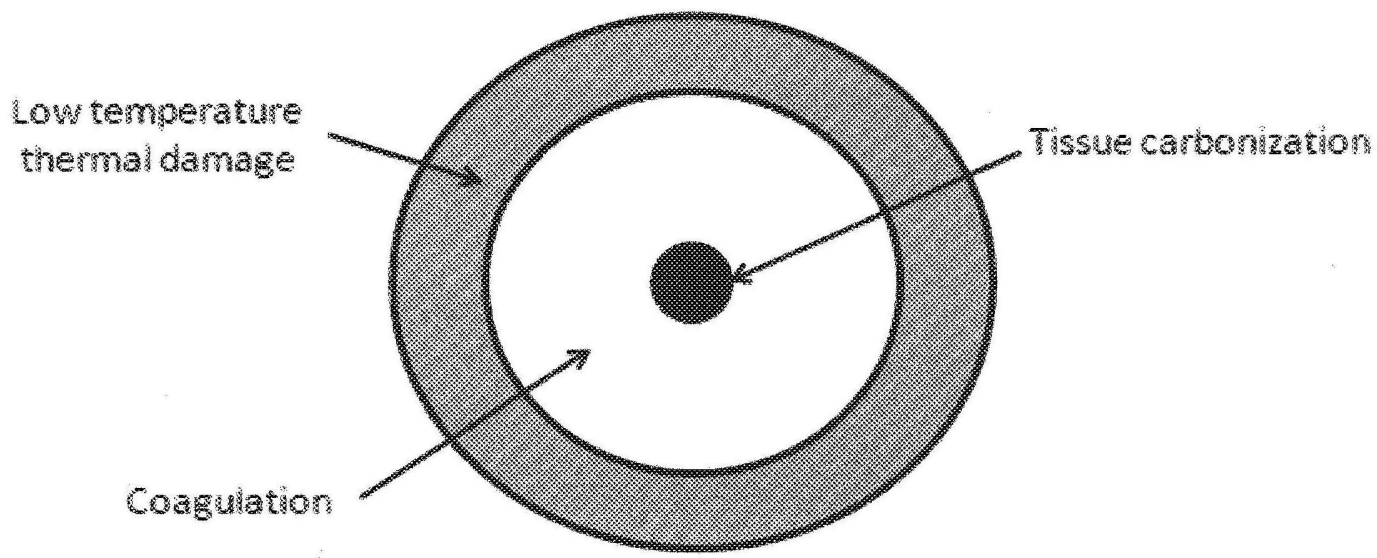

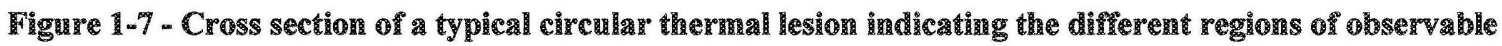
thermal damage.

The outermost (grey) area of the lesion in figure 1.7 is the area of low temperature thermal damage where temperatures can range from anywhere between $43^{\circ} \mathrm{C}$ to $60^{\circ} \mathrm{C}$. The effects of irradiation may not be visible immediately, but within a few hours, swelling caused by damage to the cellular and vascular cell membranes of living tissue can be observed. The middle region (white) of figure $1-7$ is known as the coagulation zone, with temperatures ranging anywhere from $60^{\circ} \mathrm{C}$ to $100^{\circ} \mathrm{C}$. In this region, a whitening of the tissue can be observed by the naked eye due to protein denaturation resulting from alterations in $2^{\circ}$ and $3^{\circ}$ protein structures. With these alterations of tissue come very important changes in the optical properties associated with it, most importantly an increase in the scattering coefficient $\left(\mu_{s}\right)$ [61]. The innermost region of figure $1-7$ is the area of tissue carbonization (or charring), reaching temperatures of over $100^{\circ} \mathrm{C}$. During treatment, water vaporization along with the production of smoke in the form of carbon monoxide $(\mathrm{CO})$ and carbon dioxide $\left(\mathrm{CO}_{2}\right)$ occurs at these extreme temperatures [62]. It has also been observed that charring forms around the delivery fiber, which seriously affects the light distribution from the fiber and creates even higher temperatures adjacent to the fiber, which 
can damage the fiber itself [63]. Therefore, it is beneficial to ensure that tissue temperatures are maintained below $100^{\circ} \mathrm{C}$ to avoid these effects.

\section{8 - Thermal Dose Determination in Thermal Therapy}

Damage to tissue due to thermal coagulation is a function of both temperature and exposure time. Thermal damage can be quantified by the thermal dose and is defined as the time at which tissue should be maintained at $43^{\circ} \mathrm{C}$ for an equivalent therapeutic effect to occur. It can be calculated from the time-temperature history using [64]:

$$
t_{43}=\int_{t_{\text {initial }}}^{t_{\text {tinal }}} C^{(43-T)} d t
$$

where $t_{43}$ is the equivalent treatment time at $43^{\circ} \mathrm{C}$ and $T$ is the temperature during the time interval between $t_{\text {initial }}$ and $t_{\text {final }}$. The constant $C$ is defined to be 0.25 for $T<43^{\circ} \mathrm{C}$ and 0.5 for $T \geq$ $43^{\circ} \mathrm{C}$. For sufficiently small $\Delta t$, equation (1.7) can be approximated as:

$$
t_{43}=C^{\left(43-T_{\text {avg }}\right)} \Delta t
$$

where $T_{\text {avg }}$ is the average temperature during the time interval $\Delta t[64]$.

During LITT there are a number of dynamic changes occurring in tissues with respect to optical and mechanical properties, making it difficult to properly model and predict the treatment effects. Further, the response to treatment among patients is variable because of variations in tissue optical properties, blood flow and volume. A solution to minimize risk to patien and account for dynamic changes is to monitor and implement a system that would provide real-time information on the progression of thermal damage. Various minimally or non-invasive methods 
of guiding and monitoring LITT have been proposed, although at this time, none have proven simple, efficient and cost effective enough to become a standard procedure.

\section{9 - Current Monitoring Techniques for $\mathrm{LTT}$}

Werto

One of the major drawbacks of LITT treatment as a clinical standard is the problem of monitoring the technique accurately in real time. The current methods for monitoring a treatment are computed tomography, magnetic resonance imaging, ultrasound and point temperature and optical monitoring.

\subsection{1-Compured Tomography (CT)}

Using CT, well defined boundaries of the coagulated region can be identified. Surrounding the lesion, viable tissue is easily visible due to the uptake of contrast agents that are not absorbed by the coagulated tissue. High resolution images can be obtained, making the identification of thermal damage relatively obvious [65]. If the time between between the day of treatment and a $\mathrm{CT}$ scan is too large (greater than 72 hours), the difference between regenerating normal tissue and regenerating tumour tissue are not distinguishable [52]. Therefore, it is ideal to

perform a $\mathrm{CT}$ scan one to four days after a LITT treatment as this corresponds biologically, to the time at which maximum damage will occur [66]. However, $\mathrm{CT}$ scanners are constantly in use for a number of important patient tests, and thus their availability to monitor LITT treatments is limited at best.

\subsection{2-Magnetic Resonance Imaging (MRI)}

A number of investigators feel that MRI is the best method for monitoring LITT treatments. MRI, like CT, is also capable of producing high quality, high resolution images 
suitable for monitoring the progression of the coagulation boundary during LITT [67]. Peters and collaborators [68] as well as Shrear and collaborators [69] have shown that MRI has the ability to produce high resolution temperature maps in and around thermal lesions. Tumour tissue appears enhanced on an MRI while necrotic tissue appears as a sharply defined hypointense reigon. Vogl and co-workers showed that $\mathrm{T} 2$-weighted sequences are also able to provide information on the ablation region in the short-term following treatment [70].

Although MRI like CT, is very efficient at providing insight to the effectiveness of LITT procedures, it is quite expensive, large and occupied on a daily basis for other medical diagnostic techinques. Therefore, relying solely on these imaging techinques to monitor LITT, present limitations and restrictions to the procedure.

\subsection{3-Ultrasound (US)}

Ultrasound has the ability to provide real-time imaging of a coagulation region during LITT. The coagulated tissue appears very bright around the fiber tip, resulting from the formation of microbubbles [71] and Amin and collaborators [52] have made use of this to evaluate the extent of tumour damage. However, in comparison to CT and MRI, US has very poor resolution which makes identifying the degree of tissue necrosis very difficult either during or after treatment. Furthermore, coagulated tissue and tumour tissue have similar echogenic properties. Thus estimating the degree of thermal damage and the tissue damage boundary can be problematic with US $[52,72,73]$.

\subsection{4-Poinet Monitoring}

Currently, there are two methods of point monitoring for LITT: temperature and optical fluence. Using point temperature measurements, treatments can be monitored at key locations 
such as the boundary of non-targeted tissue. These measurements can provide feedback about the temperatures being attained inside and around the coagulation region. Wyman and collaborators have previously developed a quasi-linear control algorithm to produce uniform temperature distrubition in a lesion to within $\pm 0.5^{\circ} \mathrm{C}$ of desired temperatures [74]. Beyond a few millimeters into the tissue, heating is mainly caused by thermal conduction away from the source. However, Wyman and colleagues [75] have shown that there is a delay in the diffusion of heat in the tissue away from the fiber tip which results in a time discrepancy between the temperatures at the center and the periphery of the lesion. Ivarsson and collaborators attempted to develop a stepwise power regulation system through temperature feedback in order to create a uniform temperature distribution with a lesion. The system was shown to be able to produce large enough lesions to treat a relatively large size tumour in a single session [76]. Although point temperature measurements have the advantage of providing a good indication of the effects of treatment at a specific point, they also come with the disadvantage of not being able to provide information anywhere other than the sensor location.

Using optical fluence measurements, it is possible to assess the propogation of the coagulation boundary $[77,78]$. As the coagulation zone approaches the fluence sensor, the sensor will register a decrease in the light fluence. This is due to the whitened region of coagulation scattering much more light than the untreated region, essentially 'trapping' light within it, limiting the amount of light reaching the sensor. However, once the coagulation reaches and overlaps the location of the sensor, the fluence begins to increase due to the large amount of light inside the coagulated region. Recently, Whelan and collaborators applied diffusion theory to develop a strategy to accurately determine the optimal position of a four-sensor linear array to determine coagulation-induced changes in optical propagation during LITT [79]. Chin and 
collaborators utilized the perturbative solution of the diffusion equation in heterogeneous media to show how changes in light intensity are associated with the extent and location of the volume of a thermal lesion during LITT [80].

Point measurements are generally portable and less expensive than other imaging modalities. Also, they are not in high demand for other treatments and thus, are usually readily available. However, the information feedback is entirely location-dependent and very limited in comparison to modalities such as CT or MRI.

\subsection{0-Experimental and Clinical Applications of LITT}

Over the last few decades, LITT has been applied to a number of tumour types in humans and animals. Matthewson et. al. documented some of the earliest work in delivering Nd:YAG laser light intrahepatically in normal rats [66]. They were able to produce lesions of up to $1.6 \mathrm{~cm}$ in diameter with well defined boundaries between normal and coagulated liver tissue. As a follow-up, this same group transplanted fibrosarcoma into rats and were able to show that after a treatment at $2 \mathrm{~W}$ for 600 seconds, there was complete loss of palpable tumour and no case of local recurrence in $50 \%$ of cases [81]. A number of studies on treating hepatic tumours using LITT have been published in the literature. Among these, Vogl and collaborators were able to completely eradicate small tumours using a single, diffusing tip fiber, but were unable to completely treat tumours larger than $2-3 \mathrm{~cm}$ in diameter [82]. As a method of treating local liver metastases, Amin et. al. [83] comparatively studied percutaneous ethanol injection and LITT treatments. Their results showed that in 28 of the 54 tumours treated vith LITT, complete necrosis was obtained. Complete necrosis was obtained in none of the tumours treated simply 
with ethanol. A number of clinical studies involving patients undergoing LITT treatment for liver metastases hyeen conducted. Hahl and collaborators employed a Nd:YAG laser to treat seven patients with liver metastases. Although there were complications to the treatment, one being fatal, they concluded that it was feasible to selectively destroy malignant tumours [84]. More recently, Pacella et. al. evaluated 44 patients that underwent laser ablation treatment for 75 liver metastases with mean diameters and volumes of $3.4 \mathrm{~cm}$ and $16.8 \mathrm{~cm}^{3}$, respectively. After ablation, $61 \%$ of tumours were completely treated with the likelihood of a total ablation being significantly higher in tumours less than $3.0 \mathrm{~cm}$ in diameter. Overall, patients with complete ablation survived for $30.0 \pm 12.7$ months and patients with partial ablation survived for $20.2 \pm$ 10.2 months [85].

LITT has also been used frequently in an attempt to treat solid breast tumours. Harries and collaborators reported on the results of 44 patients treated with LITT for small breast cancers. $\mathrm{CT}$ and MRI were used to attempt to identify the necrotic region after treatment. Results showed that it is beneficial to wait at least 24 hours after surgery to image the patient. Necrotic regions of up to $1.5 \mathrm{~cm}$ were visible with MRI [86]. Mumtaz et. al. investigated MRI as an imaging modality to guide LITT treatments for primary breast cancer. In total, 27 tumours in 20 patients were treated with follow-up MRI exams 4 hours and $24-96$ hours after treatment. Early exams failed to indicate the laser effects while later exams clearly showed the necrotic zone. It was concluded that MRI can aid in monitoring and evaluation of LITT treatments [87].

LTT has been employed in many other clinical applications such as treatment of hepatocellular carcinoma [88], benign cystic thyroid nodules [89], vascular lesions [90], penile carcinoma [91], head and neck cancers [92] as well as cervical cancer [93]. In all cases, the 
overall outcome of treatments are quite good, but as with all LITT procedures, they lack a simple but effective real-time monitoring system.

\subsection{1 - Thesis Organization and Objectives}

There is a need to develop an optical monitoring system for monitoring LITT. While temperature measurements can be obtained during LITT, these alone are not reliable enough to effectively monitor treatment. It has been shown that the changes in the optical properties of tissues can be exploited to estimate the degree of damage during LITT. These changes result from the sharp gradient between the thermal dose delivered to the center and the periphary of a thermal lesion [94]. The work in this thesis investigates the potential of Raman Spectroscopy to identify changes in tissue properties resulting from thermal coagulation of tissue equivalent phantoms and bovine muscle tissue samples.

Chapter 2 outlines the methods used in this work including the preparation and water bath heating of albumen based phantoms and bovine muscle samples. Laser photocoagulation of bovine muscle was also performed. Raman spectral acquisition from these samples is discussed as well as an analysis program written in Matlab to analyze all of the acquired Raman spectra in a standard and reproducible manner. Monte Carlo simulations using known optical properties of albumen phantoms were performed and are also discussed. Chapter 3 presents the results and discussion of these findings and illustrates that RS may be employable as a method to monitor changes in tissue structure and optical properties during LITT. The final chapter presents conclusions and future work ideas. Appendix I contains the Matlab code for the spectral analysis program. 


\section{2-Materials and Methods}

\section{1 - The Raman System}

\subsection{1-System Overview}

An overview of the Raman system employed in this work is depicted in figure 2-1. A titanium-sapphire laser operating at $785 \mathrm{~nm}$ is used as the excitation source and is pumped by a $\mathrm{Nd}: \mathrm{YVO}_{4}$ solid state laser operating at $532 \mathrm{~nm}$. The backscattered photons from the sample surface are collected through two autofocusing lenses and a holographic notch filter with approximately zero percent transmission at a wavelength of $785 \mathrm{~nm}$. This light is passed through a bundle of 43 CeramOptec fibers coupled to a Holospec spectrograph f/1.8i connected to a liquid nitrogen-cooled CCD detector.

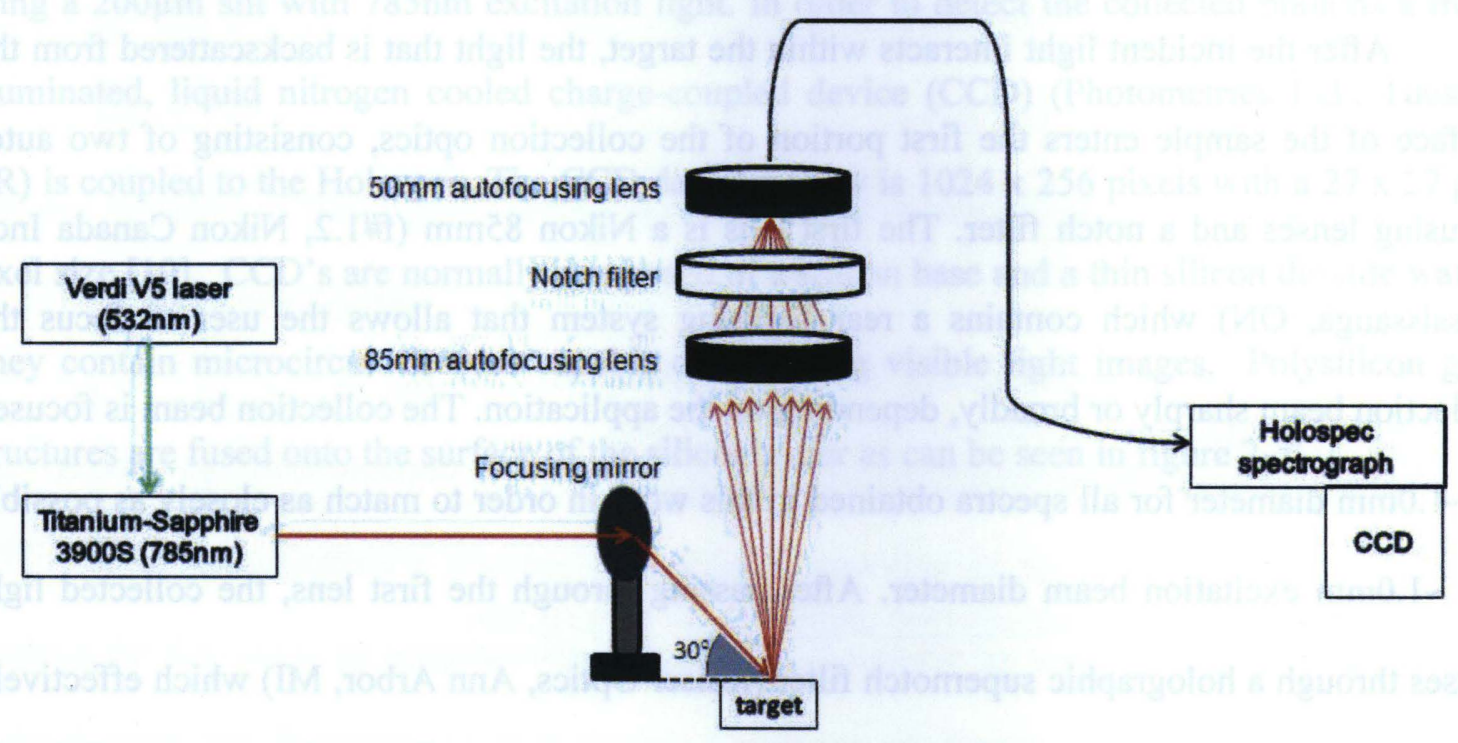

Figure 2-1 - Overview of the Raman System. 


\subsection{2 - The Excilation Lasers}

The initial component of the excitation laser source is the Verdi V5 laser (Coherent Inc., Santa Clara, CA) [95]. The V5 is a compact solid-state, diode-pumped, frequency-doubled $\mathrm{Nd}$ :Vanadate $\left(\mathrm{Nd}: \mathrm{YVO}_{4}\right)$ laser that provides single-frequency green $(532 \mathrm{~nm})$ output light at a power of up to $5 \mathrm{~W}$. The laser head and power supply are connected via an umbilical which includes a fiber optic cable that transmits light from the power supply to the laser head. The V5 pumps the titanium-sapphire $3900 \mathrm{~S}$ which is tuned to $785 \mathrm{~mm}$ for photon excitation and has a diameter of $\sim 1.0 \mathrm{~mm}$. The titanium-sapphire 3900 S (Spectra-Physics Inc., Mountain View, CA) is a solid state IR laser which delivers tunable CW output from 675 to $1100 \mathrm{~nm}$ [96]. Pumped by the Verdi V5, the $3900 \mathrm{~S}$ can produce up to $3.5 \mathrm{~W}$ of ultra-low-noise output power.

\subsection{3 - Photon Collection and Detection Componerts}

After the incident light interacts within the target, the light that is backscattered from the surface of the sample enters the first portion of the collection optics, consisting of two autofocusing lenses and a notch filter. The first lens is a Nikon $85 \mathrm{~mm}$ (f\#1.2, Nikon Canada Inc., Mississauga, ON) which contains a rear focusing system that allows the user to focus the collection beam sharply or broadly, depending on the application. The collection beam is focused to $1.0 \mathrm{~mm}$ diameter for all spectra obtained in this work in order to match as closely as possible the $\sim 1.0 \mathrm{~mm}$ excitation beam diameter. After passing through the first lens, the collected light passes through a holographic supemotch filter (Kaiser Optics, Ann Arbor, MI) which effectively filters out the excitation wavelength of $785 \mathrm{~nm}$. The collected light is then passed through a Nikon $50 \mathrm{~mm}$ autofocusing lens (f\#1.2, Nikon Canada Inc., Mississauga, ON).

After passing through the lens system, the backscattered light enters a fiber optic bundle coupled to the collection optics via a SMA adapter. This bundle consists of 43 CeramOptec $\mathrm{P} / \mathrm{N}$ 
UV105/115/140P28 fibers with NA of 0.28 (Ceramoptec Industries, Inc., East Longmeadow, MA). The bundle is connected to the Holospec $f / 1.8 \mathrm{i}$, an axial transmissive imaging spectrograph (Kaiser Optical Systems Inc., Ann Arbor, MD) which is compact and has an optical transmission of greater than $50 \%$. A schematic of the intemal components of the Holospec is shown in figure 2-2. Light from the fiber bundle is collimated inside the Holospec, passed through the holographic diffraction grating, oriented in a $90^{\circ}$ transmission geometry, and then focused onto a flat image plane co-incident with the image plane of the detector [10]. By using the Holospec, off-axis aberrations such as astigmatism and comas can be avoided since holographic optical elements (HOE) (notch filter and grating) are combined with high efficiency lenses [97]. The HOE's used in the Raman system are low scattering optical elements, wavelength specific and have high transmission. The holographic grating has a spectral range of $150-1750 \mathrm{~cm}^{-1}$ when using a $200 \mu \mathrm{m}$ slit with $785 \mathrm{~nm}$ excitation light. In order to detect the collected photons a front illuminated, liquid nitrogen cooled charge-coupled device (CCD) (Photometrics Ltd., Tucson, $\mathrm{AR}$ ) is coupled to the Holospec. The CCD detector array is $1024 \times 256$ pixels with a $27 \times 27 \mu \mathrm{m}$ pixel size [10]. CCD's are normally composed of a silicon base and a thin silicon dioxide wafer. They contain microcircuit devices capable of recording visible light images. Polysilicon gate structures are fused onto the surface of the silicon wafer as can be seen in figure $2-3$. 


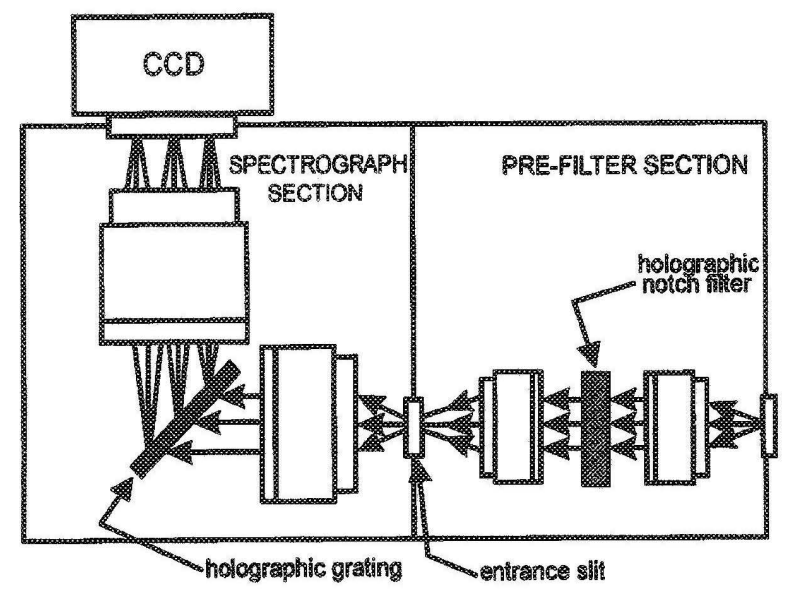

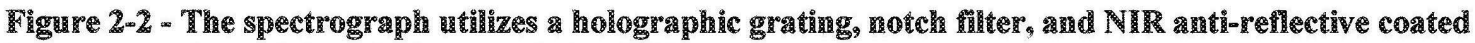
lexses to prodice high optical tramsmission $[10 !$.

\section{incident photons}

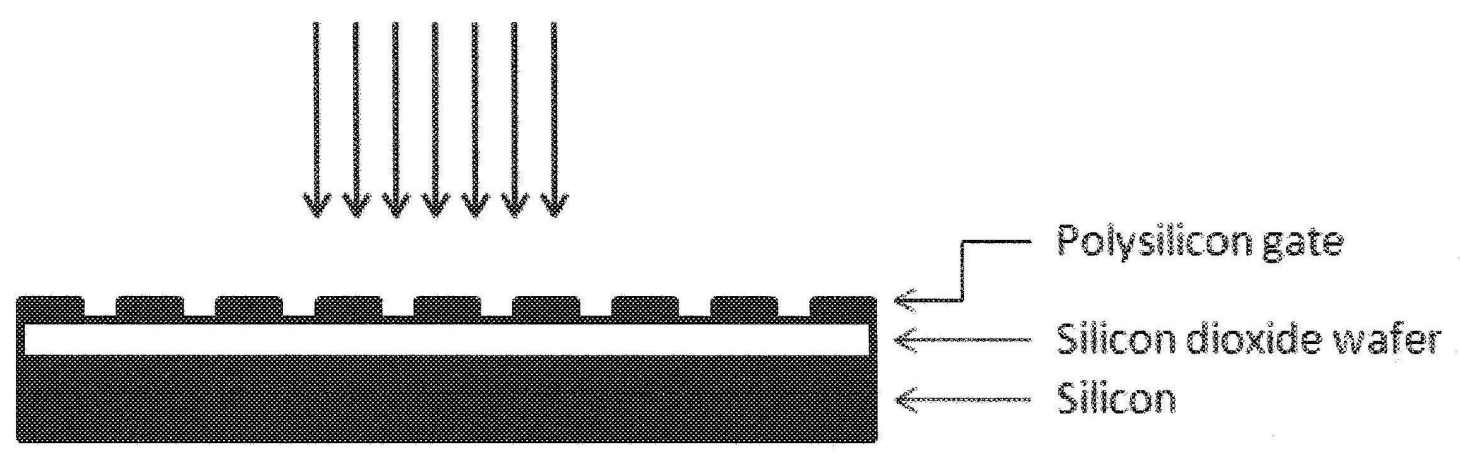

Figure 2-3 - Schematic of a front illuminated charge-coupled device (CCD).

Interactions with the $\mathrm{CCD}$ are measured when incident photons disrupt the crystalline lattice of the silicon wafer, creating an electrical charge. This charge is then collected in a potential well that is formed in the wafer. 


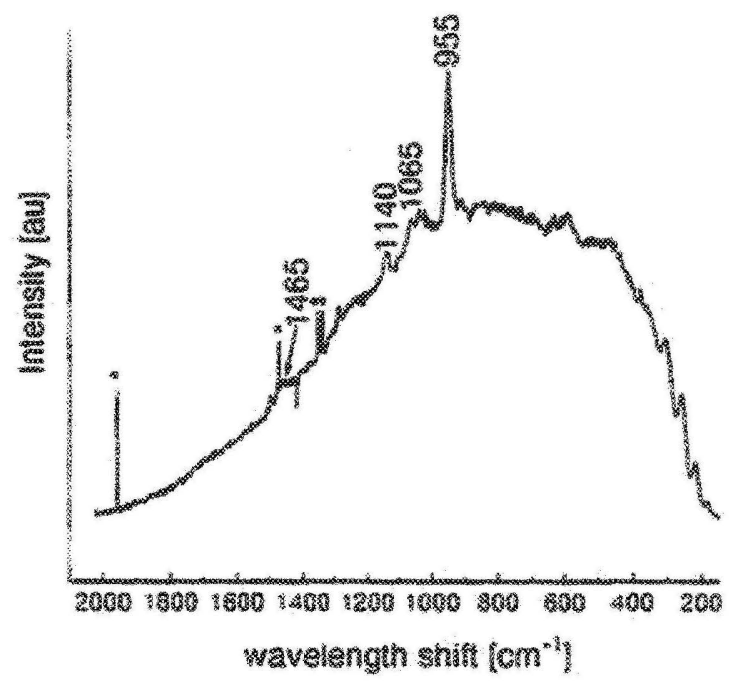

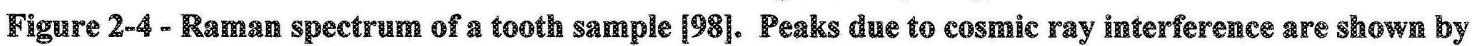
æsterishis.

CCD detectors are transparent to light with wavelengths greater than $1000 \mathrm{~nm}$ and cannot distinguish between optical photons from the excitation source and cosmic rays. These cosmic ray events shown in the Raman spectrum of a tooth sample (figure 2-4) [98], are typically avoided by reducing the single-scan time and minimizing the active area of the CCD [99].

\section{2-Raman Spectral Analysis}

After investigating a number of software programs to perform the required spectral analysis for this work, no program was found to be acceptable for calibrating the Raman spectra. and rejecting the fluorescence background. Therefore all Raman spectral analysis has been performed using an in-house program developed in Matlab. A brief description of the code is presented in the following sections and the code itself can be found in Appendix I. The following describes the steps necessary to obtain Raman spectra from the raw detected signals. 


\subsection{1-Pixel to Wverumber Conversion}

Calibration of the pixel-wavenumber relationship is vital to the accurate assessment of Raman shifts when using multichannel detectors, such as a CCD [100]. Thus, a conversion must be performed to assign each pixel an appropriate wavenumber value in order to properly represent the Raman shift.

Emission lines from neon or argon lamps can be used to perform the calibration, but these only provide absolute calibration of the spectrometer and hence cannot account for small shifts in the Raman spectrum due to shifts in the excitation wavelength [101]. To provide generalized relative calibration of the pixel-wavenumber relationship, a standard sample that has several Raman lines of accurately known wavenumber shift can be measured and used for calibration.

The Raman system used in this work displays all collected spectra in a plot of intensity versus pixel values as seen in the Tylenol ${ }^{\circledR}$ spectrum shown in figure $2-5$. The pixel values along the $\mathrm{x}$-axis correspond to the 1024 pixels on the surface of the CCD camera. Calibration of the pixel-wavenumber conversion in this work is performed using a Tylenol ${ }^{\circledR}$ tablet since the Raman spectrum due to the acetaminophen content contains a number of easily identifiable peaks [102]. Sixteen peaks are used to perform the conversion and the wavenumber values of these peaks have been determined by Zhao and McCreery and are shown in figure 2-6(a). Their corresponding pixel values have been measured at $785.0 \mathrm{~nm}$ excitation to ensure the most accurate calibration possible for all subsequently collected Raman spectra. 


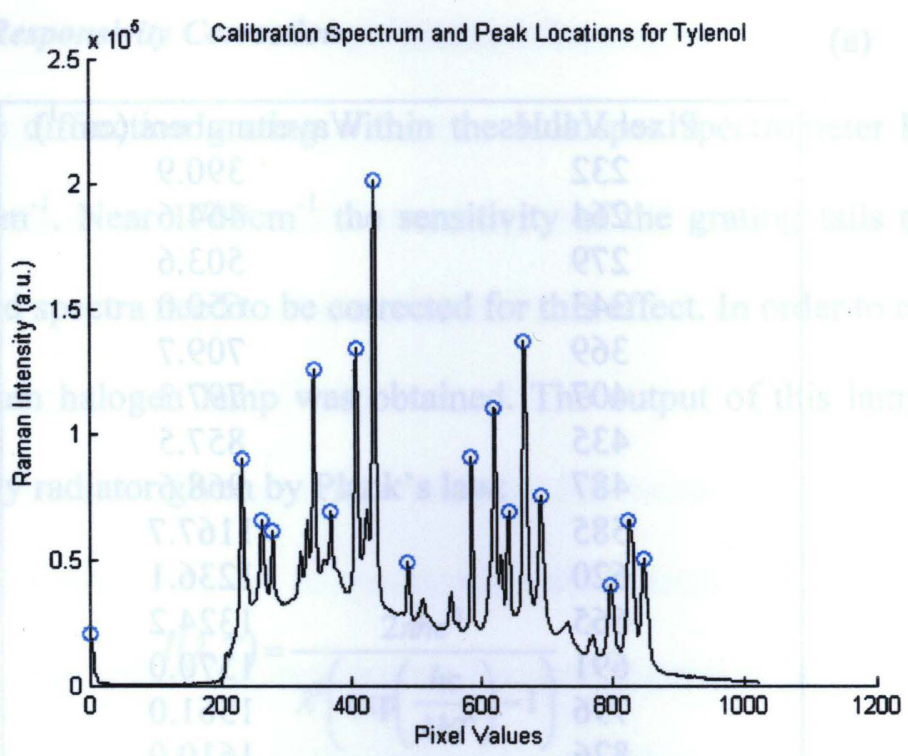

Figure 2-5 - Raman spectrum of Tylenol $B$ used for calibration. The peak-finding portion of the program is used to identify peak locations.

The values in figure 2-6(a) are stored in an array and used as reference for all other Tylenol ${ }^{\circledR}$ calibration spectra obtained. This allows for calibration to be performed daily and can easily account for excitation wavelength fluctuation that would slightly alter the pixelwavenumber relationship. After the relationship between pixel values and known wavenumbers is obtained, these values are plotted and a second-order polynomial is obtained as shown in figure 2-6(b). This polynomial allows the conversion of all pixel values to a corresponding wavenumbers in any collected Raman spectrum. As seen by other investigators [100], a quadratic polynomial was found to give an optimal fit. Third or higher order polynomials did not add any accuracy to the fit, since all higher order terms simply become very small. 
(a)

(b)

\begin{tabular}{|cc|}
\hline Pixel Values & Wavenumbers $\left(\mathrm{cm}^{-1}\right)$ \\
232 & 390.9 \\
264 & 464.6 \\
279 & 503.6 \\
343 & 650.0 \\
369 & 709.7 \\
407 & 797.3 \\
435 & 857.5 \\
487 & 968.6 \\
585 & 1167.7 \\
620 & 1236.1 \\
665 & 1324.2 \\
691 & 1370.0 \\
796 & 1561.0 \\
826 & 1610.0 \\
847 & 1647.8 \\
\hline
\end{tabular}

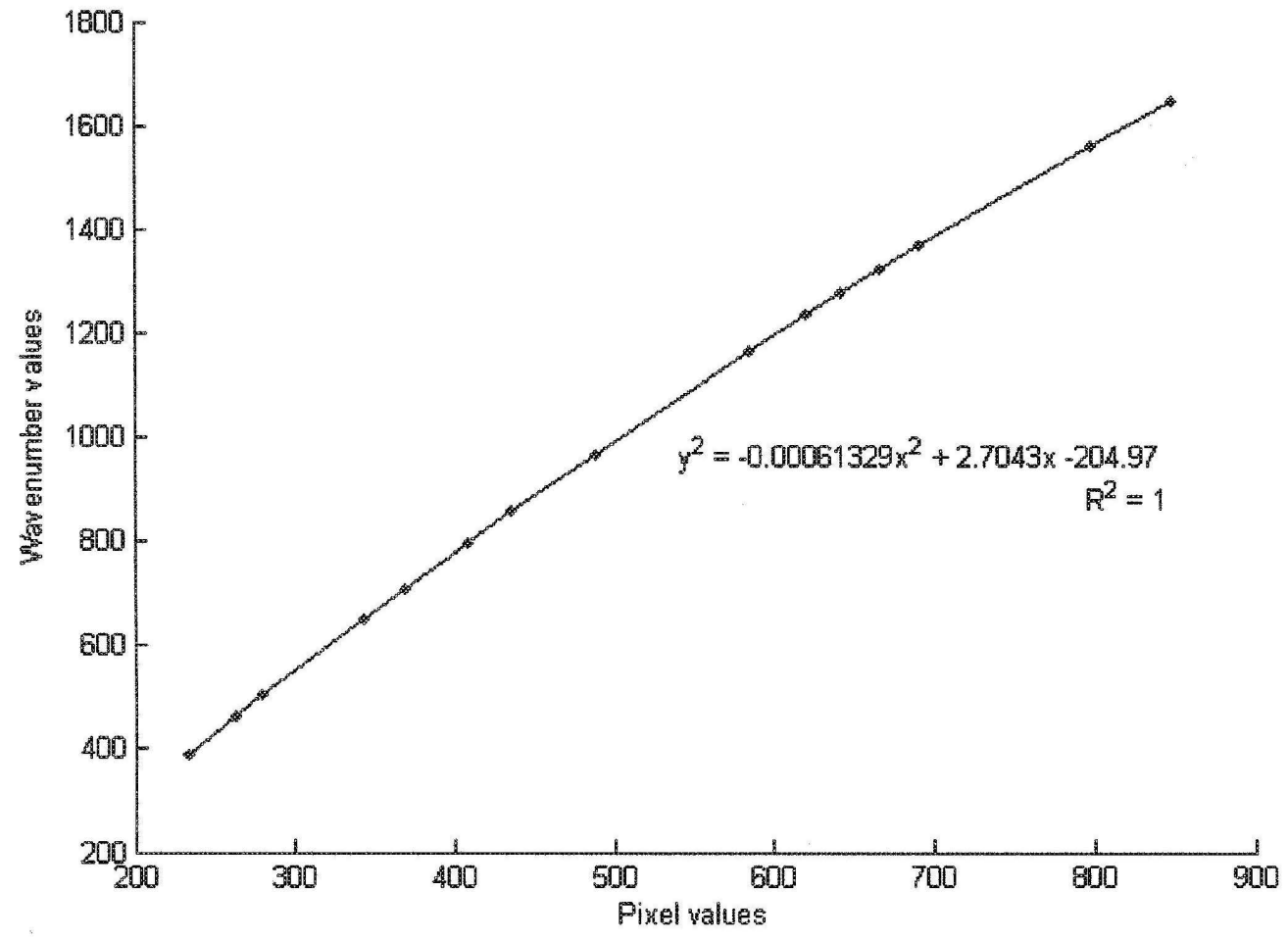

Figure 2-6 - (a) Pixel values and wavenumbers for Tylenol (B) (b) Plot of wavenumbers versus pixel values and the quadratic equation of the line of best int. 


\subsection{2-Detector Responsivity Correction}

The holographic diffraction grating within the Holospec spectrometer has a maximum transmission near $700 \mathrm{~cm}^{-1}$. Near $1700 \mathrm{~cm}^{-1}$ the sensitivity of the grating falls off and thus the intensity of the measured spectra need to be corrected for this effect. In order to correct for this, a spectrum from a tungsten halogen lamp was obtained. The output of this lamp is assumed to approximate a blackbody radiator given by Plank's law:

$$
I(\lambda, T)=\frac{2 \pi h c^{2}}{\lambda^{5}\left(\exp \left(\frac{h c}{\lambda k T}\right)-1\right)}
$$

where $I(\lambda, T)$ is the power emitted per unit area in the wavelength interval $d \lambda$ where $\lambda$ is the wavelength, which ranges from $771.5 \mathrm{~nm}$ to $925.3 \mathrm{~nm}$ in the system, $h$ is Planck's constant $\left(6.626 \times 10^{-34} \mathrm{~J} \cdot \mathrm{s}\right), k$ is the Boltzmann constant $\left(1.38 \times 10^{-23} \mathrm{~J} / \mathrm{K}\right), c$ is the speed of light $\left(3 \times 10^{8} \mathrm{~m} / \mathrm{s}\right)$ and $T$ is the absolute temperature of the tungsten filament $\left(2750^{\circ} \mathrm{K}\right)$. A correction for the responsivity of the system can then be obtained through the following expression:

$$
\Psi(\lambda)=\frac{I(\lambda)}{I(\lambda)}
$$

where $\Psi(\lambda)$ is the correction spectrum, $I(\lambda)$ is the calculated spectrum from a blackbody radiator and $I^{\prime}(\lambda)$ is the measured spectrum of the tungsten halogen lamp [10]. $\Psi(\lambda)$ is then normalized and multiplied by the measured Raman spectrum $S_{M}(\lambda)$ in order to obtain the corrected Raman spectrum, $S_{A}(\lambda)$.

$$
S_{A}(\lambda)=\Psi(\lambda) * S_{M}(\lambda)
$$




\subsection{3-Finorescence Background Rejection}

Tissues contain several substances that produce fluorescence when excited by light in the visible to near-infrared region. Raman spectra of tissue typically also contain unwanted broad background tissue fluorescence, which needs to be removed. Most background subtraction techniques involve some degree of user intervention, which can lead to subjective results that vary from spectrum to spectrum and operator to operator. Thus, an automated method for removing the background fluorescence is necessary. A variety of polynomial fitting techniques have been developed, since these techniques approximate the background fluorescence and leave the Raman peaks relatively un-altered. Gao et. al. [103] Brennan et. al. [104] and Huang et. al. [105] employed third, fourth and fifth order polynomial fits respectively, to exclude the Raman

peaks. Vickers and collaborators [106] used a third-order polynomial to remove the background fluorescence and a fifth-order polynomial to smooth the spectrum. Short et. al. [107] used a cubic spline function, choosing the points along the spectrum by trial and error and Lieber and Mahadevan-Jansen [108] have developed a least squares method to fit a fifth-order polynomial to the fluorescence background while excluding the Raman peaks. Although these methods have been used by many investigators, they are lacking robustness as they do not perform the polynomial fit based on any rigorous analysis of the input data. Fluorescence background rejection in this work is performed using the Adaptive Minmax Method recently developed by Cao et. al. [109] since it is robust and free of user-subjectivity. This method first performs both unconstrained and constrained polynomial fits for two different orders based on the fluorescenceto-signal ratio of the input spectrum. The maximum value among the initial fits is then taken as the points for the final fit. The first part of the algorithm takes the minimum point between the spectrum and the polynomial fit to avoid overfitting the data and the second part of the algorithm 
that takes the maximum value among all the polynomial fits performed to avoid underfitting the data. This method is more robust than other software programs that simply fit one polynomial to the data since it calculates the optimal polynomial fit based on the input data. The Minmax Method differs from other methods in that it analyzes the input data and determines the optimal polynomial fit to reject the background fluorescence. Hence, this method is much more robust than the other methods discussed above, and is used in the Raman analysis of this thesis.

\section{3-Raman System Verification}

To verify that our Raman detection and analysis approach was working correctly, spectra from Sulfur and Polystyrene were acquired and compared to published spectra. A Raman spectrum of a powdered sample of sulfur was acquired for 10 seconds and averaged 5 times for a

total collection time of 50 seconds. The average spectrum compared to a known spectrum of sulfur by Pasteris and collaborators [110] in figure $2-7$. 

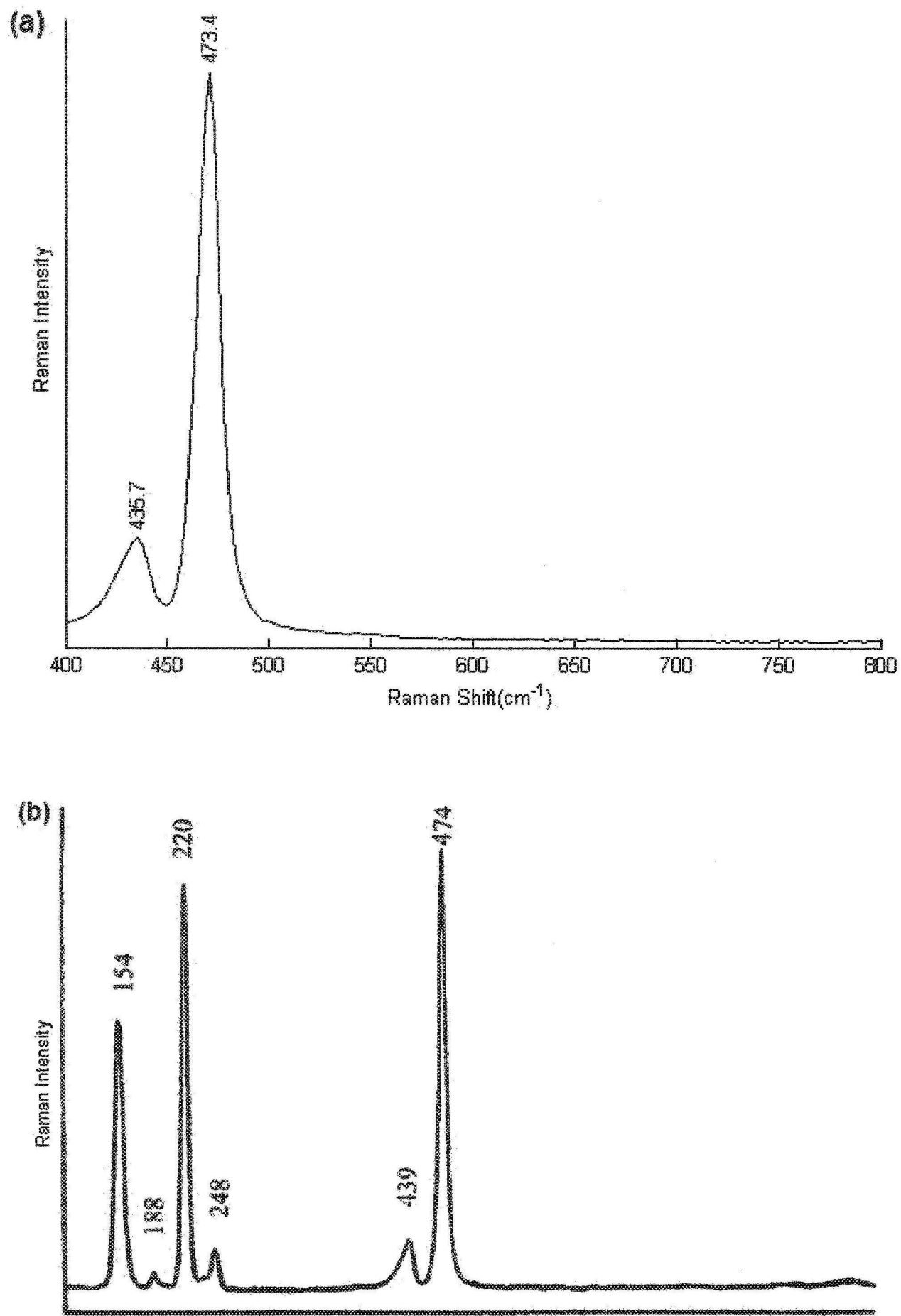

Xigure 2-7 - (a) Collected Raman spectrum of sulfur indicating the two major bands resolvable by the system. (b) Ramar spectram of sulfur from Pasteris et. al. $[110]$. 
The peaks in figure $2-7$ (a) at $435.7 \mathrm{~cm}^{-1}$ and $473.4 \mathrm{~cm}^{-1}$ match well to the peaks in (b) at $439 \mathrm{~cm}^{-1}$ and $474 \mathrm{~cm}^{-1}$ respectively. The slight offset of the band at $435.7 \mathrm{~cm}^{-1}$ may be due to the fact that the band is quite broad and the exact peak location can vary slightly more than very narrow bands. Figure 2-8 (a) depicts an acquired Raman spectrum of polystyrene ( 5 seconds, 10 cycles) and (b) shows the Raman spectrum of polystyrene by McCreery et. al.[111]. 


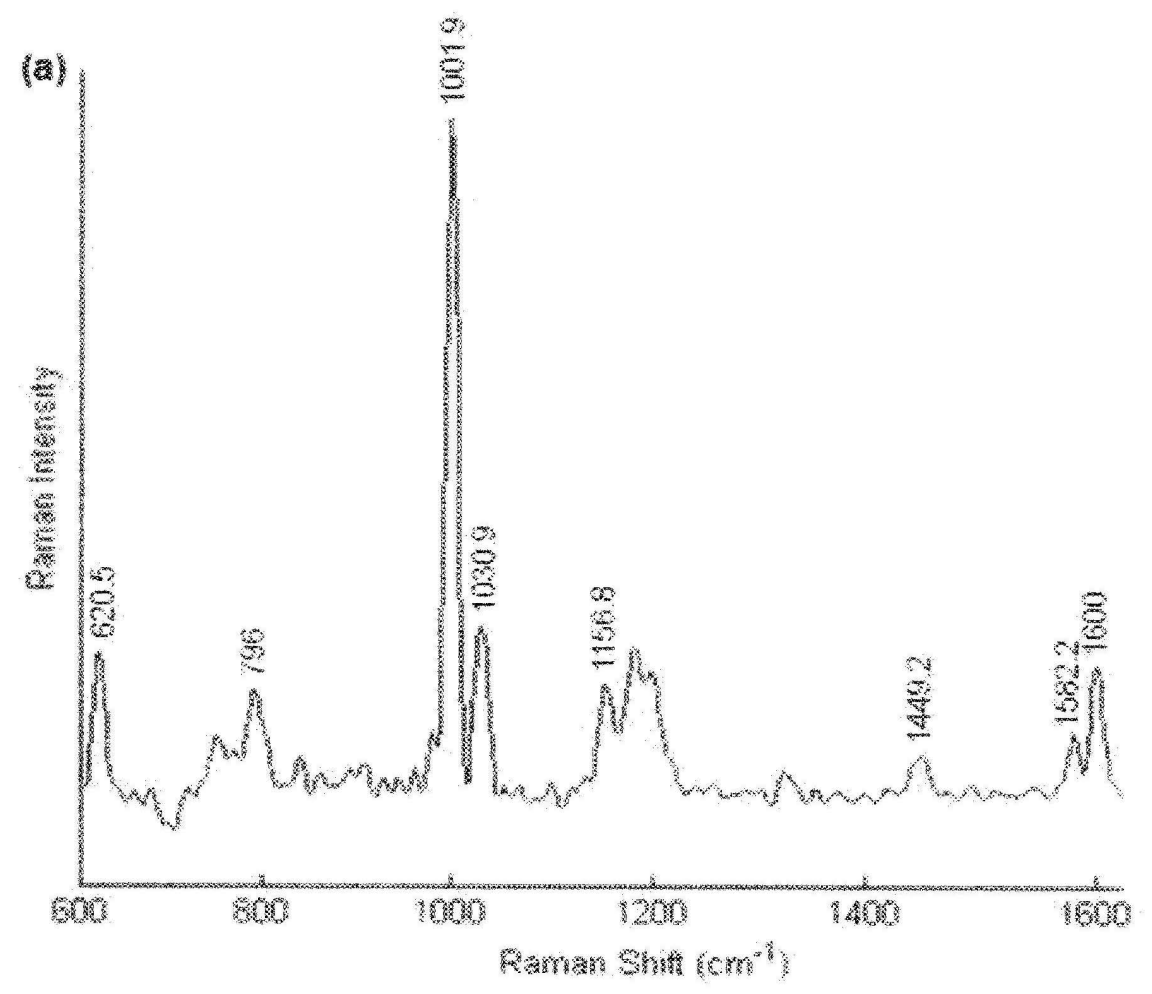

(b)

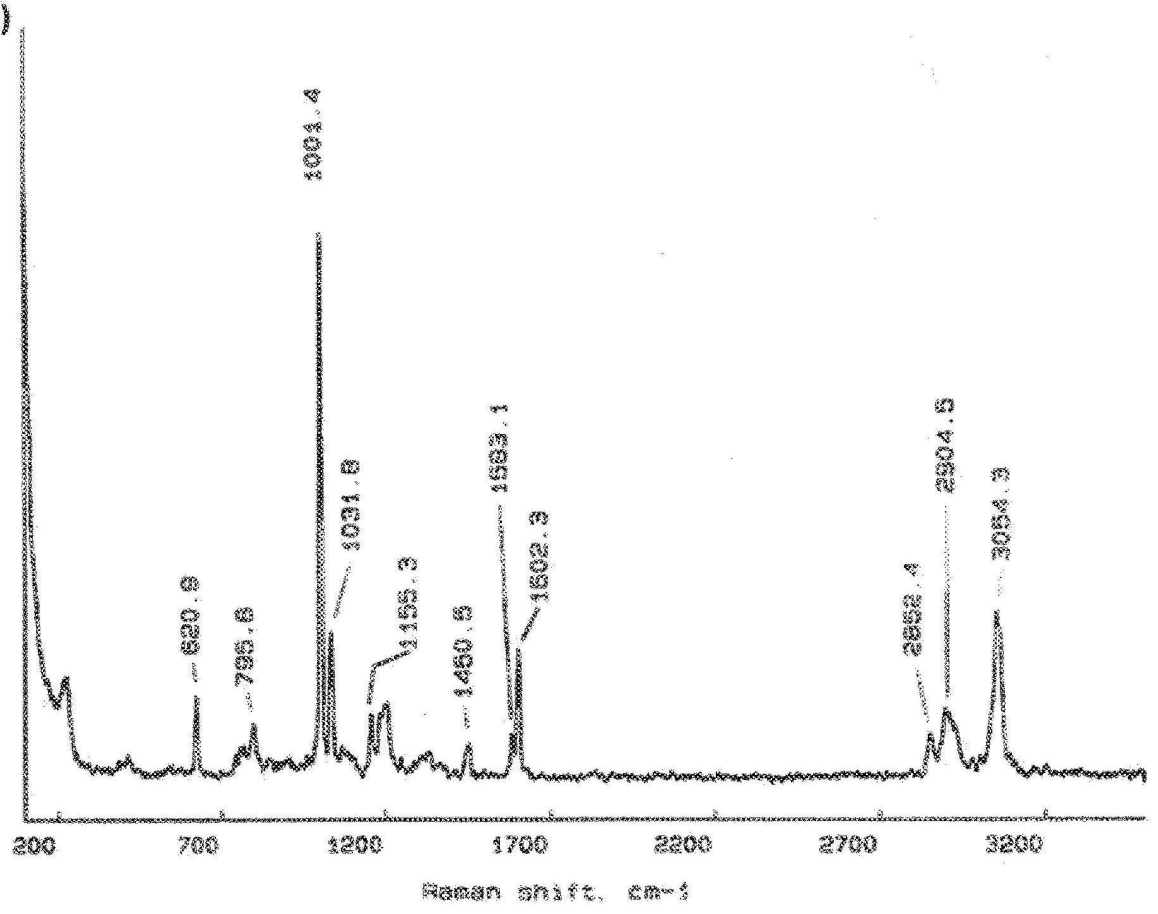

Figure 2-8 - (a) Collected Raman spectrum of polystyrene indicating the major bands. (b) Raman spectrum of polystyrene from McCreery et. al. 1111 . 
The major bands in figure $2-8(a)$ at $1001.9 \mathrm{~cm}^{-1}, 1030.9 \mathrm{~cm}^{-1}$ and $1600.0 \mathrm{~cm}^{-1}$ match very well to the known peaks in figure $2-8(\mathrm{~b})$ at $1001.4 \mathrm{~cm}^{-1}, 1031.8 \mathrm{~cm}^{-1}$ and $1602.3 \mathrm{~cm}^{-1}$, thus indicating that the system is able to generate accurate Raman spectra for samples with well known Raman signatures.

\section{4- Tissue Equivalent Albumen Phantoms}

Albumen-based phantoms were employed in this work due to their ability to mimic tissue coagulation and were fabricated based on work by lizuka et. al.[112]. Albumen protein is comprised mainly of water $(88.1 \%)$, globular proteins $(10.2 \%)$ and lipids $(0.05 \%)$ and is commercially available in powered form composed of dehydrated egg white. The phantom consists of chicken egg albumen (Crude, Grade II, Sigma, St. Louis, MO, USA), bacteriological agar (Oxoid, Hampshire, England) and Naphthol Green dye (Sigma, St. Louis, MO, USA). It is prepared by combining two mixtures: a stock albumen solution and an agar-dye solution. Stock solution of the albumen mixture consists of $77.8 \%$ by weight distilled water and $22.2 \%$ by weight powdered egg white. The albumen-distilled water mixture is stirred until the albumen is fully dissolved. A $53.3 \%$ by weight albumen stock solution is then measured and warmed in a water bath held at $40^{\circ} \mathrm{C}$. The dye solution is prepared separately by dissolving $0.387 \mathrm{~g}$ of Naphthol Green dye powder into 1 liter of distilled water. A $13.3 \%$ by weight dye solution is then combined with a $32.0 \%$ by weight amount of distilled water. It is heated up to $70^{\circ} \mathrm{C}$ before adding agar powder of $1.4 \%$ by weight. The agar-dye solution is slowly heated to its activation temperature of $85^{\circ} \mathrm{C}$ and then cooled down to $45^{\circ} \mathrm{C}$. At this temperature, the agar-dye solution is mixed into the albumen stock solution, poured into cylindrical molds with diameter of $6 \mathrm{~cm}$ and height of $3 \mathrm{~cm}$, and cooled to room temperature. 
Thermal coagulation was performed by submerging each phantom in a water bath maintained at $75^{\circ} \mathrm{C}$ until the target temperature was reached at the center of the phantom, as reported by a micro-themocouple temperature probe placed at the center of the phantom. Performing the coagulation in this manner mimics thermal therapy treatments in that once a defined target temperature is reached heating ceases and the tissue is allowed to cool. The phantom was then immediately removed, placed into a cold water bath at approximately $22^{\circ} \mathrm{C}$, and allowed to cool. The cold water bath is necessary to halt the heating process and mimics as closely as possible the effect that blood flow would have on heating within the human body. Target temperatures of $45,55,65$ and $75^{\circ} \mathrm{C}$ were used. Time-temperature histories were recorded for each target temperature allowing the calculation of thermal dose values in equivalent minutes at $43^{\circ} \mathrm{C}$.

\section{5 - Water Bath Heating of Bovine Muscle}

Bovine muscle was purchased from a local grocery store and cut into pieces approximately $3 \mathrm{~cm}$ by $3 \mathrm{~cm}$ with a thickness of approximately $2 \mathrm{~cm}$, depending on the sample. Top sirloin was chosen as it has higher collagen content than other available cuts of bovine muscle [113]. Each sample was then wrapped in plastic wrap to prevent water penetration. Two microthermocouples were inserted into the sample as can be seen in figure $2-10$. The first thermocouple was located approximately $2 \mathrm{~mm}$ from one edge of the sample and inserted to a depth of approximately $1.5 \mathrm{~cm}$, or halfway into the sample. The second thermocouple was located approximately in the center of the sample and again was inserted approximately $1.5 \mathrm{~cm}$ into the sample. The thermocouple lead contains markings which indicate $1 \mathrm{~cm}$ increments, making the process of placing the probes reasonably accurate. The sample was then submerged in a water 
bath held at a constant temperature as seen in figure $2-9$. Water bath temperatures of $45^{\circ} \mathrm{C}, 55^{\circ} \mathrm{C}$, $65^{\circ} \mathrm{C}$ and $75^{\circ} \mathrm{C}$ were used to be consistent with previous albumen phantom work. In this experiment, two thermocouples were used in order to ensure accuracy in the heating process. The thermocouple nearest to the edge of the sample reaches the target temperature before the thermocouple near the center of the sample. However, given the size of the sample, the heating should be relatively uniform throughout. Table $2-1$ shows the maximum temperature recorded by the thermocouple near the edge of the sample and near the center of the sample. It can be seen that for each sample, the temperatures recorded by each thermocouple are nearly equal, indicating that the tissue did indeed reach the desired temperature. Once the thermocouple near the edge reached the maximum temperature, the sample was removed and immediately placed in a cold water bath at approximately $22^{\circ} \mathrm{C}$ to halt the heating process as mentioned in section 2.4 , and allowed to cool. The maximum temperature recorded by each thermocouple is shown in table 2-2. Time-temperature histories were recorded by the microthermocouple temperature sensor for each sample and thermal dose values in equivalent minutes at $43^{\circ} \mathrm{C}$ were calculated. 


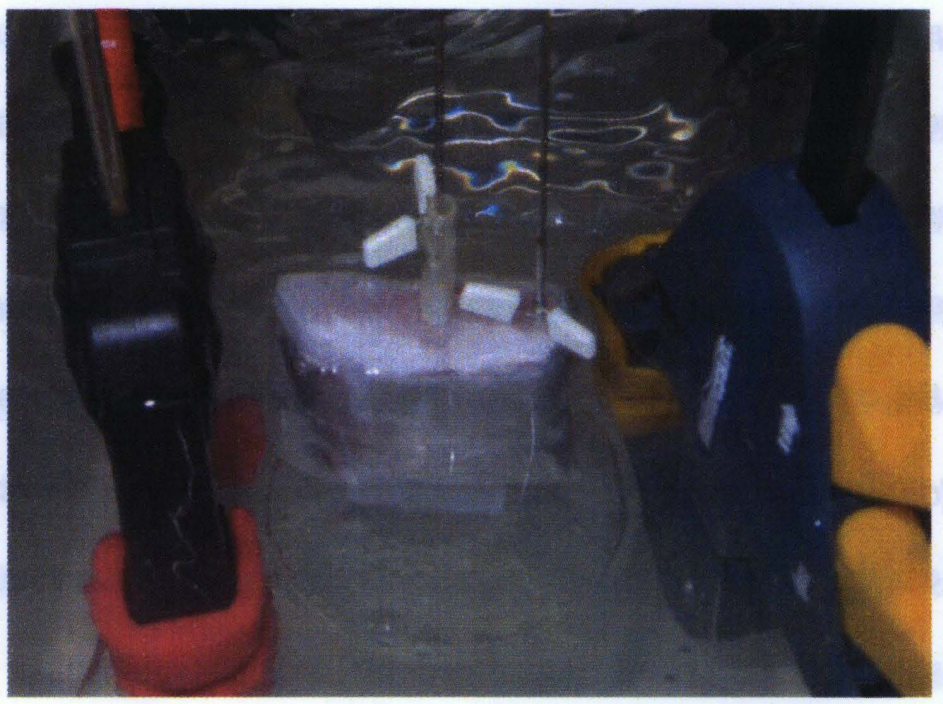

Figure 2-9- Experimental setup used for water bath heating of bovine muscle samples. One thermocouple is placed near the edge of the sample and another is placed approximately in the center of the sample.

\begin{tabular}{|c|c|c|}
\hline $\begin{array}{c}\text { Muscle } \\
\text { Sample }\end{array}$ & $\begin{array}{c}\text { Thermocouple } \\
\text { number/location }\end{array}$ & $\begin{array}{c}\text { Maximum } \\
\text { temperature }\left({ }^{\circ} \mathrm{C}\right)\end{array}$ \\
\hline \multirow{2}{*}{1} & edge & 45.0 \\
\cline { 2 - 3 } & center & 44.0 \\
\hline \multirow{2}{*}{2} & edge & 55.0 \\
\cline { 2 - 3 } & center & 54.6 \\
\hline \multirow{2}{*}{3} & edge & 65.0 \\
\cline { 2 - 3 } & center & 64.4 \\
\hline \multirow{2}{*}{4} & edge & 75.0 \\
\cline { 2 - 3 } & center & 73.0 \\
\hline
\end{tabular}

Table 2-1 - The muscle sample, thermocouple location and maximum temperature recorded by each thermocouple.

\section{6 - Laser Photocoagulation of Bovine Muscle}

Bovine muscle was selected for laser photocoagulation based on previous experimental results and the knowledge of the Raman spectra for muscle [19, 114]. Photocoagulation was performed using an $805 \mathrm{~nm}$ diode laser (Diomed Inc., Andover, MA) coupled to a $400 \mu \mathrm{m}$ core optical fiber with a cylindrical $20 \mathrm{~mm}$ diffusing tip. Three thermocouple probes were placed at 
$2 \mathrm{~mm}, 5 \mathrm{~mm}$ and $10 \mathrm{~mm}$ from the laser fiber along the semi-minor axis as seen in figure $2-10$. The laser fiber and thermocouples were sandwiched between two slabs of bovine muscle tissue, the input laser power was set to $7 \mathrm{~W}$ and the irradiation was terminated when a temperature of $90^{\circ} \mathrm{C}$ was recorded by the thermocouple at $2 \mathrm{~mm}$ from the laser fiber. The tissue slab was then allowed to cool to room temperature $\left(\sim 24^{\circ} \mathrm{C}\right)$.

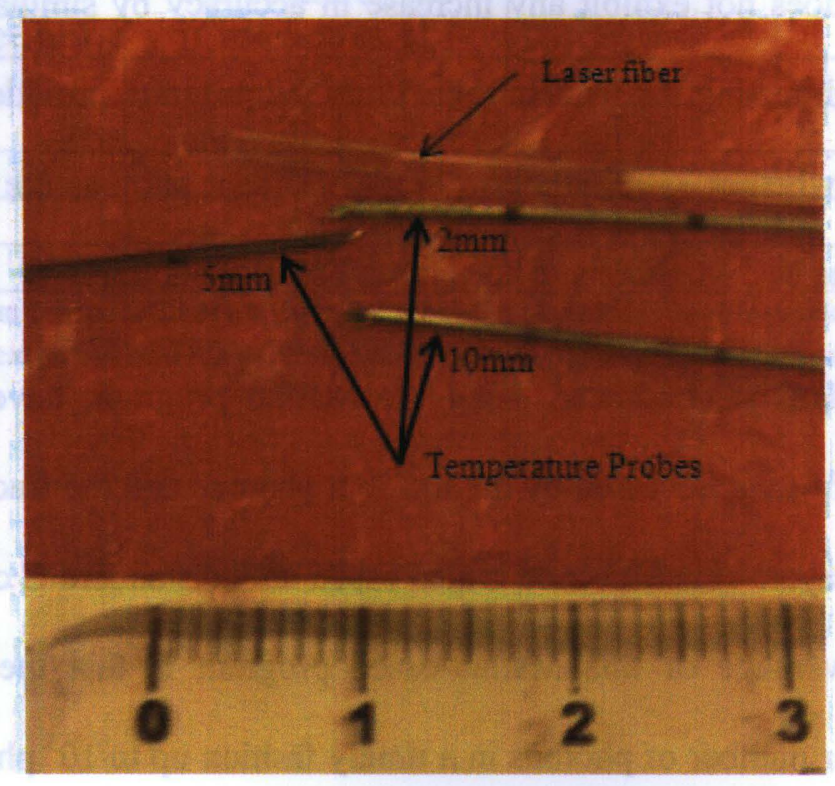

Figure 2-10 - Experimental setup for laser photocoagulation of bovine muscle. Thermocouple temperature sensors were placed at $2 \mathrm{~mm}, 5 \mathrm{~mm}$ and $10 \mathrm{~mm}$ from the laser fiber.

\section{7-Monte Carlo Simulations of Photon Migration in Tissue}

Monte Carlo simulations were performed using both a Monte Carlo (MC) Maplet code written by Yip and Carvalho [115] and a Matlab MC code written in-house. Two MC codes are used in this thesis as each code provides different, but useful information. The MC Maplet program has been designed so that the input data and output display can be handled by a graphical user interface (GUI) and the simulation code is based on the standard C code written 
by Wang et. al. [116]. Using this code, values for the diffuse reflectance are determined by dividing the total number of photons escaping the simulated tissue layer, by the total number of incident photons. Further, plots of the fraction of absorbed photons versus tissue depth are also generated. Being written in Maple, one disadvantage of the program is the long simulation times that can run over 2 hours if simulating more than 5000 photons. However, according to the authors, the program does not exhibit any increase in accuracy by simulating more than 3000 photons [115]. Through testing it was determined that the program provides the same graphical and numerical results whether 3500,8000 or 20,000 incident photons are launched. Therefore, all simulations using the MC Maplet have been run with 3500 photons.

The $\mathrm{MC}$ simulations conducted using the Matlab program, have been performed to estimate the volume of tissue traversed by the incident photons and the fraction of backscattered photons from a tissue layer. This MC code is also based on the standard C code written by Wang et. al. [116]. The advantage of this Matlab-based program is that the simulations can be performed with a larger number of photons in a timely fashion up to $10^{5}$ photons, at which point memory errors on all available PC's halted the simulations. This program also provides an excellent visualization of photon absorption, scatter and can estimate the volume of tissue being traversed by the incident photons. This program launches individual photons from a single point normal to the surface of the layer and counts the number of photons escaping from the surface of the sample. Photons escaping other surfaces of the sample are terminated and not counted. All simulations have been run with $10^{5}$ incident photons.

The MC simulations have been conducted using the absorption coefficients $\left(\mu_{\mathrm{a}}\right)$ and scattering coefficients $\left(\mu_{\mathrm{s}}\right)$ of albumen phantoms as determined at $740 \mathrm{~nm}$ by Castelino et. al. [117] and shown in table 2-2. The anisotropy factor was set to 0.90 as determined by Castelino 
et. al. [117]. Photons were launched normal to the surface $\left(90^{\circ}\right)$ using both the MC Maplet and the Matlab MC code. Using the MC Maplet, values for the diffuse reflectance and a plot of absorption versus penetration depth were determined for each combination of $\mu_{a}$ and $\mu_{s}$. Using the Matlab-based MC program, the number of backscattered photons were recorded.

\begin{tabular}{|c|c|c|c|}
\hline $\begin{array}{c}\text { Maximum } \\
\text { temperature }\left({ }^{\circ} \mathrm{C}\right) \\
\text { (Rodrigues et. al.) }\end{array}$ & $\begin{array}{c}\text { Maximum } \\
\text { temperature }\left({ }^{\circ} \mathrm{C}\right) \\
\text { (Castelino et. al.) }\end{array}$ & $\left(\mu_{\mathrm{a}}\right)\left[\mathrm{cm}^{-1}\right]$ & $\left(\mu_{\mathrm{s}}\right)\left[\mathrm{cm}^{-1}\right]$ \\
\hline 21.0 & 21.0 & 1.11 & 10.35 \\
\hline 48.6 & 45.6 & 1.20 & 23.01 \\
\hline 57.5 & 55.5 & 1.22 & 40.44 \\
\hline 66.2 & 65.4 & 1.36 & 126.0 \\
\hline 75.0 & 69.7 & 1.60 & 170.77 \\
\hline
\end{tabular}

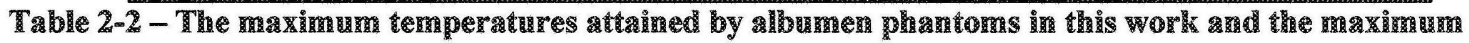

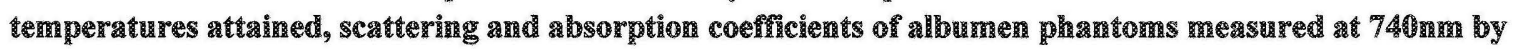

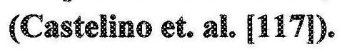




\section{3 - Results and Discussion}

\section{1 - Tissue Equivalent Albumen Phantoms}

Albumen phantoms were heated to target temperatures of $45,55,64$ and $75^{\circ} \mathrm{C}$ in a water bath held at $75^{\circ} \mathrm{C}$, and then allowed to cool to approximately $22^{\circ} \mathrm{C}$. Time-temperature histories were recorded for each phantom and are shown in figure 3-1. As expected the maximum temperature increase at the center of the phantom was slightly above the target temperature (for the 45,55 and $65^{\circ} \mathrm{C}$ trials) due to thermal diffusion from the phantom boundary in contact with the $75^{\circ} \mathrm{C}$ water. The maximum temperature reached as well as the thermal dose values based on the time-temperature histories were calculated and are shown in table 3-1.

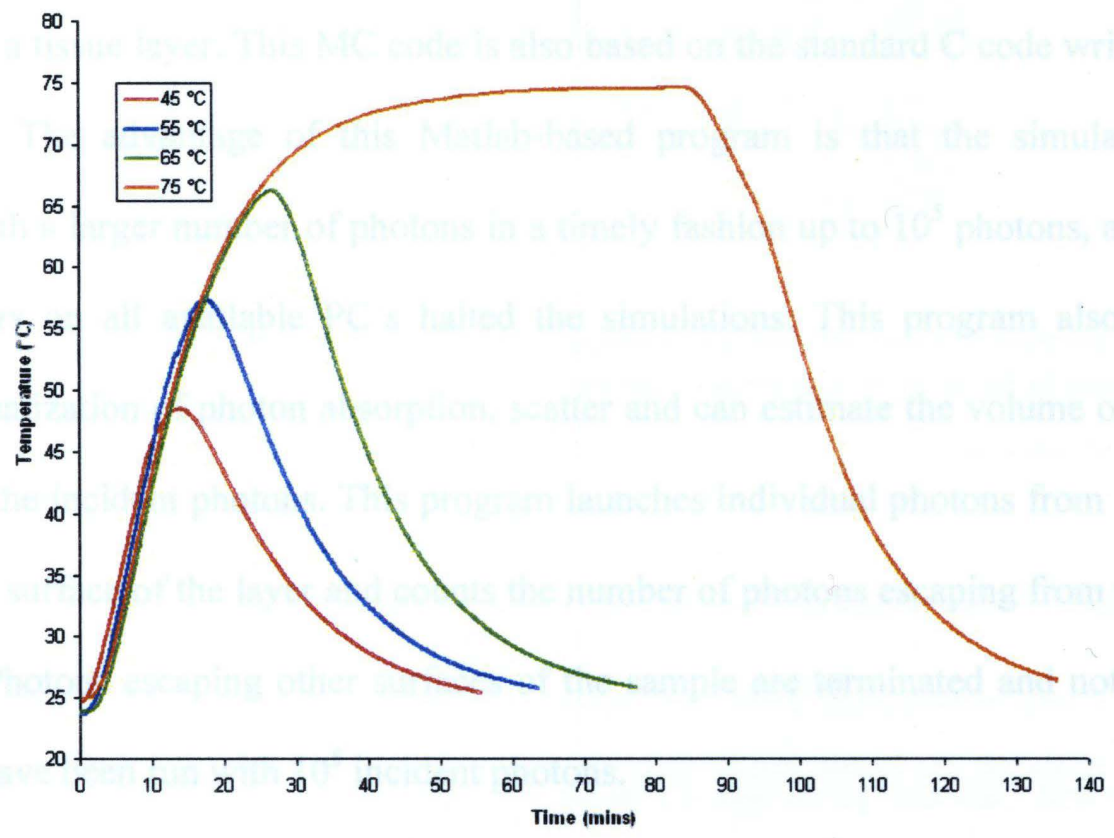

Figure 3-1 - Time-temperature histories for albumen phantoms heated to target temperatures of $45^{\circ} \mathrm{C}, 5^{\circ} \mathrm{C}$, $65^{\circ} \mathrm{C}$ and $75^{\circ} \mathrm{C}$ in a water bath maintained at $75^{\circ} \mathrm{C}$. 


\begin{tabular}{|c|c|c|}
\hline Target temperature $\left({ }^{\circ} \mathrm{C}\right)$ & $\begin{array}{c}\text { Maximum } \\
\text { temperature }\left({ }^{\circ} \mathrm{C}\right)\end{array}$ & $\begin{array}{c}\text { Thermal dose (eq. } \\
\left.\text { mins. at } 43^{\circ} \mathrm{C}\right)\end{array}$ \\
\hline 45 & 48.6 & 3.70 \\
\hline 55 & 57.5 & $1.44 \times 10^{3}$ \\
\hline 65 & 66.2 & $7.33 \times 10^{5}$ \\
\hline 75 & 75.0 & $2.65 \times 10^{9}$ \\
\hline
\end{tabular}

Table 3-1 - The target temperature at which each phantom was removed from the water bath, maximum temperature attained at the center of the phantom, and the thermal dose in equivalent minutes at $43^{\circ} \mathrm{C}$.

Each phantom was then cut in half as shown in figure 2-9. From a visual perspective, the phantoms have a light green color at room temperature due to the naphthol green dye component. No visible whitening was observed until the target temperature of $55^{\circ} \mathrm{C}$, where whitening around the edges of the phantom was observed while the center remained relatively green in color. Upon heating to $65^{\circ} \mathrm{C}$ and then $75^{\circ} \mathrm{C}$, visible whitening throughout the phantom was easily observable, indicating that the albumen protein component of the phantom had undergone thermal denaturation.

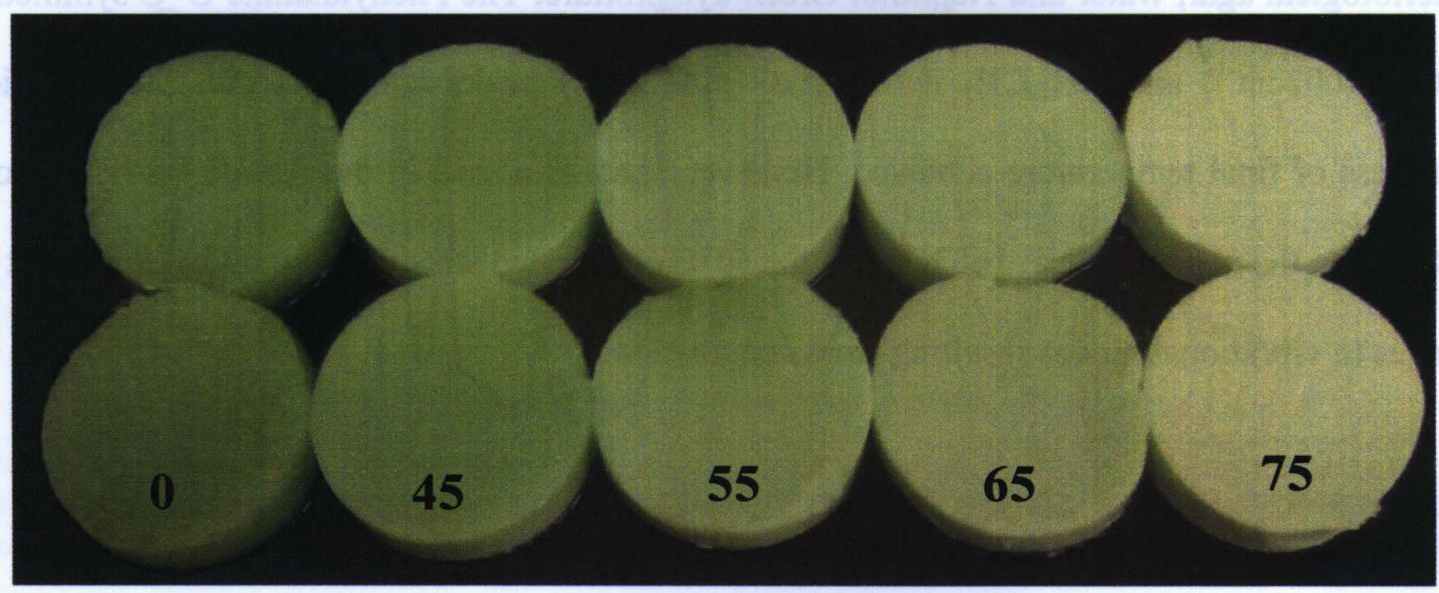

Figure 3-2 - Tissue-mimicking albumen phantoms heated to $45,55,65$ and $75^{\circ} \mathrm{C}$. Each phantom was cut in half and Raman spectra were acquired at the center. 
Raman spectra were then acquired at the center of each sample. The microthermocouple left an indentation in the phantom that was used as a guide to ensure that the Raman excitation and collection beams were focused on the exact region where the temperature was recorded during heating. For Raman acquisition, the integration time was set to 15 seconds and repeated for 15 cycles, for a total collection time of 225 seconds per spectrum, giving an acceptable SNR. These parameters were used to collect two spectra for each phantom half and therefore all Raman spectra collected for the phantoms are an average of 60 data sets. Raman spectra for each phantom are shown in figure 3-3. All spectra have been normalized to the largest intensity band $\left(1352 \mathrm{~cm}^{-1}\right)$ in the $75^{\circ} \mathrm{C}$ spectrum, and it can be seen that Raman peak intensity increases with temperature. For the $75^{\circ} \mathrm{C}$ target temperature, large peak intensity increases relative to the native state are observed, specifically in major bands due to albumen protein such as Phenylalanine $\mathrm{C}=\mathrm{C}$ symmetric stretch $\left(1002 \mathrm{~cm}^{-1}\right), \mathrm{CH}_{2}, \mathrm{CH}_{3}$ deformation $\left(1463 \mathrm{~cm}^{-1}\right)$ and the Amide I $\alpha$-helix $\left(1663 \mathrm{~cm}^{-1}\right)[5,16,23]$. Raman spectra obtained for a phantom with no albumen protein, shown in figure $3-4$, indicates that all other bands shown in figure $3-3$ can be assigned to the bacteriological agar, water and Naphthol Green dye mixture. The Phenylalanine $\mathrm{C}=\mathrm{C}$ symmetric stretch $\left(1002 \mathrm{~cm}^{-1}\right)$ and $\mathrm{CH}_{2}, \mathrm{CH}_{3}$ deformation $\left(1463 \mathrm{~cm}^{-1}\right)$ peaks remain at the same location regardless of final temperature achieved. However, there is a shift in the Amide I $\alpha$-helix from $1658 \mathrm{~cm}^{-1}$ in the native state to $1663 \mathrm{~cm}^{-1}$ in the $75^{\circ} \mathrm{C}$ coagulated state which may be as a result of changes in vibrational modes resulting from coagulation. 


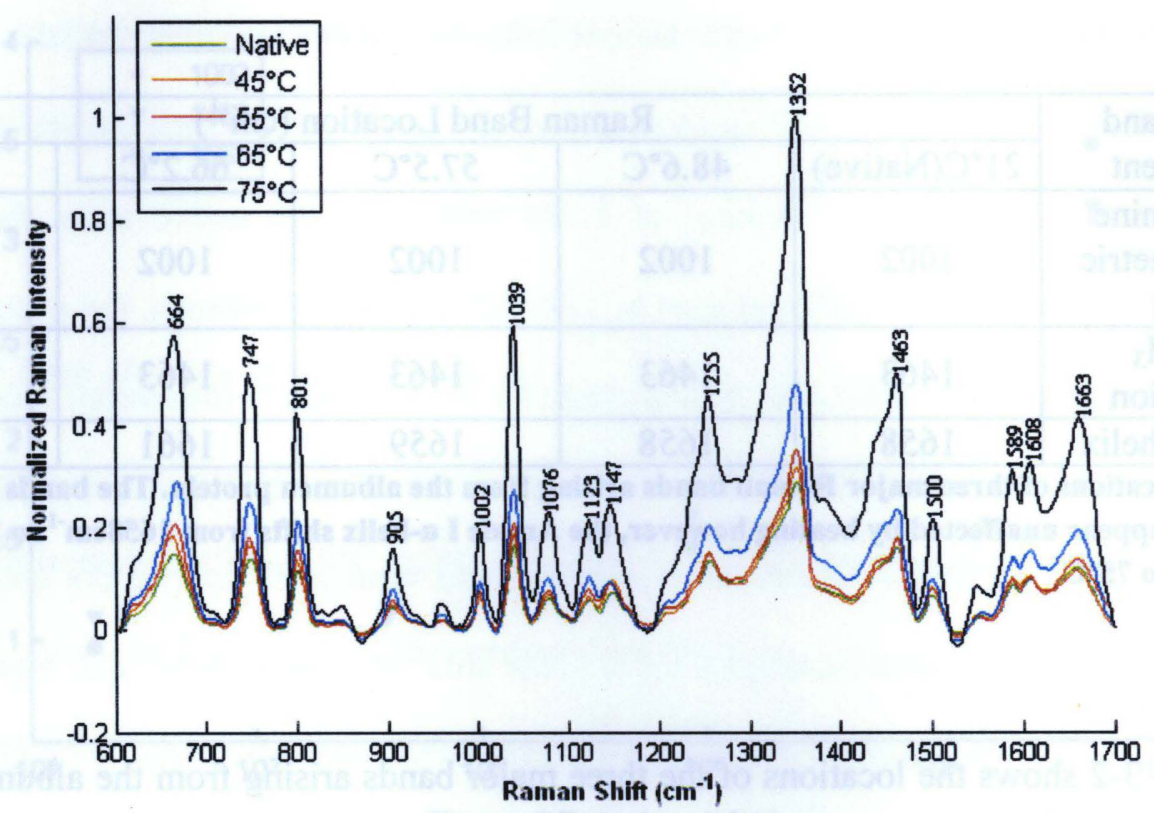

Figure 3-3 - Raman spectra of albumen phantoms at room temperature, and heated in a $75^{\circ} \mathrm{C}$ water bath to $45,55,65$ and $75^{\circ} \mathrm{C}$.

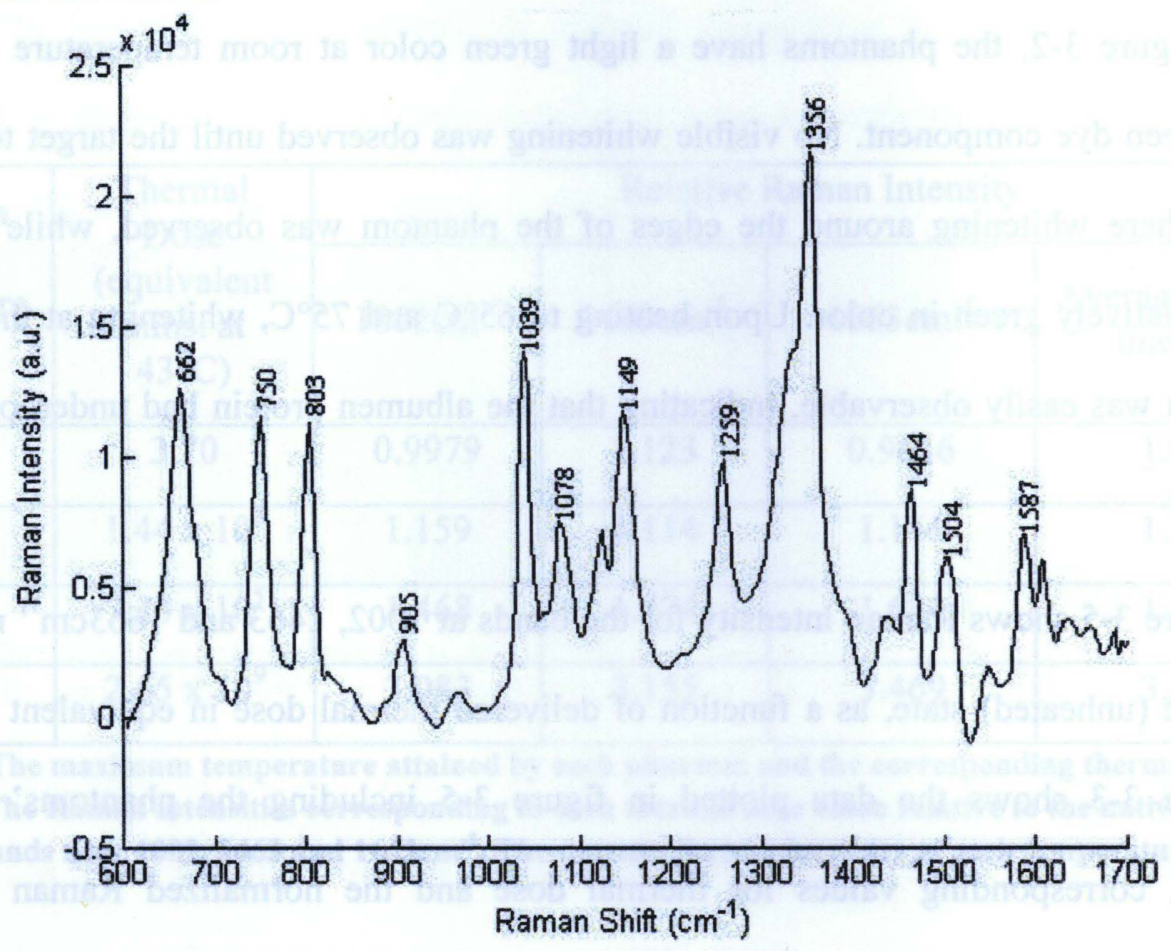

Figure 3-4 - Raman spectra of a phantom without albumen protein. Components include water, bacteriological agar and naphthol green dye. 


\begin{tabular}{|c|c|c|c|c|c|}
\hline Raman Band & \multicolumn{5}{|c|}{ Raman Band Location $\left(\mathrm{cm}^{-1}\right)$} \\
\cline { 2 - 6 } Assignment & $21^{\circ} \mathrm{C}$ (Native) & $48.6^{\circ} \mathrm{C}$ & $57.5^{\circ} \mathrm{C}$ & $66.2^{\circ} \mathrm{C}$ & $75.0^{\circ} \mathrm{C}$ \\
\hline $\begin{array}{c}\text { Phenylalanine } \\
\begin{array}{c}\mathrm{C}=\mathrm{C} \text { symmetric } \\
\text { stretch }\end{array}\end{array}$ & 1002 & 1002 & 1002 & 1002 & 1002 \\
\hline $\begin{array}{c}\mathrm{CH}_{2}, \mathrm{CH}_{3} \\
\text { deformation }\end{array}$ & 1463 & 1463 & 1463 & 1463 & 1463 \\
\hline Amide I $\alpha$-helix & 1658 & 1658 & 1659 & 1661 & 1663 \\
\hline
\end{tabular}

Table 3-2 - Locations of three major Raman bands arising from the albumen protein. The bands at $1002 \mathrm{~cm}^{-1}$ and $1463 \mathrm{~cm}^{-1}$ appear unaffected by heating however, the Amide I whelix shifts from $1658 \mathrm{~cm}^{-1}$ to $1663 \mathrm{~cm}^{-1}$ upon heating to $75^{\circ} \mathrm{C}$.

Table 3-2 shows the locations of the three major bands arising from the albumen protein $\left(1002 \mathrm{~cm}^{-1}, 1463 \mathrm{~cm}^{-1}\right.$ and near $\left.1663 \mathrm{~cm}^{-1}\right)$, illustrating the shift in the Amide I $\alpha$-helix from $1658 \mathrm{~cm}^{-1}$ to $1663 \mathrm{~cm}^{-1}$ due to thermal denaturation of albumen. From a visual perspective, as shown in figure $3-2$, the phantoms have a light green color at room temperature due to the naphthol green dye component. No visible whitening was observed until the target temperature of $55^{\circ} \mathrm{C}$, where whitening around the edges of the phantom was observed, while the center remained relatively green in color. Upon heating to $65^{\circ} \mathrm{C}$ and $75^{\circ} \mathrm{C}$, whitening at the center of the phantom was easily observable, indicating that the albumen protein had undergone thermal denaturation.

Figure 3-5 shows Raman intensity for the bands at 1002,1463 and $1663 \mathrm{~cm}^{-1}$ normalized to the native (unheated) state, as a function of delivered thermal dose in equivalent minutes at $43^{\circ} \mathrm{C}$. Table $3-3$ shows the data plotted in figure $3-5$ including the phantoms' maximum temperature, corresponding values for thermal dose and the normalized Raman intensities relative to the native state for the bands at 1002,1463 and $1663 \mathrm{~cm}^{-1}$. 


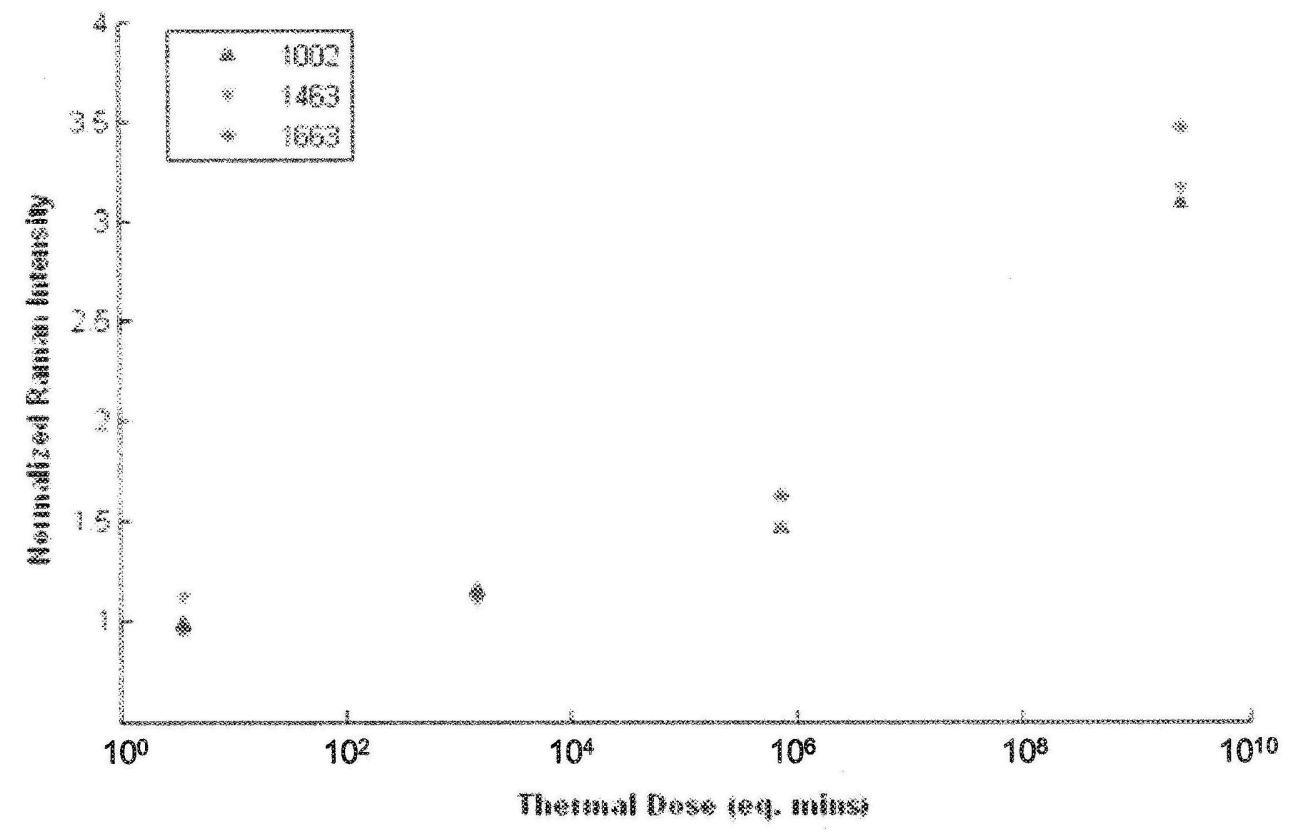

Figure 3-5 - Relationship between the relative Raman intezsity and the logm mear 1002,1463 and $1663 \mathrm{~cm}^{-1}$.

\begin{tabular}{|c|c|c|c|c|c|}
\hline \multirow{2}{*}{$\begin{array}{c}\text { Maximum } \\
\text { Phantom } \\
\text { Temperature } \\
\left({ }^{\circ} \mathrm{C}\right)\end{array}$} & \multirow{2}{*}{$\begin{array}{l}\text { Thermal } \\
\text { Dose } \\
\text { (equivalent } \\
\text { mins. at } \\
43^{\circ} \mathrm{C} \text { ) }\end{array}$} & \multicolumn{4}{|c|}{ Relative Raman Intensity } \\
\hline & & $1002 \mathrm{~cm}^{-1}$ & $1463 \mathrm{~cm}^{-1}$ & $1663 \mathrm{~cm}^{-1}$ & $\begin{array}{l}\text { Average Raman } \\
\text { Intensity }\end{array}$ \\
\hline 48.6 & 3.70 & 0.9979 & 1.123 & 0.9616 & 1.028 \\
\hline 57.5 & $1.44 \times 10^{3}$ & 1.159 & 1.114 & 1.146 & 1.140 \\
\hline 66.2 & $7.33 \times 10^{5}$ & 1.468 & 1.474 & 1.634 & 1.525 \\
\hline 75.0 & $2.65 \times 10^{9}$ & 3.083 & 3.155 & 3.469 & 3.236 \\
\hline
\end{tabular}

Tahle 3-3-The maximum temperature attained by exch phantome smo the contesponding thermal dose values are shown. The Raman intensities corresponding to each thermal dose valne relative co

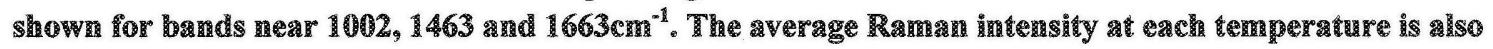
S 
As can be seen in figure 3-5 and table 3-3, Raman peak intensities remain near native values (normalized to 1) up to a thermal dose of $1.44 \times 10^{3}$ equivalent minutes, where the average Raman intensity increases to an average of 1.140 relative to the native state. As delivered thermal dose increases to $7.33 \times 10^{5}$ and then to $2.65 \times 10^{9}$ equivalent minutes, the average Raman intensity increases to 1.525 and 3.236. This trend holds for all bands in the overall spectra seen in figure 3-3. The overall Raman signal intensity increases with increasing target temperature as shown in figure 3-2. A shift in the Amide I $\alpha$-helix band from $1658 \mathrm{~cm}^{-1}$ in the native state to $1663 \mathrm{~cm}^{-1}$ was observed upon heating to $75^{\circ} \mathrm{C}$. This shift is in agreement with Ngarize et. al. who observed a $3 \mathrm{~cm}^{-1}$ shift in the Amide I $\alpha$-helix band in egg albumen heated to $90^{\circ} \mathrm{C}$ [17]. The absence of shifts in other major bands (Phenylalanine $\mathrm{C}=\mathrm{C}$ at $\sim 1002 \mathrm{~cm}^{-1}$ and $\mathrm{CH}_{2} / \mathrm{CH}_{3}$ deformation at $\sim 1463 \mathrm{~cm}^{-1}$ ) may be indicative of the more stable $2^{\circ}$ protein structure being less susceptible to the effects of coagulation. Further, the denaturation temperature of two major components of albumen (ovalbumin and conalbumin), have been determined to be $84.5^{\circ} \mathrm{C}$ and $61.0^{\circ} \mathrm{C}$ respectively [18]. The shift in the Amide I $\alpha$-helix may be an indication of the $2^{\circ}$ structure of conalbumin being affected by heating to $65^{\circ} \mathrm{C}$ and $75^{\circ} \mathrm{C}$ in addition to $3^{\circ}$ structure alterations due to thermal coagulation.

The increase in the Raman intensities may be due to changes in the optical properties of the phantoms upon coagulation. Recently, Castelino et. al. [117] showed that the scattering coefficient $\left(\mu_{s}\right)$ of albumen phantoms increased by a factor of $\sim 17$ after 40 minutes of heating in a $70^{\circ} \mathrm{C}$ water bath. These results are consistent with other reports of coagulation-induced increased optical scattering and diffuse reflectance in tissues shown by Lin et. al. and Parekh et. al. $[118,119]$. It is believed that these increases in scattering result from denaturation and hyalinization (a glassy appearance) of collagen and other proteins. The coagulation-induced 
increase in scattering may increase the photon flux from the sample surface, producing in increase in diffuse reflectance as shown by Parekh et. al. [119].

\section{2 - Water Bath Heating of Bovine Muscle}

Bovine muscle samples, cut into $3 \mathrm{~cm}$ squares approximately $2 \mathrm{~cm}$ thick depending on the sample, were heated to $45^{\circ} \mathrm{C}, 55^{\circ} \mathrm{C}, 65^{\circ} \mathrm{C}$ and $75^{\circ} \mathrm{C}$ following the procedure described in section 2.5 and are shown in figure 3-6. Time-temperature histories were recorded for each sample at locations described in section 2.5, and are shown in figure 3-7. Depending on the sample and room temperature, the initial tissue temperatures ranged from $22.9^{\circ} \mathrm{C}$ to $24.8^{\circ} \mathrm{C}$ as seen in figure 3-7. Thermal dose values based on the time-temperature histories were calculated and are shown in table 3-4.

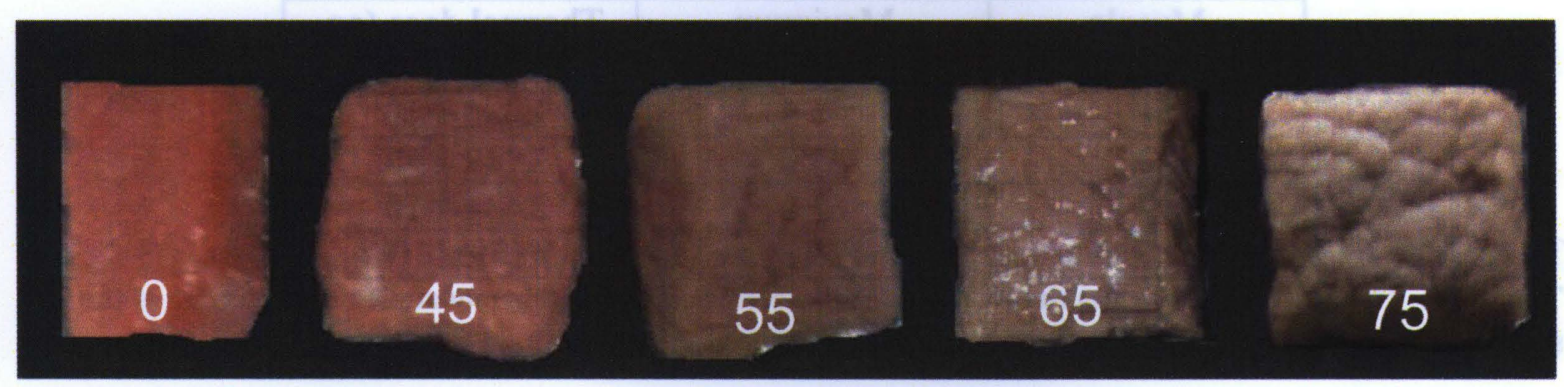

Figure 3-6- Bovine muscle samples heated to $45^{\circ} \mathrm{C}, 55^{\circ} \mathrm{C}, 65^{\circ} \mathrm{C}$ and $75^{\circ} \mathrm{C}$ in a water bath. 


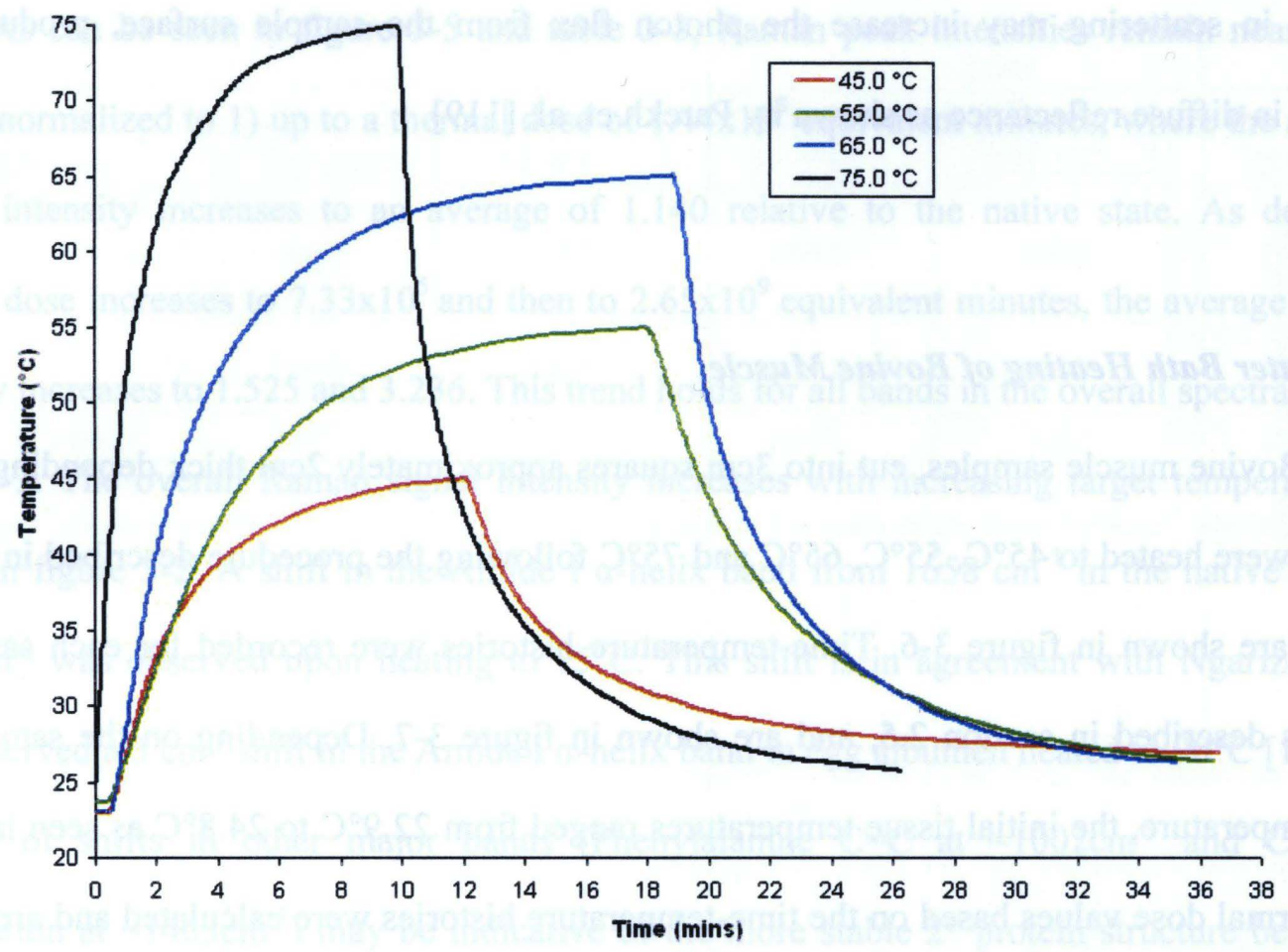

Figure 3-7 - Time-temperature histories for bovine muscle samples heated to target temperatures of $45^{\circ} \mathrm{C}$, $55^{\circ} \mathrm{C}, 65^{\circ} \mathrm{C}$ and $75^{\circ} \mathrm{C}$.

\begin{tabular}{|c|c|c|}
\hline $\begin{array}{c}\text { Muscle } \\
\text { Sample }\end{array}$ & $\begin{array}{c}\text { Maximum } \\
\text { temperature }\left({ }^{\circ} \mathrm{C}\right)\end{array}$ & $\begin{array}{c}\text { Thermal dose (eq. } \\
\left.\text { mins. at } 43^{\circ} \mathrm{C}\right)\end{array}$ \\
\hline 1 & 45.0 & $1.445 \times 10^{1}$ \\
\hline 2 & 55.0 & $2.149 \times 10^{4}$ \\
\hline 3 & 65.0 & $2.434 \times 10^{7}$ \\
\hline 4 & 75.0 & $1.169 \times 10^{10}$ \\
\hline
\end{tabular}

Table 3-4 - The muscle sample, maximum temperature recorded by the thermocouple near the edge of the sample and the thermal dose in equivalent minutes at $43^{\circ} \mathrm{C}$.

From the temperature profiles shown in figure 3-7 it can be seen that steepness of the slopes in both the heating and cooling portions of the curve increase as the water bath temperature increases, as expected. Raman spectra were then acquired from the edges of each sample. Two spectra were acquired from one side of the sample and two spectra were acquired from the opposite side of the sample. The integration time of the acquisitions were 15 seconds 
and repeated for 15 cycles, for a total collection time of 225 seconds per spectrum again giving an acceptable SNR. Therefore all Raman spectra collected for the bovine muscle samples are an average of 60 data sets.

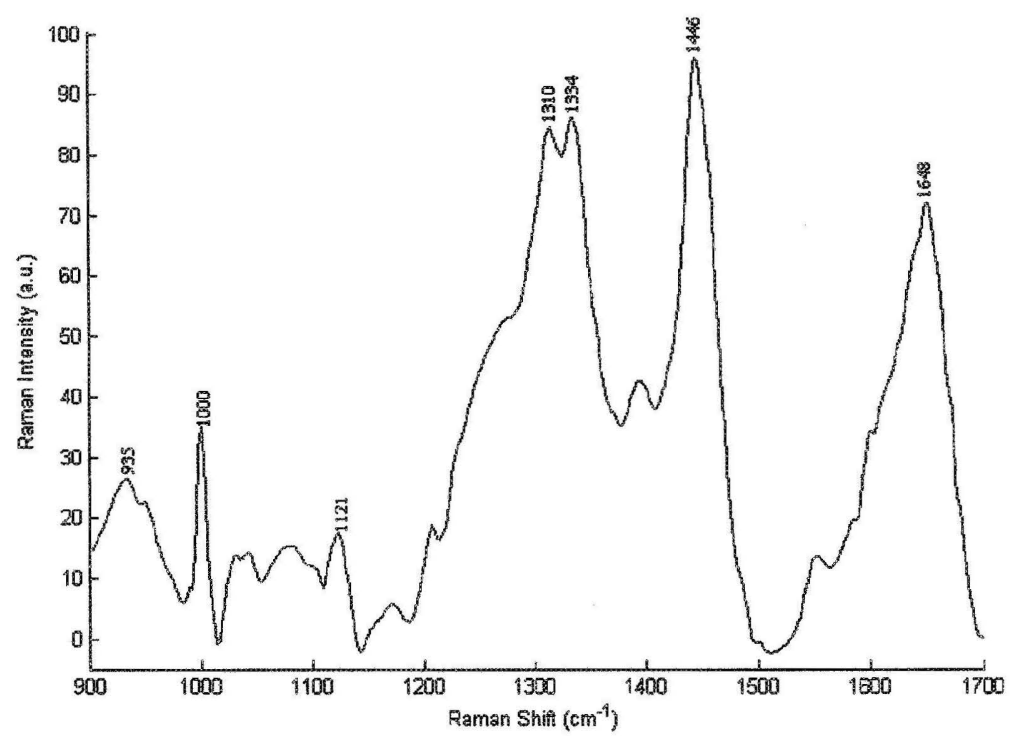

Figure 3-8 - Raman spectrum of bovine muscle with major bands arising from collagen labeled.

Figure 3-8 shows the Raman spectrum of bovine muscle in the native state. A number of strong Raman bands are easily identifiable, including many stretch vibrations $(v)$ and

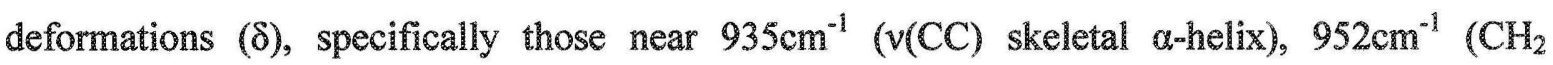
bending), $1000 \mathrm{~cm}^{-1}$ (Phenylalanine $\left.v(\mathrm{C}=\mathrm{C})\right), 1121 \mathrm{~cm}^{-1}(\mathrm{v}(\mathrm{CN})), 1310 \mathrm{~cm}^{-1}(\mathrm{v}(\mathrm{Ca}-\mathrm{H})), 1334 \mathrm{~cm}^{-1}$ (Tryptophan), $1446 \mathrm{~cm}^{-1}\left(\delta\left(\mathrm{CH}_{2} / \mathrm{CH}_{3}\right)\right)$ and $1648 \mathrm{~cm}^{-1}$ (Amide I $\alpha$-helix) $[5,19,23]$. Figure 3-9 compares the Raman spectra for bovine muscle in the native state and the target temperatures of $45^{\circ} \mathrm{C}, 55^{\circ} \mathrm{C}, 65^{\circ} \mathrm{C}$ and $75^{\circ} \mathrm{C}$. All spectra have been normalized to the largest in intensity band $\left(1446 \mathrm{~cm}^{-1}\right)$ and it can again be seen that Raman peak intensity increases with temperature. 


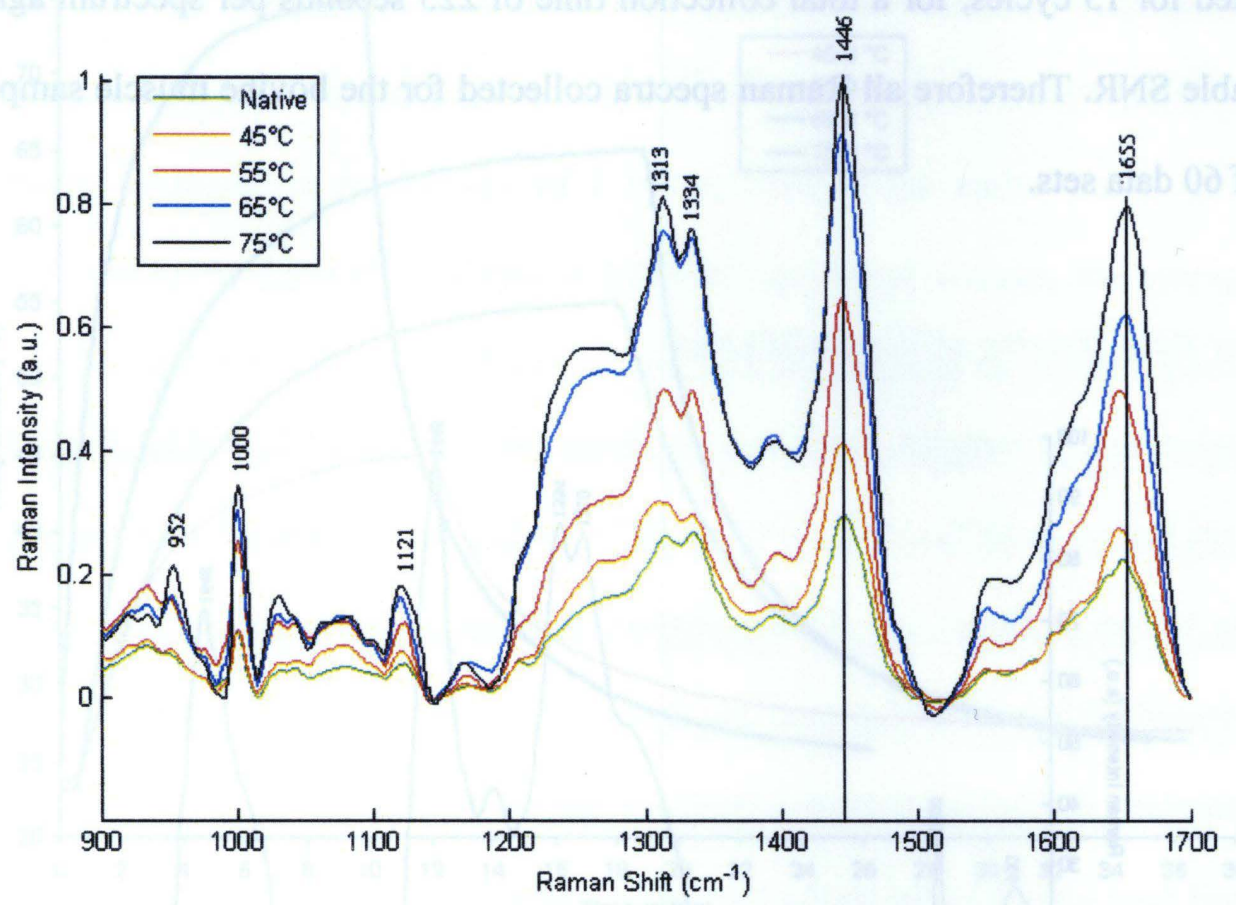

Figure 3-9 - Raman spectra of bovine muscle heated in a water bath to target temperatures of $45^{\circ} \mathrm{C}, 55^{\circ} \mathrm{C}$, $65^{\circ} \mathrm{C}$ and $75^{\circ} \mathrm{C}$. The black vertical lines have been inserted to make the band shift at $1655 \mathrm{~cm}^{-1}$ more clear.

The major bands at $952,1000,1121,1334$ and $1446 \mathrm{~cm}^{-1}$ remain at the same location regardless of temperature, perhaps indicating that the $2^{\circ}$ and $3^{\circ}$ structures of these particular components of the collagen protein are very stable and less susceptible to effects of thermal denaturation. However, there is a shift in the $(\mathrm{C} \alpha-\mathrm{H})$ group from $1310 \mathrm{~cm}^{-1}$ in the native state to $1313 \mathrm{~cm}^{-1}$ in the $65^{\circ} \mathrm{C}$ and $75^{\circ} \mathrm{C}$ coagulated states. Again, as seen in the albumen phantom results presented in section 3.1, a shift in the Amide I $\alpha$-helix is observed from $1648 \mathrm{~cm}^{-1}$ in the native state to $1655 \mathrm{~cm}^{-1}$ in the $75^{\circ} \mathrm{C}$ coagulated state. Further, there is a broadening of the shoulder leading up to the band at $1313 \mathrm{~cm}^{-1}$. In the native state, this shoulder gradually rises towards the peak at $1313 \mathrm{~cm}^{-1}$, however, in the $65^{\circ} \mathrm{C}$ and $75^{\circ} \mathrm{C}$ spectra, the shoulder rises sharply from 
$\sim 1200 \mathrm{~cm}^{-1}$ to $\sim 1250 \mathrm{~cm}^{-1}$ and then plateaus, followed by another very sharp rise at $\sim 1290 \mathrm{~cm}^{-1}$ towards the peak at $1313 \mathrm{~cm}^{-1}$.

\begin{tabular}{|c|c|c|c|c|c|}
\hline \multirow{2}{*}{$\begin{array}{l}\text { Raman Band } \\
\text { Assignment }\end{array}$} & \multicolumn{5}{|c|}{ Raman Band Location $\left(\mathrm{cm}^{-1}\right)$} \\
\hline & $21^{\circ} \mathrm{C}$ (Native) & $45.0^{\circ} \mathrm{C}$ & $55.0^{\circ} \mathrm{C}$ & $65.0^{\circ} \mathrm{C}$ & $75.0^{\circ} \mathrm{C}$ \\
\hline $\begin{array}{c}\text { Skeletal } \alpha \text {-helix } \\
\text { stretch }\end{array}$ & 935 & 935 & 935 & 935 & 935 \\
\hline $\mathrm{CH}_{2}$ bending & 952 & 952 & 952 & 952 & 952 \\
\hline $\begin{array}{c}\text { Phenylalanine } \\
\mathrm{C}=\mathrm{C} \text { symmetric } \\
\text { stretch }\end{array}$ & 1000 & 1000 & 1000 & 1000 & 1000 \\
\hline CN stretch & 1121 & 1121 & 1121 & 1121 & 1121 \\
\hline $\mathrm{C} \alpha-\mathrm{H}$ stretch & 1310 & 1310 & 1310 & 1313 & 1313 \\
\hline Tryptophan & 1334 & 1334 & 1334 & 1334 & 1334 \\
\hline $\begin{array}{c}\mathrm{CH}_{2}, \mathrm{CH}_{3} \\
\text { deformation }\end{array}$ & 1446 & 1446 & 1446 & 1446 & 1446 \\
\hline Amide I $\alpha$-helix & 1648 & 1648 & 1648 & 1653 & 1655 \\
\hline
\end{tabular}

Table 3-5 - Locations of the major Raman bands, specine to collagen, arising from bovine mascle samples. All bands are unaffected by heating however, the $\mathrm{C} Q-\mathrm{H}$ stretch group shifts from $1310 \mathrm{~cm}^{-1}$ to $1313 \mathrm{~cm}^{-1}$ and the Amide I a-helix shifts from $1648 \mathrm{~cm}^{-1}$ to $1655 \mathrm{~cm}^{-1}$ upon heating to $75^{\circ} \mathrm{C}$.

Table 3-5 shows the locations of the major bands arising from the collagen protein component of the bovine muscle samples, illustrating the shift in the $\mathrm{Ca}-\mathrm{H}$ stretch from $1310 \mathrm{~cm}^{-1}$ to $1313 \mathrm{~cm}^{-1}$ and in the Amide I $\alpha$-helix from $1648 \mathrm{~cm}^{-1}$ to $1655 \mathrm{~cm}^{-1}$ due to thermal denaturation. From a visual perspective, as shown in figure $3-6$, the bovine muscle samples have a dark-red color at room temperature due to the blood content, specifically myoglobin. No visible coagulation, or whitening, was observed until the target temperature of $55^{\circ} \mathrm{C}$. The dark-red color began to appear whiter, possibly indicating that some of the blood content was being removed due to heating. Upon heating to $65^{\circ} \mathrm{C}$ and $75^{\circ} \mathrm{C}$, whitening throughout the samples was easily observable, indicating that the collagen protein had undergone thermal denaturation. 
Figure 3-10 shows Raman intensity for the bands at 1000, 1446 and $1655 \mathrm{~cm}^{-1}$ normalized to the native (unheated) state, as a function of delivered thermal dose in equivalent minutes at $43^{\circ} \mathrm{C}$. Table 3-6 shows the data plotted in figure 3-10 including the target temperature of the muscle samples, corresponding values for thermal dose and the normalized Raman intensities relative to the native state for the bands at 1000,1446 and $1655 \mathrm{~cm}^{-1}$.

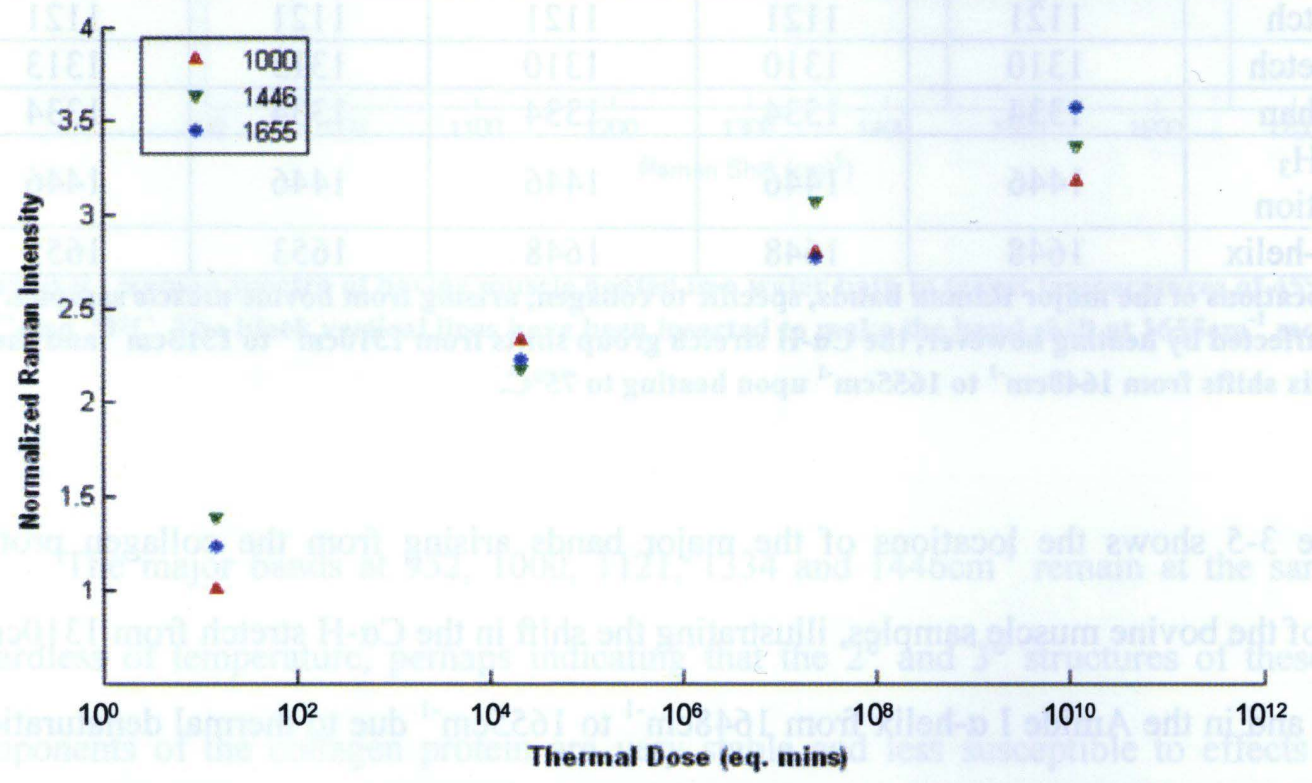

Figure 3-10 - Relationship between the relative Raman intensity and the logarithm of thermal dose for bands near 1000,1446 and $1655 \mathrm{~cm}^{-1}$. 


\begin{tabular}{|c|c|c|c|c|c|}
\hline \multirow{2}{*}{$\begin{array}{c}\text { Maximum } \\
\text { Temperature } \\
\left({ }^{\circ} \mathrm{C}\right)\end{array}$} & $\begin{array}{c}\text { Thermal } \\
\text { Dose } \\
\text { (equivalent } \\
\text { mins. at } \\
\left.43^{\circ} \mathrm{C}\right)\end{array}$ & $1000 \mathrm{~cm}^{-1}$ & $1446 \mathrm{~cm}^{-1}$ & $1655 \mathrm{~cm}^{-1}$ & $\begin{array}{c}\text { Average Raman } \\
\text { Intensity }\end{array}$ \\
\cline { 3 - 6 } & $1.445 \times 10^{1}$ & 1.012 & 1.385 & 1.230 & 1.239 \\
\hline 45.0 & $2.149 \times 10^{4}$ & 2.333 & 2.176 & 2.229 & 2.246 \\
\hline 55.0 & $2.434 \times 10^{7}$ & 2.804 & 3.075 & 2.776 & 2.885 \\
\hline 65.0 & $1.169 \times 10^{10}$ & 3.179 & 3.372 & 3.575 & 3.375 \\
\hline 75.0 & & &
\end{tabular}

Table 3-6 - The maximum temperature attained by the muscle sample and the corresponding thermal dose values are shown. The Raman intensities corresponding to each thermal dose value relative to the native state (normalized to 1) are shown for bands near 1000, 1446 and $1655 \mathrm{~cm}^{-1}$.

As can be seen in figure 3-10 and table 3-6, Raman peak intensities remain near native values (normalized to 1 ) up to a thermal dose of $1.445 \times 10^{1}$ equivalent minutes, as expected from previous phantom work. As the delivered thermal dose increases to $2.149 \times 10^{4}$, the average Raman intensity increases to 2.246 relative to the native state. Further, as the delivered thermal dose increases to $2.434 \times 10^{7}$ and then to $1.169 \times 10^{10}$, the average Raman intensities increase to 2.885 and 3.375 , respectively. However, this trend does not appear to hold for all bands in the overall spectrum. The bands near $1121 \mathrm{~cm}^{-1}$ and $1334 \mathrm{~cm}^{-1}$ clearly show increases with thermal dose up until the $65^{\circ} \mathrm{C}$ target temperature. The Raman intensities for these bands at $65^{\circ} \mathrm{C}$ and $75^{\circ} \mathrm{C}$ are essentially equal, perhaps indicating that the protein constituents responsible for these bands do not exhibit much variation in structure in the $65^{\circ} \mathrm{C}-75^{\circ} \mathrm{C}$ temperature range. Also, there is a shift in the $(\mathrm{C} \alpha-\mathrm{H})$ group from $1310 \mathrm{~cm}^{-1}$ in the native state to $1313 \mathrm{~cm}^{-1}$ in the $65^{\circ} \mathrm{C}$ and $75^{\circ} \mathrm{C}$ coagulated states and a shift in the Amide I $\alpha$-helix is observed from $1648 \mathrm{~cm}^{-1}$ in the native state to $1655 \mathrm{~cm}^{-1}$ in the $75^{\circ} \mathrm{C}$ coagulated state as seen in table $3-6$. 
There do not appear to be any studies in the literature on the analysis of thermal denaturation of bovine muscle using Raman Spectroscopy. However, the shift in the Amide I $\alpha$ helix band, a major functional group in collagen, appears to be in agreement with Dong et. al. who observed a $3 \mathrm{~cm}^{-1}$ shift $\left(1655 \mathrm{~cm}^{-1}\right.$ to $\left.1652 \mathrm{~cm}^{-1}\right)$ in Raman spectra of collagen I fiber collected at a temperature of $80^{\circ} \mathrm{C}$ [23]. Another important point worth noting is the direction of the shift in this band. At room temperature, the Stokes Raman process dominates, producing longer wavelengths and band shifts that increase in wavenumber $\left(1648 \mathrm{~cm}^{-1}\right.$ to $\left.1655 \mathrm{~cm}^{-1}\right)$ as seen in table 3-6. However, at higher temperatures, the anti-Stokes Raman process dominates, due to more molecules being found in excited states, producing shorter wavelengths and band shifts that decrease in wavenumber. Dong et. al. heated collagen fiber to $80^{\circ} \mathrm{C}$ and collected Raman spectra at this temperature. The anti-Stokes Raman effect produces a shift in the Amide I $\alpha$-helix from $1655 \mathrm{~cm}^{-1}$ at $20^{\circ} \mathrm{C}$ to $1652 \mathrm{~cm}^{-1}$ at $80^{\circ} \mathrm{C}$ [23]. Moreover, this shift in the Amide I $\alpha$-helix appears to be an indication of the $2^{\circ}$ and $3^{\circ}$ structures being affected by heating to $75^{\circ} \mathrm{C}$. However, the absence of shifts in other major bands (Phenylalanine $\mathrm{C}=\mathrm{C}$ at $\sim 1000 \mathrm{~cm}^{-1}$ and $\mathrm{CH}_{2} / \mathrm{CH}_{3}$ deformation at $\sim 1446 \mathrm{~cm}^{-1}$ ) may again be as a result of the more stable $2^{\circ}$ protein structure being less susceptible to the effects of heating at $75^{\circ} \mathrm{C}$ despite the denaturation temperature of collagen being $\sim 63^{\circ} \mathrm{C}[22]$.

The increase in the Raman intensities may be due to changes in the optical properties of bovine muscle as a result of coagulation. Agah et. al. showed that the scattering coefficient of bovine muscle myocardial tissue was $(0.08 \pm 0.06) \mathrm{mm}^{-1}$ in unheated samples. After heating to temperatures of $51.5-53.6^{\circ} \mathrm{C}$ and $56.8-75^{\circ} \mathrm{C}, \mu_{\mathrm{s}}$ increased to $(0.12 \pm 0.06) \mathrm{mm}^{-1}$ and $(0.14 \pm$ $0.04) \mathrm{mm}^{-1}$ respectively [120]. Similar results were reported by Thomsen et. al and Derbyshire et. al. $[121,122]$. It is believed that these increases in scattering result from the denaturation of 
collagen in the muscle tissues. Also, the coagulation-induced increase in $\mu_{s}$ may reduce the penetration depth of incident photons and therefore increase the photon flux from the sample surface [120] which most likely accounts for the increase in Raman intensity observed in this work.

\section{3-Lase Photocoagulation of Bovine Muscle}

Photocoagulation of bovine muscle was performed according to the procedure described in section 2.6. Time-temperature histories recorded for at each thermocouple are shown in figure 3-11. Thermal dose values based on the time-temperature histories were calculated and are shown in table 3-7. The maximum temperature recorded by the thermocouple $2 \mathrm{~mm}$ from the laser fiber reached $90^{\circ} \mathrm{C}$, at which point the laser power was turned off. The temperature at this location rises very quickly at the beginning of the heating process and the slope remains quite steep throughout. After the laser is turned off, the slope in the cooling portion of the curve is very sharp, illustrating the rapid cooling that occurs after the laser is tumed off. Maximum temperatures of $57.0^{\circ} \mathrm{C}$ and $46.6^{\circ} \mathrm{C}$ were recorded by the thermocouples at $5 \mathrm{~mm}$ and $10 \mathrm{~mm}$ from the laser fiber respectively. The slopes in the heating portion of these curves are less steep than the curve with a maximum temperature of $90^{\circ} \mathrm{C}$. Also, the cooling process is more gradual from these temperatures than from $90^{\circ} \mathrm{C}$ as seen in figure 3.11 . The thermal lesion created is shown in figure $3-12$, indicating the locations where the laser fiber and three thermocouples left indentations in the tissue. 


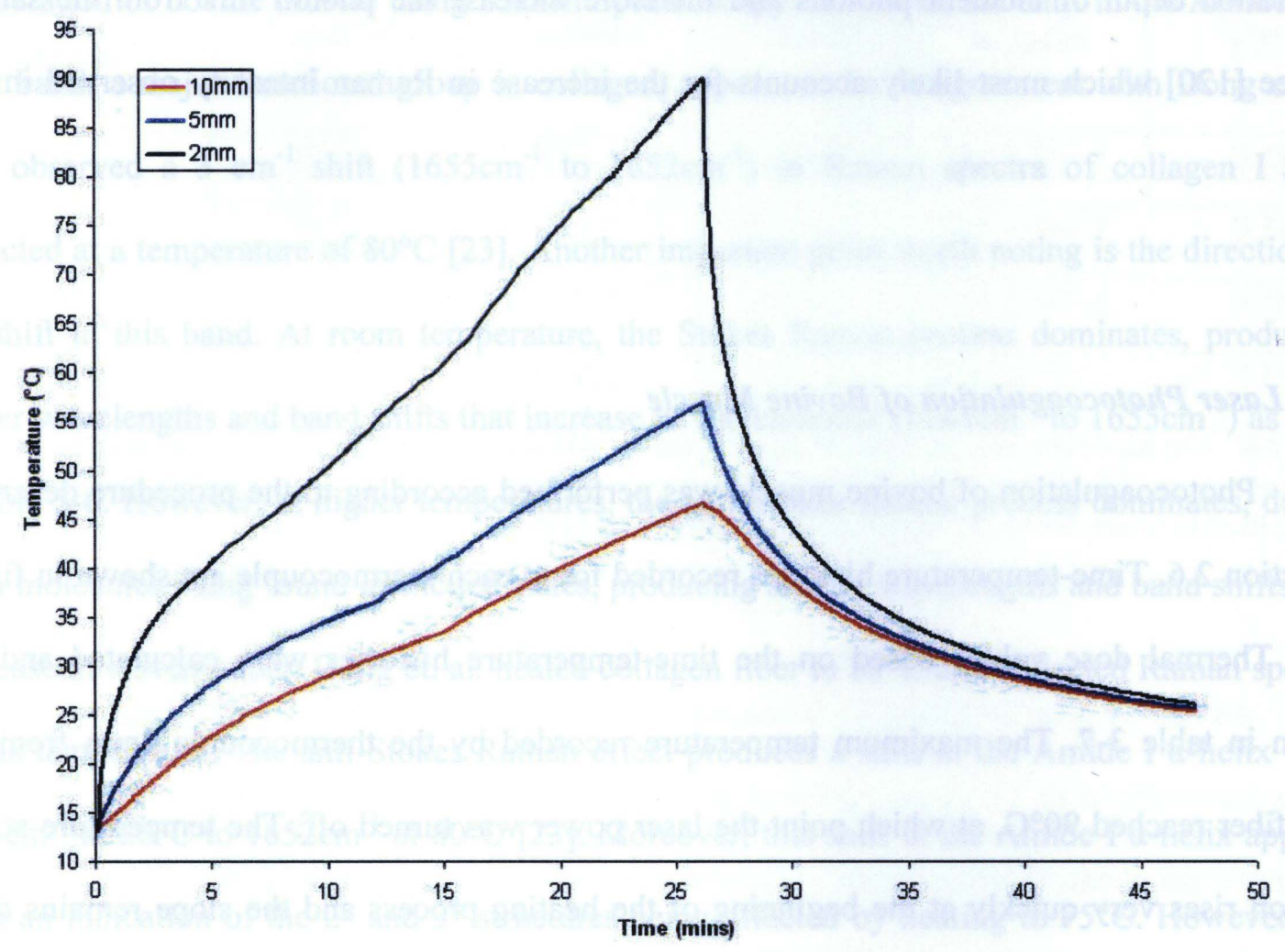

Figure 3-11 - Time-temperature histories for laser photocoagulation of bovine muscle measured at $10 \mathrm{~mm}$, $5 \mathrm{~mm}$ and $2 \mathrm{~mm}$ from the laser fiber.

\begin{tabular}{|c|c|c|}
\hline $\begin{array}{c}\text { Thermocouple Distance } \\
\text { from Laser Fiber }\end{array}$ & $\begin{array}{c}\text { Maximum } \\
\text { temperature }\left({ }^{\circ} \mathrm{C}\right)\end{array}$ & $\begin{array}{c}\text { Thermal dose (eq. } \\
\left.\text { mins. at } 43^{\circ} \mathrm{C}\right)\end{array}$ \\
\hline $2 \mathrm{~mm}$ & 90.0 & $9.478 \times 10^{13}$ \\
\hline $5 \mathrm{~mm}$ & 57.0 & $1.909 \times 10^{4}$ \\
\hline $10 \mathrm{~mm}$ & 46.6 & $2.508 \times 10^{1}$ \\
\hline
\end{tabular}

Table 3-7 - The thermocouple location, maximum temperature recorded by each thermocouple and the thermal dose in equivalent minutes at $43^{\circ} \mathrm{C}$. 


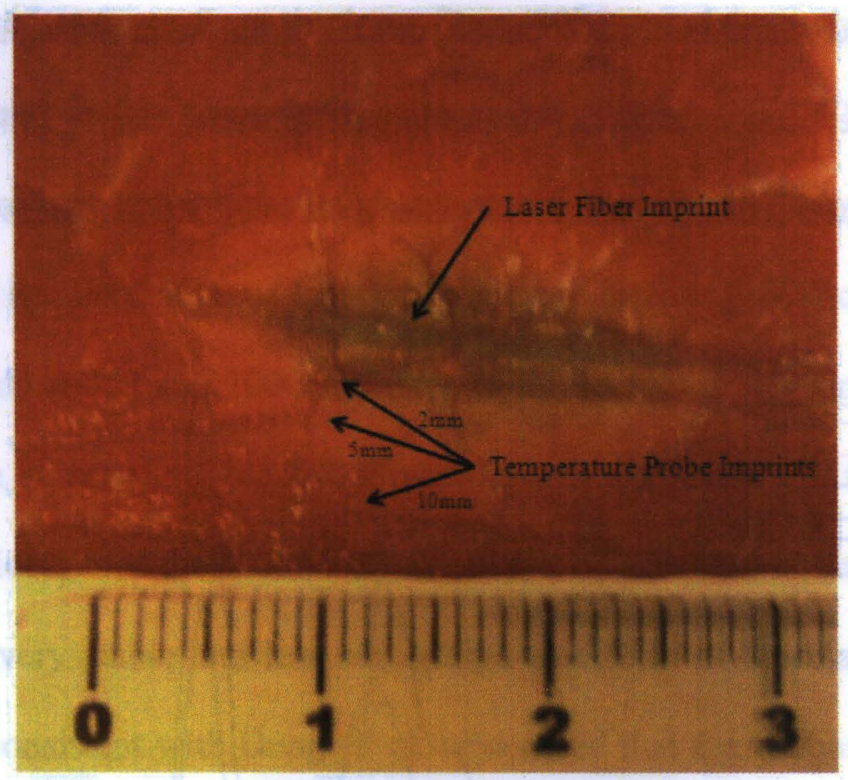

Figure 3-12 - Thermal lesion created in bovine muscle samples heated with an 805nm laser operating at $7 \mathrm{~W}$. Indentations by the laser fiber and three thermocouples are indicated.

Raman spectra were acquired from different locations within the lesion. Each thermocouple left an indentation in the tissue sample as can be seen in figure 3-12, which were used as a guide to ensure that the excitation beam overlapped the location where the temperature was recorded during heating. Raman spectra were collected at each thermocouple location as well as $5 \mathrm{~cm}$ away from the laser fiber. This distance ensured that a Raman spectrum of the native state of the sample was acquired and that the light from the laser fiber did not affect the temperature measurements. Although the temperature of the tissue was not recorded at this location, it was assumed that $5 \mathrm{~cm}$ was a sufficient distance from the laser fiber avoiding direct heating as seen by the visible radius of the thermal lesion in figure 3-12. For Raman acquisition, the integration time was set to 15 seconds and repeated for 15 cycles, for a total collection time of 225 seconds per spectrum. These parameters were used to collect two spectra at each location and therefore all Raman spectra collected for the phantoms are an average of 30 data sets. Raman 
spectra collected at each thermocouple location, as well as in the native state are shown in figure 3-13. All spectra have been normalized to the largest intensity band $\left(1446 \mathrm{~cm}^{-1}\right)$ in the $90.0^{\circ} \mathrm{C}$ spectrum, and once again it can be seen that Raman peak intensity increases with temperature.

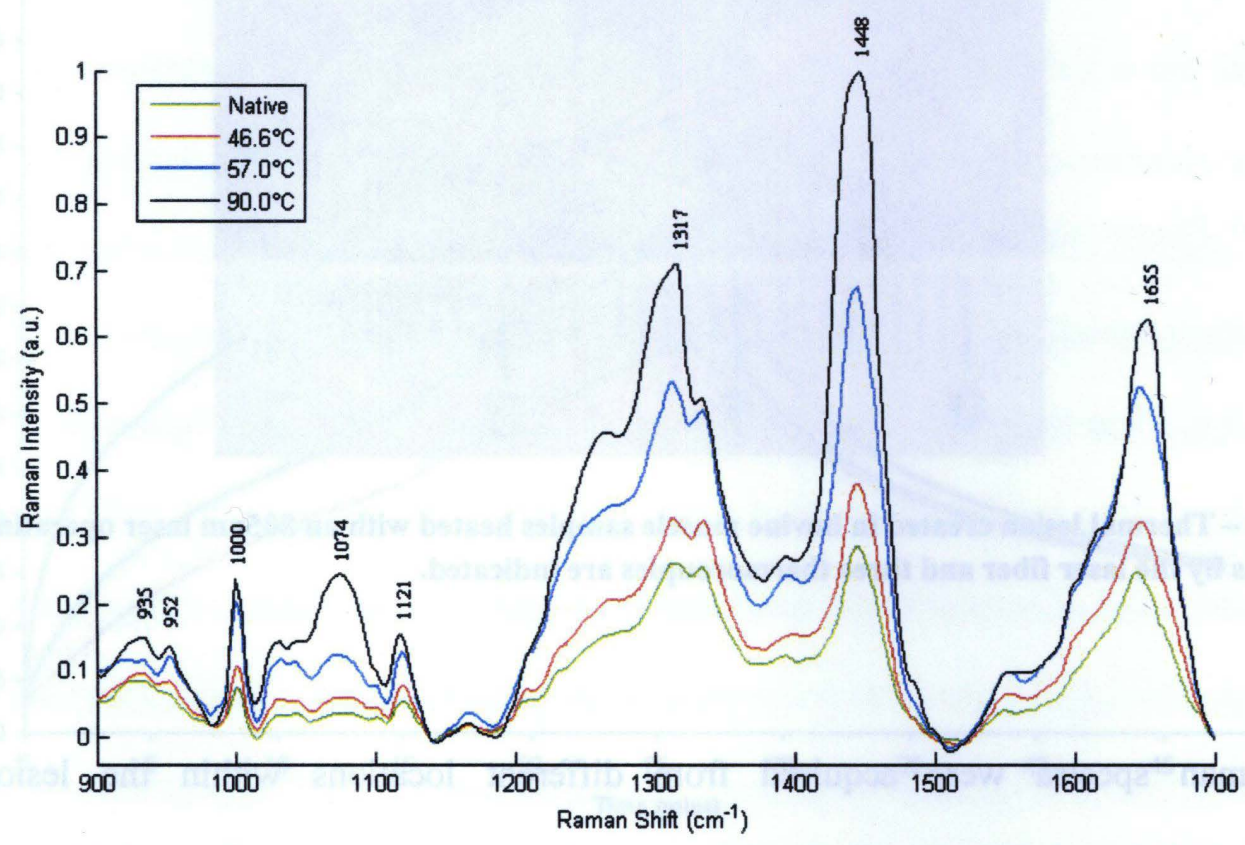

Figure 3-13 - Raman spectra of bovine muscle in the native state and heated by laser photocoagulation. Temperatures of $90.0^{\circ} \mathrm{C}, 57.0^{\circ} \mathrm{C}$ and $46.6^{\circ} \mathrm{C}$ were recorded at $2 \mathrm{~mm}, 5 \mathrm{~mm}$ and $10 \mathrm{~mm}$ respectively from the laser fiber. Raman spectra were collected at these locations.

Figure 3-13 shows the Raman spectrum of bovine muscle following laser photocoagulation collected from regions where temperatures reached $46.6^{\circ} \mathrm{C}, 57.0^{\circ} \mathrm{C}$ and $90.0^{\circ} \mathrm{C}$ as well as the unheated area of the tissue. Once again, many strong Raman bands are easily identifiable, including many stretch vibrations $(v)$ and deformations $(\delta)$, specifically those near $935 \mathrm{~cm}^{-1}\left(v(\mathrm{CC})\right.$ skeletal $\alpha$-helix), $952 \mathrm{~cm}^{-1}\left(\mathrm{CH}_{2}\right.$ bending), $1000 \mathrm{~cm}^{-1}$ (Phenylalanine $v(\mathrm{C}=\mathrm{C})$ ), $1074 \mathrm{~cm}^{-1}$ and $1123 \mathrm{~cm}^{-1}(\mathrm{v}(\mathrm{CN})), 1317 \mathrm{~cm}^{-1}(\mathrm{v}(\mathrm{C} \alpha-\mathrm{H})), 1334 \mathrm{~cm}^{-1}$ (Tryptophan), $1448 \mathrm{~cm}^{-1}$ $\left(\delta\left(\mathrm{CH}_{2} / \mathrm{CH}_{3}\right)\right)$ and $1655 \mathrm{~cm}^{-1}$ (Amide I $\alpha$-helix) $[5,19,23]$. As expected from previous results, the 
Raman spectra acquired at $2 \mathrm{~mm}$ from the laser fiber $\left(90^{\circ} \mathrm{C}\right)$ produce more intense bands and a number of notable band shifts. Also, the spectra acquired $5 \mathrm{~mm}\left(57.0^{\circ} \mathrm{C}\right)$ and $10 \mathrm{~mm}\left(46.6^{\circ} \mathrm{C}\right)$ from the laser fiber produce less intense bands as seen in figure 3-11. However, the major bands in the Raman spectra acquired at these locations are more intense than those in the native state, as expected. The bands at 952 and $1000 \mathrm{~cm}^{-1}$ once again, remain at the same location regardless of temperature as can be seen in table 3-8. Given the extreme heating of the tissue $\left(90^{\circ} \mathrm{C}\right)$, this further seems to indicate that the $2^{\circ}$ and $3^{\circ}$ structures of these particular components of the collagen protein are very stable and less susceptible to effects of thermal denaturation. These results appear to be consistent with Dong et. al. who noted that the Raman band near $1000 \mathrm{~cm}^{-1}$ (Phenylalanine $v(C=C)$ ) remained at the same location upon heating to $80^{\circ} \mathrm{C}[23]$. A number of notable band shifts upon heating to $90^{\circ} \mathrm{C}$ can be seen in table $3-8$. There are band shifts in the (v(CN)) group from $1121 \mathrm{~cm}^{-1}$ to $1123 \mathrm{~cm}^{-1}$, the $(\mathrm{C \alpha}-\mathrm{H})$ group from $1312 \mathrm{~cm}^{-1}$ to $1317 \mathrm{~cm}^{-1}$ and the $\left(\delta\left(\mathrm{CH}_{2} / \mathrm{CH}_{3}\right)\right)$ group from $1446 \mathrm{~cm}^{-1}$ to $1448 \mathrm{~cm}^{-1}$. Again, as in previous results, a shift in the Amide I $\alpha$-helix is observed from $1648 \mathrm{~cm}^{-1}$ in the native state to $1655 \mathrm{~cm}^{-1}$ in the $90^{\circ} \mathrm{C}$ coagulated state.

\begin{tabular}{|c|c|c|c|c|}
\hline Raman Band & \multicolumn{4}{|c|}{ Raman Band Location $\left(\mathrm{cm}^{-1}\right)$} \\
\cline { 2 - 5 } Assignment & Native $\left(20^{\circ} \mathrm{C}\right)$ & $46.6^{\circ} \mathrm{C}$ & $57.0^{\circ} \mathrm{C}$ & $90.0^{\circ} \mathrm{C}$ \\
\hline $\begin{array}{c}\text { Skeletal } \alpha \text {-helix } \\
\text { stretch }\end{array}$ & 935 & 935 & 935 & 935 \\
\hline $\mathrm{CH}_{2}$ bending & 952 & 952 & 952 & 952 \\
\hline $\begin{array}{c}\text { Phenylalanine } \\
\mathrm{C}=\mathrm{C} \text { symmetric } \\
\text { stretch }\end{array}$ & 1000 & 1000 & 1000 & 1000 \\
\hline $\begin{array}{c}\mathrm{CN} \text { stretch } \\
\mathrm{C} \alpha \text {-H stretch }\end{array}$ & 1121 & 1121 & 1121 & 1123 \\
\hline $\begin{array}{c}\mathrm{CH},{ }_{2}, \mathrm{CH} \\
\text { deformation }\end{array}$ & 1446 & 1312 & 1312 & 1317 \\
\hline Amide I $\alpha$-helix & 1648 & 1646 & 1446 & 1448 \\
\hline
\end{tabular}

Table 3-8 - Locations of the major Raman bands, specific to collagen, after laser photocoagulation of bovine muscle. Shifting in a mumber of bands is noted upon heating the tissue to $90^{\circ} \mathrm{C}$. 
As seen in the Raman spectra of bovine muscle heated in a water bath (figure 3-9), there is again a change in the shape of the shoulder leading up to the band at $(\mathrm{C} \alpha-\mathrm{H}) 1317 \mathrm{~cm}^{-1}$. In the native and $46.6^{\circ} \mathrm{C}$ states, this shoulder gradually rises towards the peak, however, in the $57.0^{\circ} \mathrm{C}$ state, the shoulder becomes steeper and in the $90.0^{\circ} \mathrm{C}$ spectrum, the shoulder rises sharply from $\sim 1230 \mathrm{~cm}^{-1}$ to $\sim 1270 \mathrm{~cm}^{-1}$ and then plateaus. A second very sharp rise can be seen at $\sim 1290 \mathrm{~cm}^{-1}$ towards the peak at $1313 \mathrm{~cm}^{-1}$. Another point of note is the significant reduction in intensity of the Tryptophan band at $1334 \mathrm{~cm}^{-1}$ upon heating to $90^{\circ} \mathrm{C}$. This band nearly disappears from the Raman spectrum at this temperature. This may be due to the degradation of Tryptophan's large indole side chain due to heating. Cuq et. al. showed that protein-bound Tryptophan residues were degraded upon heating to temperatures over $100^{\circ} \mathrm{C}[123,124]$. Moreaux and Birlouez-Aragon showed that $46-55 \%$ of Tryptophan residues were lost upon heating a Lactose-Tryptophan mixture to a temperature of $155^{\circ} \mathrm{C}$ for 2 minutes. Therefore, heating the bovine muscle sample to $90^{\circ} \mathrm{C}$ may cause a reduction in the protein-bound Tryptophan residues thus reducing the number of Raman interactions which causes the Tryptophan band at $1334 \mathrm{~cm}^{-1}$ to be reduced in intensity.

Figure 3-14 shows Raman intensity for the bands at $1000,1317,1448$ and $1655 \mathrm{~cm}^{-1}$ normalized to the native (unheated) state, as a function of delivered thermal dose in equivalent minutes at $43^{\circ} \mathrm{C}$. Table 3.9 shows the data plotted in figure 3.14 including the maximum temperature recorded by each thermocouple, corresponding values for thermal dose and the normalized Raman intensities relative to the native state for the bands at $1000,1317,1448$ and $1655 \mathrm{~cm}^{-1}$. The standard deviation between points in figure 3-14 appears slightly larger than previous figures showing Raman intensity versus thermal dose. This may be due to the fact that laser heating produces a less uniform thermal dose delivery to the tissue than water bath heating. 


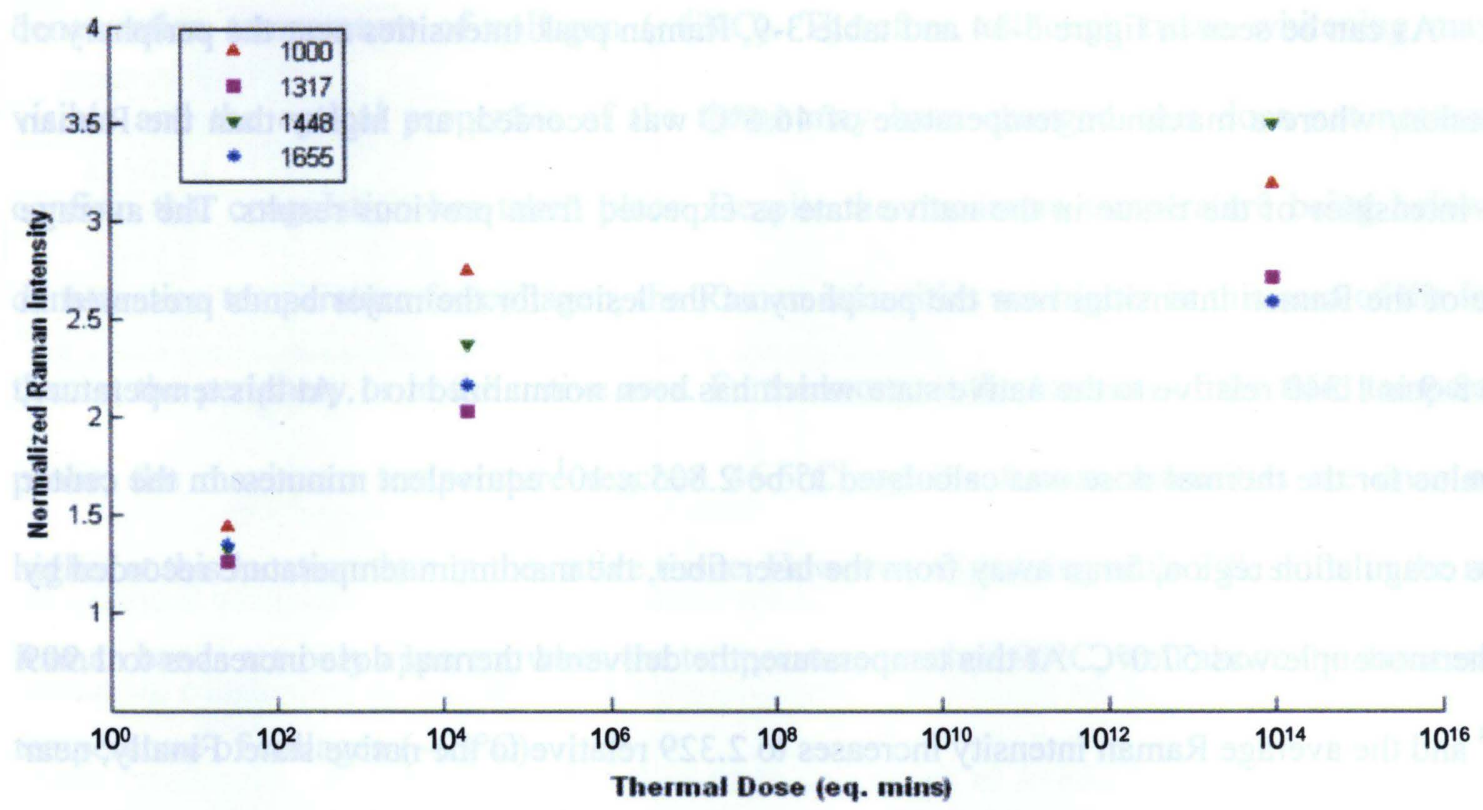

Figure 3-14 - Relationship between the relative Raman intensity and the logarithm of thermal dose for bands near $1000,1317,1448$ and $1655 \mathrm{~cm}^{-1}$.

\begin{tabular}{|c|c|c|c|c|c|c|}
\hline \multirow{2}{*}{$\begin{array}{c}\text { Maximum } \\
\text { Temperature } \\
\left({ }^{\circ} \mathrm{C}\right)\end{array}$} & $\begin{array}{c}\text { Thermal } \\
\text { Dose } \\
\text { (equivalent } \\
\text { mins. at } \\
\left.43^{\circ} \mathrm{C}\right)\end{array}$ & \multicolumn{5}{|c|}{ Relative Raman Intensity } \\
\cline { 3 - 7 } & $2.508 \times 10^{1}$ & 1.438 & 1.255 & 1.328 & 1.339 & 1.340 \\
\hline 46.6 & $1.909 \times 10^{4}$ & 2.754 & 2.029 & 2.366 & 2.166 & 2.329 \\
\hline 57.0 & $9.478 \times 10^{13}$ & 3.193 & 2.717 & 3.498 & 2.589 & 3.000 \\
\hline 90.0 & & & $1317 \mathrm{~cm}^{-1}$ & $1446 \mathrm{~cm}^{-1}$ & $1655 \mathrm{~cm}^{-1}$ & $\begin{array}{c}\text { Average } \\
\text { Intensity }\end{array}$ \\
\hline
\end{tabular}

Table 3-9 - The maximum temperature recorded by each thermocouple and the corresponding thermal dose values are shown. The Raman intensities corresponding to each thermal dose value relative to the native state (normalized to 1) are shown for bands near $1000,1317,1448$ and $1655 \mathrm{~cm}^{-1}$. 
As can be seen in figure 3-14 and table 3-9, Raman peak intensities near the periphery of the lesion, where a maximum temperature of $46.6^{\circ} \mathrm{C}$ was recorded, are higher than the Raman peak intensities of the tissue in the native state as expected from previous results. The average value of the Raman intensities near the periphery of the lesion for the major bands presented in table 3-9 is 1.340 relative to the native state which has been normalized to 1 . At this temperature, the value for the thermal dose was calculated to be $2.805 \times 10^{1}$ equivalent minutes. In the center of the coagulation region, $5 \mathrm{~mm}$ away from the laser fiber, the maximum temperature recorded by the thermocouple was $57.0^{\circ} \mathrm{C}$. At this temperature, the delivered thermal dose increases to 1.909 $\times 10^{4}$ and the average Raman intensity increases to 2.329 relative to the native state. Finally, near the center of the lesion, $2 \mathrm{~mm}$ away from the laser fiber, a maximum temperature of $90^{\circ} \mathrm{C}$ was recorded, at which point the heating was terminated. Although the thermal dose value increased to $9.478 \times 10^{13}$, the Raman intensity only increases to 3.000 relative to the native state. Overall, consistent with water bath heating of bovine muscle, there once again appears to be a correlation between Raman signal intensity and increasing thermal dose delivered to the sample. As seen in table $3-8$, there are once again shifts in the major bands near $1121 \mathrm{~cm}^{-1}, 1312 \mathrm{~cm}^{-1}, 1446 \mathrm{~cm}^{-1}$ and $1648 \mathrm{~cm}^{-1}$. These band shifts only appear once the tissue is heated above the coagulation temperature of collagen $\left(\sim 63^{\circ} \mathrm{C}\right)$. At a thermal dose of $9.478 \times 10^{13}$, the average Raman intensity only increases to 3.000 relative to the native state.

Examining the thermal lesion shown in figure $3-12$, it can be seen that a near the imprint of the laser fiber and the temperature probe at $2 \mathrm{~mm}$ from the laser fiber, the tissue has a dark grey color, indicating that tissue coagulation has certainly taken place. At $5 \mathrm{~mm}$ from the laser fiber where the temperature probe was located, a whitening of the tissue can be seen. However, the maximum temperature recorded at this location was only $57.0^{\circ} \mathrm{C}$, which is below the 
denaturation temperature of collagen $\left(-63^{\circ} \mathrm{C}\right)$. Therefore, although tissue whitening may be visible and the optical properties of the tissue may have changed, this does not necessarily confirm that coagulation has taken place. Despite the maximum temperature being below the denaturation temperature for collagen, the Raman intensities are higher in this area of the lesion than at the periphery or in the native area. Furthermore, at the location of the third temperature probe, the maximum temperature reached $46.6^{\circ} \mathrm{C}$ and the Raman intensities are once again higher at this location than in the native tissue. However, examining table $3-8$, shifts in the major Raman bands are only apparent when the temperature reached $90^{\circ} \mathrm{C}$, well above the denaturation temperature of collagen $\left(\sim 63^{\circ} \mathrm{C}\right)$.

\section{4-Monte Carlo Simulations of Photon Migration in Tissue}

Monte Carlo (MC) simulations were performed using both a MC Maplet code written by Yip and Carvalho [115] and a Matlab MC code written in-house. Photons were launched at an angle of $90^{\circ}$ into the simulated tissue layer. Using the MC Maplet, values for the diffuse reflectance and plots of photons absorption versus tissue depth were obtained. Table 3-10 shows the values for $\mu_{2}$ and $\mu_{\mathrm{s}}$ as determined by Castelino et. al. [117] for tissue equivalent albumen phantoms heated to the temperatures shown. Values for the diffuse reflectance have been determined for each simulation performed using the MC Maplet. Figure 3-15 shows the plots of absorbance versus tissue depth generated by the MC Maplet for each combination of $\mu_{a}$ and $\mu_{\mathrm{s}}$. 


\begin{tabular}{|c|c|c|c|c|}
\hline $\begin{array}{c}\text { Simulation } \\
\text { Number }\end{array}$ & $\begin{array}{c}\text { Phantom } \\
\text { Temperature }\left({ }^{\circ} \mathrm{C}\right)\end{array}$ & $\left(\mu_{\mathrm{a}}\right)\left[\mathrm{cm}^{-1}\right]$ & $\left(\mu_{\mathrm{s}}\right)\left[\mathrm{cm}^{-1}\right]$ & $\begin{array}{c}\text { Diffuse } \\
\text { Reflectance }\end{array}$ \\
\hline 1 & 21.0 & 1.11 & 10.35 & 0.06414 \\
\hline 2 & 48.6 & 1.20 & 23.01 & 0.06618 \\
\hline 3 & 57.5 & 1.22 & 40.44 & 0.1060 \\
\hline 4 & 65.4 & 1.36 & 126.0 & 0.2366 \\
\hline 5 & 69.7 & 1.60 & 170.77 & 0.2443 \\
\hline
\end{tabular}

Table 3-10 -- Shows the values for $\mu_{a}$ and $\sharp_{s}$ (rom Castelino et. al. [117]) and the diffuse reflectance values for each simulation run using the Monte Carlo Maplet.

Examining table $3-10$ it can be seen that the values of the diffuse reflectance increase as the scattering coefficient of the phantoms increase, as expected. The diffuse reflectance increases by a factor of 3.80 from 0.06414 in the native state to 0.2443 in the $69.7^{\circ} \mathrm{C}$ coagulated state. These results are consistent with the increases in Raman intensity observed in the albumen phantoms and bovine muscle samples. Figure 3-15 shows the photon absorption versus tissue depth for each combination of $\mu_{\mathrm{a}}$ and $\mu_{\mathrm{s}}$ shown in table 3-10. As the value of $\mu_{\mathrm{s}}$ increases, the absorption in the first millimeter of simulated tissue increases from $\sim 1.25$ in the native state to $\sim 3.5$ in the $69.7^{\circ} \mathrm{C}$ coagulated state. Furthermore, it is apparent that the tissue depth decreases from $\sim 2.5 \mathrm{~cm}$ in figure $3-15(1)$ to $\sim 0.5 \mathrm{~cm}$ in figure $3-15(5)$ since no photons are absorbed beyond these depths. 

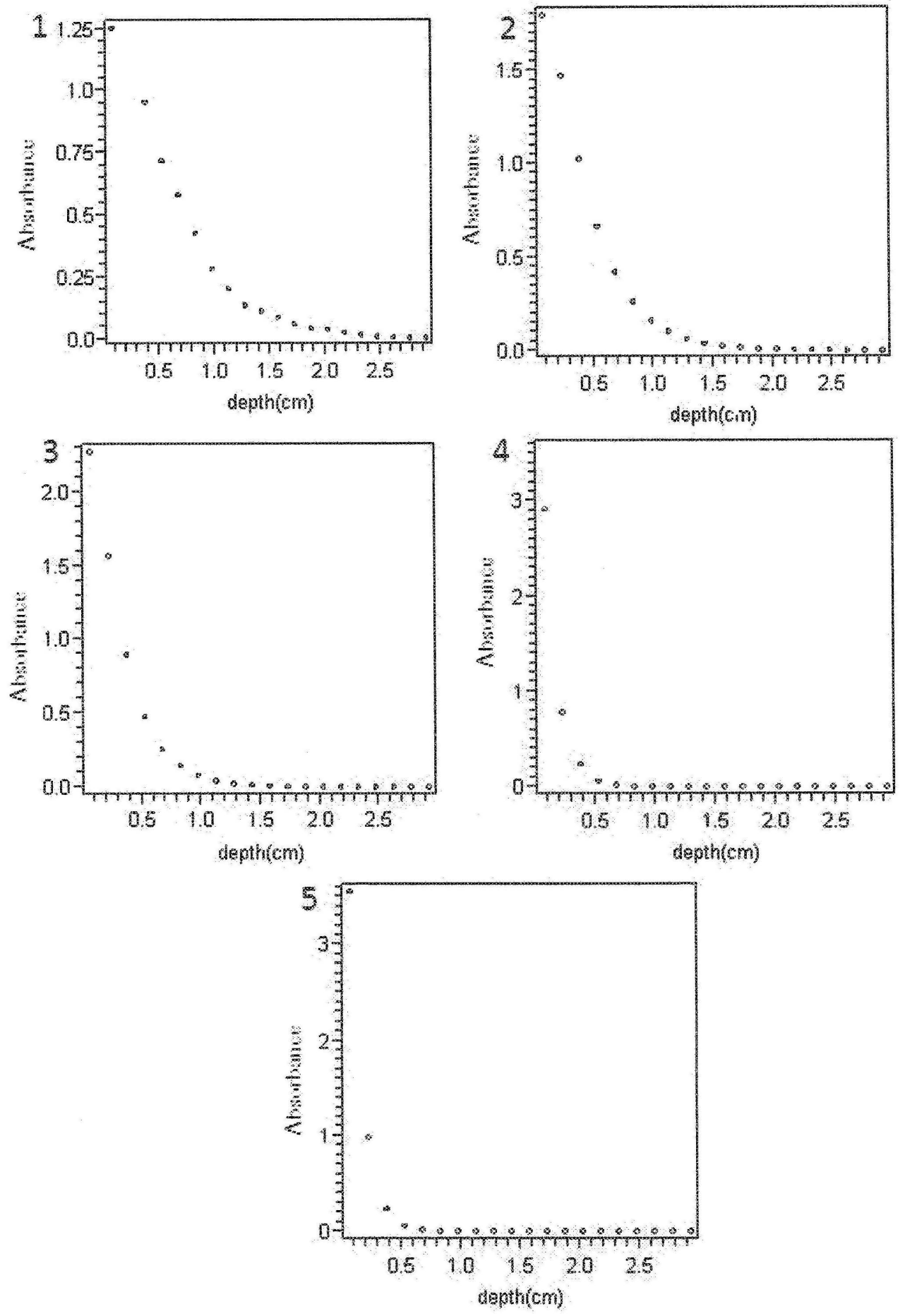

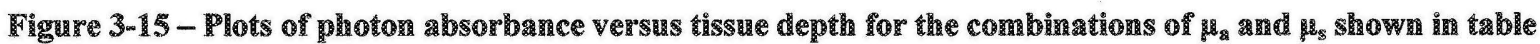
3-10. 


\begin{tabular}{|c|c|c|}
\hline$\left(\mu_{a}\right)\left[\mathrm{cm}^{-1}\right]$ & $\left(\mu_{s}\right)\left[\mathrm{cm}^{-1}\right]$ & $\begin{array}{c}\text { Number of } \\
\text { Photons } \\
\text { backscattered }\end{array}$ \\
\hline 1.11 & 10.35 & 9484 \\
\hline 1.20 & 23.01 & 16660 \\
\hline 1.22 & 40.44 & 24252 \\
\hline 1.36 & 126.0 & 41563 \\
\hline 1.60 & 170.77 & 44092 \\
\hline
\end{tabular}

Table 3-11 - Shows the values of $\beta_{a}$ and $\mu_{s}$ and the number of photons backscattered from $10^{5}$ incident photors.

Figure $3-16$ shows the graphical results of the $\mathrm{MC}$ simulations with $10^{5}$ incident photons using the the Matlab-based program for each combination of $\mu_{\mathrm{a}}$ and $\mu_{\mathrm{s}}$ given in table 3-10. The black horizontal line at $(0,0)$ indicates the surface of the simulated layer. Once a photon is backscattered out of the layer it is counted and is then terminated. Table 3-11 shows the number of photons backscattered from the simulated tissue layer from the simulations conducted using $10^{5}$ incident photons. It can be seen from table 3-11 that as the $\mu_{\mathrm{s}}$ of the simulated tissue layer increases, the number of photons backscattered out of the layer increases. For the phantoms in the unheated state, the number of photons backscattered from $10^{5}$ incident photons was determined to be 9484 compared to 44092 in the $69.7^{\circ} \mathrm{C}$ coagulated state. This agrees with the increases in the diffuse reflectance determined by the MC Maplet. 

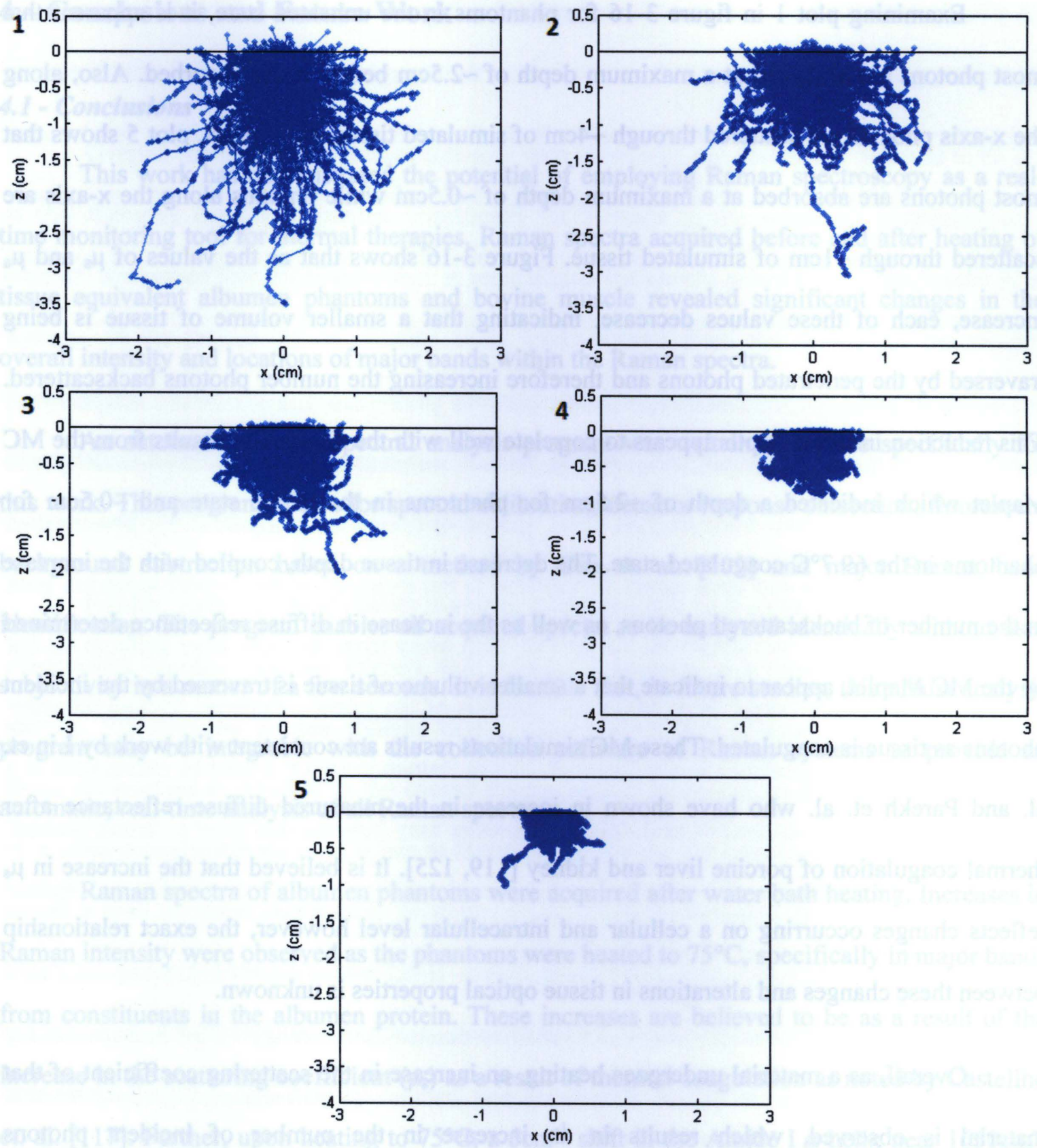

Figure 3-16 - Graphical results of the MC simulations for $10^{5}$ incident photons. (1) $\mu_{\mathrm{a}}=1.11 \mathrm{~cm}^{-1}, \mu_{\mathrm{s}}=$ $10.35 \mathrm{~cm}^{-1}$, (2) $\mu_{\mathrm{a}}=1.20 \mathrm{~cm}^{-1}, \mu_{\mathrm{s}}=23.01 \mathrm{~cm}^{-1}$, (3) $\mu_{\mathrm{a}}=1.22 \mathrm{~cm}^{-1}, \mu_{\mathrm{s}}=40.44 \mathrm{~cm}^{-1}$, (4) $\mu_{\mathrm{a}}=1.36 \mathrm{~cm}^{-1}, \mu_{\mathrm{s}}=126.0 \mathrm{~cm}^{-1}$ and (5) $\mu_{\mathrm{a}}=1.60 \mathrm{~cm}^{-1}, \mu_{\mathrm{s}}=170.77 \mathrm{~cm}^{-1}$. 
Examining plot 1 in figure $3-16$ for phantoms in the unheated state, it is apparent that most photons are absorbed at a maximum depth of $\sim 2.5 \mathrm{~cm}$ before being absorbed. Also, along the $\mathrm{X}$-axis photons are scattered through $\sim 4 \mathrm{~cm}$ of simulated tissue. In contrast, plot 5 shows that most photons are absorbed at a maximum depth of $\sim 0.5 \mathrm{~cm}$ while photons along the $\mathrm{x}$-axis are scattered through $\sim 1 \mathrm{~cm}$ of simulated tissue. Figure 3-16 shows that as the values of $\mu_{\mathrm{s}}$ and $\mu_{\mathrm{a}}$ increase, each of these values decrease, indicating that a smaller volume of tissue is being traversed by the penetrated photons and therefore increasing the number photons backscattered. This reduction in tissue depth appears to correlate well with the simulation results from the MC Maplet which indicated a depth of $\sim 2.5 \mathrm{~cm}$ for phantoms in the native state and $\sim 0.5 \mathrm{~cm}$ for phantoms in the $69.7^{\circ} \mathrm{C}$ coagulated state. The decrease in tissue depth, coupled with the increase in the number of backscattered photons, as well as the increase in diffuse reflectance determined by the MC Maplet, appear to indicate that a smaller volume of tissue is traversed by the incident photons as tissue is coagulated. These MC simulations results are consistent with work by Lin et. al. and Parekh et. al. who have shown in increase in the measured diffuse reflectance after thermal coagulation of porcine liver and kidney $[119,125]$. It is believed that the increase in $\mu_{\mathrm{s}}$ reflects changes occurring on a cellular and intracellular level however, the exact relationship between these changes and alterations in tissue optical properties is unknown.

Overall, as a material undergoes heating, an increase in the scattering coefficient of that material is observed, which results in an increase in the number of incident photons backscattered from the material. The MC simulations performed here confirm these results and provide an explanation for the increases in Raman peak intensity measured in the results of this thesis. 


\section{4 - Conclusions and Future Work}

\section{1- Conclusions}

This work has demonstrated the potential of employing Raman spectroscopy as a realtime monitoring tool for thermal therapies. Raman spectra acquired before and after heating of tissue equivalent albumen phantoms and bovine muscle revealed significant changes in the overall intensity and locations of major bands within the Raman spectra.

An automated Raman spectral analysis program was written in Matlab specifically for this work. This program allows for spectral calibration, detector response correction, fluorescent background subtraction based on a method by Cao et. al. [109] and major Raman band identification. The program enables all acquired spectra to be analyzed identically without user subjectivity in a matter of a few seconds. It is feasible that, in future studies, this robust analysis program may be integrable with the collection software of Raman systems to provide an automatic, real-time analysis of all Raman spectra.

Raman spectra of albumen phantoms were acquired after water bath heating. Increases in Raman intensity were observed as the phantoms were heated to $75^{\circ} \mathrm{C}$, specifically in major bands from constituents in the albumen protein. These increases are believed to be as a result of the increase in the scattering coefficient $\left(\mu_{\mathrm{s}}\right)$ as a result of thermal coagulation as noted by Castelino et. al. [117]. Further, upon heating to $75^{\circ} \mathrm{C}$, a $5 \mathrm{~cm}^{-1}$ shift in the Amide I $\alpha$-helix near $1650 \mathrm{~cm}^{-1}$ was observed, consistent with results presented by other investigators. A correlation between increasing thermal dose and Raman intensity was also observed.

Bovine muscle samples were also heated to a maximum temperature of $75^{\circ} \mathrm{C}$ in a water bath. Raman spectra acquired after heating once again revealed increases in Raman intensity in 
the overall spectrum and in major bands from the collagen component of the muscle samples. These changes are also believed to be as a result of the changing optical properties of the tissue as it undergoes thermal coagulation, specifically an increase in $\mu_{s} . A 7 \mathrm{~cm}^{-1}$ shift in the Amide I a helix near $1650 \mathrm{~cm}^{-1}$ was observed, as well as a $3 \mathrm{~cm}^{-1}$ shift in the $\mathrm{C} \alpha-\mathrm{H}$ stretch group near $1310 \mathrm{~cm}^{-1}$ upon heating to $75^{\circ} \mathrm{C}$. Once again, a correlation between increasing thermal dose and Raman intensity was noted.

Laser photocoagulation of bovine muscle was performed and maximum temperatures recorded $2 \mathrm{~mm}, 5 \mathrm{~mm}$ and $10 \mathrm{~mm}$ from the laser fiber. Treatment was terminated when the probe $2 \mathrm{~mm}$ away from the laser fiber reached $90^{\circ} \mathrm{C}$. Raman spectra were acquired at the locations of the temperature probes and once again, an increase in the intensity of the overall spectrum with increasing temperature was observed. Further, at $2 \mathrm{~mm}$ away from the laser fiber shifts in all but 2 of the major Raman bands were observed. Analysis of the relation between Raman intensity and thermal dose appeared to indicate that increases in Raman intensity would be maximized at a thermal dose of $\sim 10^{11}$ equivalent minutes and therefore may indicate that after a certain amount of heating, the scattering coefficient of a sample would reach some maximum value and further heating would have no effect on optical scattering.

Monte Carlo simulations were performed to determine the effect of an increase in the scattering coefficient on the diffuse reflectance and fraction of backscattered photons from a sample. Using two MC simulation programs, it was determined that as the scattering coefficient of a material increases, the diffuse reflectance increases by a factor of 3.80 between unheated and heated albumen phantoms. It was also determined that the penetration depth of the photons decreases from $\sim 2.5 \mathrm{~cm}$ to $\sim 0.5 \mathrm{~cm}$ upon coagulation of the phantoms. Finally, the number of 
backscattered photons was found to increase by a factor of $\sim 4.65$ which correlates well with the increase in the diffuse reflectance.

Overall, the increase in Raman intensity with increasing temperature is believed to be due to the changing optical properties, specifically an increase in the scattering coefficient as a material undergoes thermal coagulation. A reduction in the photon penetration depth results in an increase in the probability of photons being backscattered from the surface of the sample. Furthermore, it is believed that the shifts observed in the major Raman bands result from thermal denaturation causing an alteration in the secondary structure of major functional groups such as Amide $\mathrm{I}$ and $\mathrm{CH}_{2} / \mathrm{CH}_{3}$ groups within proteins.

Finally, coupling these results together, it appears that as a material undergoes thermal coagulation, incident photons interact with a protein structure at a reduced depth within the sample. The resulting Raman photons have a higher probability of escaping the material and reveal an increase in intensity in the overall Raman signal. Moreover, as the secondary structure of protein constituents are altered due to thermal coagulation, the backscattered Raman photons reveal a shift in major bands such as those arising from the Amide 1 group $\left(\sim 1655 \mathrm{~cm}^{-1}\right)$, the $\mathrm{CH}_{2} / \mathrm{CH}_{3}$ group $\left(\sim 1446 \mathrm{~cm}^{-1}\right)$, the $\mathrm{Ca}-\mathrm{H}$ stretch group $\left(\sim 1312 \mathrm{~cm}^{-1}\right)$ and the $\mathrm{CN}$ stretch group $\left(\sim 1121 \mathrm{~cm}^{-1}\right)$, which may be useful in determining tissue damage due to coagulation during thermal therapies.

Although the Raman system used in this work is an open-beam geometrical setup, it is believed that the results observed will also be observed in further analyses using other Raman systems. If Raman spectroscopy is to be employed as a real-time monitoring tool for thermal therapy, Raman spectra will have to be acquired in an in vivo setting. Further, it is possible that 
performing thermal therapy in vivo will result in similar changes in the optical properties of tissues seen in this work. It is hopeful that Raman spectroscopy will be able to detect the changing optical propagation as treatment progresses. Further, the results of this work reveal shifts in the major Raman bands only after the coagulation temperature of the collagen within the tissue has been reached, $\sim 63^{\circ} \mathrm{C}$. Raman spectroscopy may therefore prove more useful than current monitoring methods as the volume of tissue interrogated is quite small $\left(\sim 3 \mathrm{~mm}^{3}\right)$.

The results of this work have shown that Raman spectroscopy is able to detect changes in intensity and band location in components of major proteins during tissue coagulation. Therefore, by being able to accurately distinguish between areas of tissue that have been coagulated and those that have not by detecting band shifts in the spectra, may prove very useful in determining tissue damage in a very specific treatment area during thermal therapy. However, Raman events are, by their nature, much less abundant than the overpowering fluorescence events.

Based on the results of this thesis, employing Raman spectroscopy as a monitoring tool for thermal therapies seems feasible and examining shifts in the Raman bands may prove to be the best approach. Although the intensity of the Raman spectra have been shown to increase as the scattering coefficient of the material increases, this may be as a result of the geometrical setup used in this work. This result may not be observed in a fiber-based setup as indicated by Parekh et. al. [119] monitored the changes in the fluorescence signal during real-time ex vivo monitoring of radiofrequency ablation of porcine renal tissue. While the diffuse reflectance signal increased, the fluorescence signal decreased as the tissue was coagulated. This may be an indication that when a fiber-based setup is employed, and Raman spectra are collected near the periphery of the lesion, the Raman intensity may remain the same or actually decrease with 
coagulation. However, as shown in this work and according to Dong et. al. [23] as tissues are heated, there are shifts in the major Raman band locations. The work in this thesis showed that these shifts were observed after the tissue had cooled to room temperature using an open-beam Raman system, while Dong et. al. noted similar shifts with the tissue sustained at different temperatures using confocal Raman micro-spectroscopy. It is believed that these band shifts occur as a result of changes in the $2^{\circ}$ and $3^{\circ}$ structure of the components of major proteins within a sample, and may be observed regardless of the Raman system employed. The results of this work, and work by others indicate that if Raman spectroscopy were to be employed as a realtime monitoring tool for thermal therapy, shifts in Raman band location during coagulation may prove more useful to monitor treatment, rather than intensity changes that may or may not be observed.

In future studies however, it may be discovered that as in vivo environments are investigated, the Raman events may become scarcer and detecting them with the intention of monitoring thermal therapies may not be possible. Studies in more complex environments similar to those found in a clinical setting are necessary in determining if it is indeed possible to employ Raman Spectroscopy as a monitoring tool for thermal therapies. 


\section{2- Futdre Work}

The following summarizes some key areas that need further investigation to identify the full potential of Raman spectroscopy as a real-time monitoring tool for thermal therapy.

1) Obtain specific temperatures at which shifts in Raman band locations are observed. As shown in the laser photocoagulation of bovine muscle results, there are shifts in the locations of a number of bands upon heating to $90^{\circ} \mathrm{C}$. However, these results do not indicate at which temperature each band shifted from its room temperature location, which would be extremely useful for thermal therapy monitoring. This may be done by using pure collagen I fiber which has been shown to have a specific Raman spectrum [23], or by using bovine muscle or some other tissue with an easily identifiable Raman spectrum. These samples should be held at constant temperatures by a water bath or some other means where a very precise temperature reading can be achieved. By increasing the temperature of the sample slowly and acquiring Raman spectra at each temperature interval (perhaps $2^{\circ} \mathrm{C}$ ), it should be possible to identify temperatures at which each major band in the Raman spectrum undergoes a shift similar to those seen in this work. Accomplishing this may be useful by providing an indication as to the extent of tissue coagulation in a particular area.

2) Analyze native and coagulated tissue samples using a fiber optic Raman probe. Typical Raman collection systems used in in vivo applications employ a fiber optic bundle collection system. The excitation fiber is usually surrounded by $6-8$ collection fibers in a hexagonal or octagonal geometry allowing for minimally-invasive Raman measurements to be obtained. A device similar to this will need to be tested to in order to determine if the results presented in this thesis can be reproduced. 
3) Analyze tissue samples using a Raman probe described above before and after thermal treatment. In order to determine if the results presented in this work can be observed within a tissue sample using a Raman probe described above, Raman spectra will have to be acquired within the tissue before and after thermal lesion formation and analyzed using the spectral analysis program developed in this work. This will determine whether any increases in intensity or shifts in band location similar to the results of this thesis are detectable after lesion formation using a fiber based setup within a tissue. This environment is similar to that of a clinical setting and will be crucial in determining if Raman spectroscopy can be used as a monitoring tool for thermal therapies.

4) Obtain Raman spectra within a tissue sample in real-time during thermal treatment. This objective will determine if Raman spectra can be collected during a thermal treatment and if the spectra reveal differences in tissue structures as heating progresses. It is possible that the Raman signal may be too weak to be detected during a laser heating treatment due to the filtering that would be necessary. However, if the Raman signal can be detected, it is believed that as the tissue is heated, the Raman peak intensities in the major bands found within the sample will increase. Also, from the results presented in this thesis, one can posit that as the tissue coagulation reaches the Raman probe, shifts in the major band locations will be observed.

5) If the results of aims 1-4 are favourable, it would then be advantageous to integrate the automated Raman spectral analysis program presented in this thesis with the Raman acquisition software. This may be difficult as most Raman acquisition programs are designed specifically for acquiring spectra and may not be integrable with the Matlab program in this work. However, if this coupling can be achieved, it will allow automatic fluorescence rejection and spectral analysis as Raman spectra are collected from the system. This will be a necessary step towards 
introducing Raman spectroscopy as an automated method to monitor thermal therapies in realtime in a clinical setting.

6) Conduct thermal therapy treatments in an animal tumour model using Raman spectroscopy as a modality for detecting tissue coagulation in real-time. Typically, in vivo Raman applications employ a fiber-based system in which an excitation fiber is surrounded by 6-8 collection fibers. This fiber bundle is inserted directly into the tissue and Raman spectra can be acquired from any desired location. This objective is clearly the most complicated of all the aims presented in this section and will need to be coupled with another monitoring modality such as CT or MRI, since Raman Spectroscopy gives highly localized information. Another difficulty with this aim will be accurate placement of fiber bundle, which can be aided through coupling with CT or MRI. However, if Raman spectroscopy proves effective in detecting real-time changes in tissue optical properties during thermal therapy in animal models, this will build the foundation for treating human tumours through thermal therapy using Raman spectroscopy as the primary real-time monitoring modality. 


\section{5 - Appendix}

This appendix contains the Matlab source code for the automated Raman spectral analysis

employed in this work.

\section{1) Peak Finder}

$\% \%$ This program finds the maximum value of the Raman peaks in any spectrum

$\% \%$ and is called by main to locate these peaks in figures 1 and 5 .

$\%[\max , \min ]=$ peak finder(vector, threshold finds the local maxima and

$\%$ minima ("peaks") in the vector.

$\% \mathrm{~A}$ point is considered a peak if it has a maximal value, and was preceded

$\%$ by a value lower than the threshold.

$\% \max$ and min contain two columns. Column 1 has the indicies in the vector

$\%$ and column 2 has the values found by peak_finder.

$\% \%$ Written by:

\%\%Matthew Rodrigues, Omar Falou, Robin F. Castelino (December 2007).

function [max, $\min ]=$ peak_finder(vector, threshold)

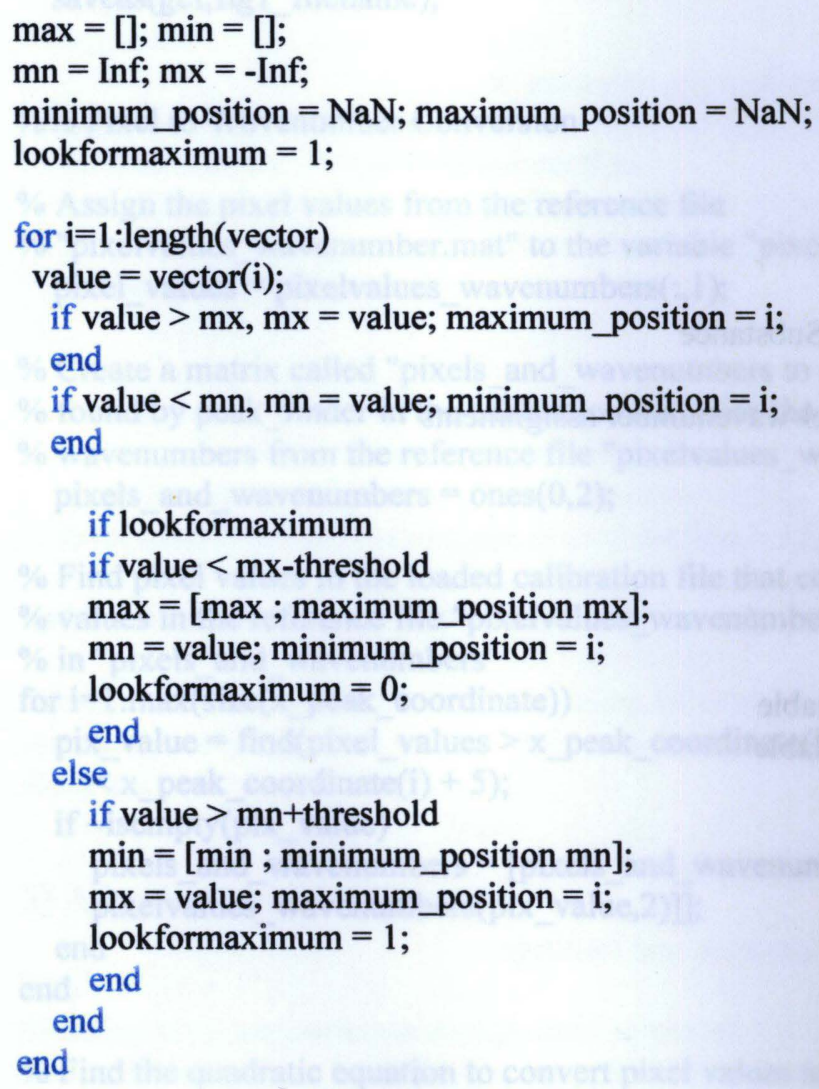




\section{2) Main Program}

$\% \%$

$\% \%$ This program converts CCD pixel values to wavenumbers $\left(\mathrm{cm}^{\wedge}-1\right)$,

$\% \%$ corrects for the responsivity of the CCD detector, corrects for the daily

$\% \%$ Raman intensity, identifies the Raman peak locationsand subtracts the

$\% \%$ fluorescence baseline using the Adaptive Minmax method.

$\% \%$ Written by:

\%\%Matthew Rodrigues, Omar Falou, Robin F. Castelino (December 2007).

$\% \%$ Initiate the Main Program ("main.m")

$\%$ Initate the main program from the command window function main(calibration_spect_file,intensity_correction_file)

$\%$ Open \& read txt file containing the names of files to work with

filelist $=$ 'datafilelist.txt';

filenames $=$ textread(filelist, $\left.{ }^{\prime} \% s^{\prime}\right)$;

nfiles = length(filenames);

disp([filelist, ' has ', num2str(nfiles), ' files.']);

$\%$ Process an individual txt file

for $\mathrm{i}=1$ :nfiles

filename $=$ char(filenames(i));

disp(filename);

$\% \%$ Spectral Calibration using Tylenol $(囚)$ or Other Substance

$\%$ Load the calibration reference .mat file with pixel-wavenumber assignments load pixelvalues_wavenumbers.mat;

$\%$ Load a calibration spectrum calibration $=[$ calibration_spect_file '.txt']; calibration_spectrum = load (calibration);

$\%$ Assign the pixel values to the 'calibration $x$ ' variable

$\%$ and the intensity values to the 'calibration $y^{\prime}$ variable calibration_x $=($ calibration_spectrum $(:, 1))$; calibration_y $=($ calibration_spectrum $(:, 2))$;

$\%$ Plot the calibration spectrum

figure (1); plot (calibration_x,calibration_y,'k')

box off;

hold on; 
$\%$ Find the maximum intensity point in the calibration file max_peak $=\max ($ calibration_y $)$;

$\%$ Set the threshold for peak finding using peak finder

$\%$ (it is set to $10 \%$ of the maximum peak in the calibration spectrum) [peaks, troughs] = peak_finder (calibration_y, $0.1 *$ max_peak);

$\%$ Assign the $\mathrm{x}$ values of the peaks to the variable 'x_peak_coordinate'

$\%$ Assign the $y$ values of the peaks to the variable 'y_peak_coordinate' x_peak_coordinate $=($ peaks $(:, 1))$;

y_peak_coordinate $=($ peaks $(:, 2))$;

$\%$ Plot peak locations found by peak_finder on top of calibration file figure(1); plot(x_peak_coordinate,y_peak_coordinate,'bo') xlabel('Pixel'); ylabel('Raman Intensity (a.u.)'); title('Calibration Spectrum and Peak Locations'); box off; set(gcf, 'color', 'white');

$\%$ Save the plot of the calibration file and the peak locations as Fig 1 fig1_filename = strcat(", 'Fig_1_Calibration_and_peaks.fig'); saveas(gcf,fig1_filename);

\section{$\% \%$ Pixel to Wavenumber Conversion}

$\%$ Assign the pixel values from the reference file

$\%$ "pixelvalues_wavenumber.mat" to the variable "pixel_values" pixel_values = pixelvalues_wavenumbers(:,1);

$\%$ Create a matrix called "pixels_and_wavenumbers to store the pixel values

$\%$ found by peak_finder in the calibration file, with the corresponding

$\%$ wavenumbers from the reference file "pixelvalues_wavenumber.mat" pixels_and_wavenumbers $=$ ones $(0,2)$;

$\%$ Find pixel values in the loaded calibration file that correspond to the

$\%$ values in the reference file "pixelvalues_wavenumber.mat" and store them

$\%$ in "pixels and wavenumbers"

for $\mathrm{i}=1: \max \left(\operatorname{size}\left(\mathbf{x} \_\right.\right.$peak_coordinate $\left.)\right)$

pix_value $=$ find(pixel_values $>x \_$peak_coordinate(i) $-5 \&$ pixel_values...

$<x \_$peak_coordinate $\left.(i)+5\right)$;

if isempty(pix_value)

pixels_and_wavenumbers $=\left[\right.$ pixels_and_wavenumbers; $\left[\mathrm{x} \_\right.$peak_coordinate $(i) .$. pixelvalues_wavenumbers(pix_value,2)]]; end

end

$\%$ Find the quadratic equation to convert pixel values to wavenumbers 
coefficient $=$ polyfit(pixels_and_wavenumbers(:,1), pixels_and_wavenumbers(:,2),2);

$\%$ Plot pixel values and wavenumber values display the quadric equation

figure(2);

plot(pixels_and_wavenumbers(:,1), pixels_and_wavenumbers(:,2), 'k');

box off;

xlabel('Pixel values');

ylabel('Wavenumber values');

title('Pixel to Wavenumber Conversion');

text(800,400,['y^2 = ',num2str(coefficient(1)),' $x^{\wedge} 2+$ ', num2str(coefficient(2)),...

' $\mathrm{x}$ ', num2str(coefficient(3))],'HorizontalAlignment','right',...

'VerticalAlignment','bottom');

set(gcf, 'color', 'white');

$\%$ Save pixel to wavenumber conversion figure as Fig 2

fig2_filename=strcat(",'Fig_2_Pixel_wavenumber_conversion.fig');

saveas(gcf,fig2_filename);

$\% \%$ Load a Raman spectrum

$\%$ Load an un-calibrated Raman spectrum in a .txt array. The name of this

$\%$ file must appear in the file called "datafilelist.txt"

data_spectrum $=[$ filename '. txt' $]$;

Raman_spectrum = load(data_spectrum);

$\%$ Assign pixel values in the spectrum to the variable 'Raman_spectrum $\mathrm{x}^{\mathrm{P}}$

Raman_spectrum_x = Raman_spectrum(:,1);

$\%$ Assign intensity values in the spectrum to the variable 'Raman_spectrum_y'

Raman_spectrum_y = Raman_spectrum(:,2);

$\% \%$ Correct for the responsitivty of the CCD

$\%$ Load the file "intensity_correction_file.txt" containing the

$\%$ responsivity correction spectrum

response_corr_filename $=$ [intensity_correction_file, '.txt'];

response_corr_spectrum $=$ load(response_corr_filename);

response_corr_intensity = response_corr_spectrum $(:, 2)$;

$\%$ correct the intensity of the data file

Raman_spectrum_y = Raman_spectrum_y .* response_corr_intensity;

$\% \%$ Correct the Raman spectrum to represent the daily intensity

$\%$ Find the maximum intensity in the input Raman spectrum and multiply

$\%$ the data file by this value

maximum_intensity $=\max ($ Raman_spectrum_y $)$;

Raman_spectrum_y $=$ Raman_spectrum_y .* maximum_intensity; 
$\% \%$ Convert Pixel Values to Wavenumbers in the Raman spectrum

$\%$ Perform the conversion from pixel values to wavenumbers

Raman_spectrum_x $=$ coefficient(1).*(Raman_spectrum_x.^2) $+\ldots$ coefficient(2).*(Raman_spectrum_x) + coefficient(3);

$\%$ Select the range of wavenumbers in the Raman spectrum to be plotted.

$\%$ (the optimal range of our detector is 400 to $1700 \mathrm{~cm}^{\wedge}-1$, but any range

$\%$ can be plotted)

minimum_wavenumber $=$ find $($ Raman_spectrum_ $x>=400,1)$;

maximum_wavenumber $=$ find $($ Raman_spectrum_ $x>=1700,1)$;

Raman_corrected_x = Raman_spectrum_x(minimum_wavenumber:maximum_wavenumber);

Raman_corrected_y = Raman_spectrum_y(minimum_wavenumber:maximum_wavenumber);

$\%$ Plot the pixel-wavenumber calibrated, responsivity and intensity

$\%$ corrected Raman spectrum

figure(3);

plot(Raman_corrected_x, Raman_corrected_y, 'k')

$x \lim \left(\left[\begin{array}{lll}400 & 1700])\end{array}\right.\right.$

xlabel('Raman Shift $\left.\left(\mathrm{cm}^{\wedge}-^{\wedge} 1\right)^{\prime}\right)$;

ylabel('Raman Intensity (а.u.)');

title('Corrected Raman Spectrum Before Fluorescence Subtraction');

set(gcf, 'color', 'white');

box off;

$\%$ Save the corrected Raman spectrum figure to file. This spectrum contains

$\%$ no fluorescence background subtraction

fig3_filename $=$ strcat( 'Fig_3_,filename,...

Raman_spectrum_before_fluorescence_subtraction.fig');

saveas(gcf,fig3_filename);

$\%$ Save the array of the corrected Raman spectrum in a .txt file

Raman_spectrum $=$ [Raman_corrected_x Raman_corrected_y $]$;

spectfilename $=[$ filename '_Raman_spectrum.txt'];

save(spectfilename,'Raman_spectrum','-ascii');

end $\%$ end processing all files in datafilelist.txt

$\% \%$ perform background subtraction using Minmax method

minmax_method();

close all;

\section{3) Adaptive Minmax Method}

$\% \%$

$\% \%$ This program performs background subtraction of Raman spectra using $\% \%$ multiple polynomial fits and optimizing them based on the input data 
$\% \%$ Written by Alex Cao (October, 2007)

$\% \%$ Modified by M. Rodrigues, O. Falou, R.F. Castelino (December, 2007)

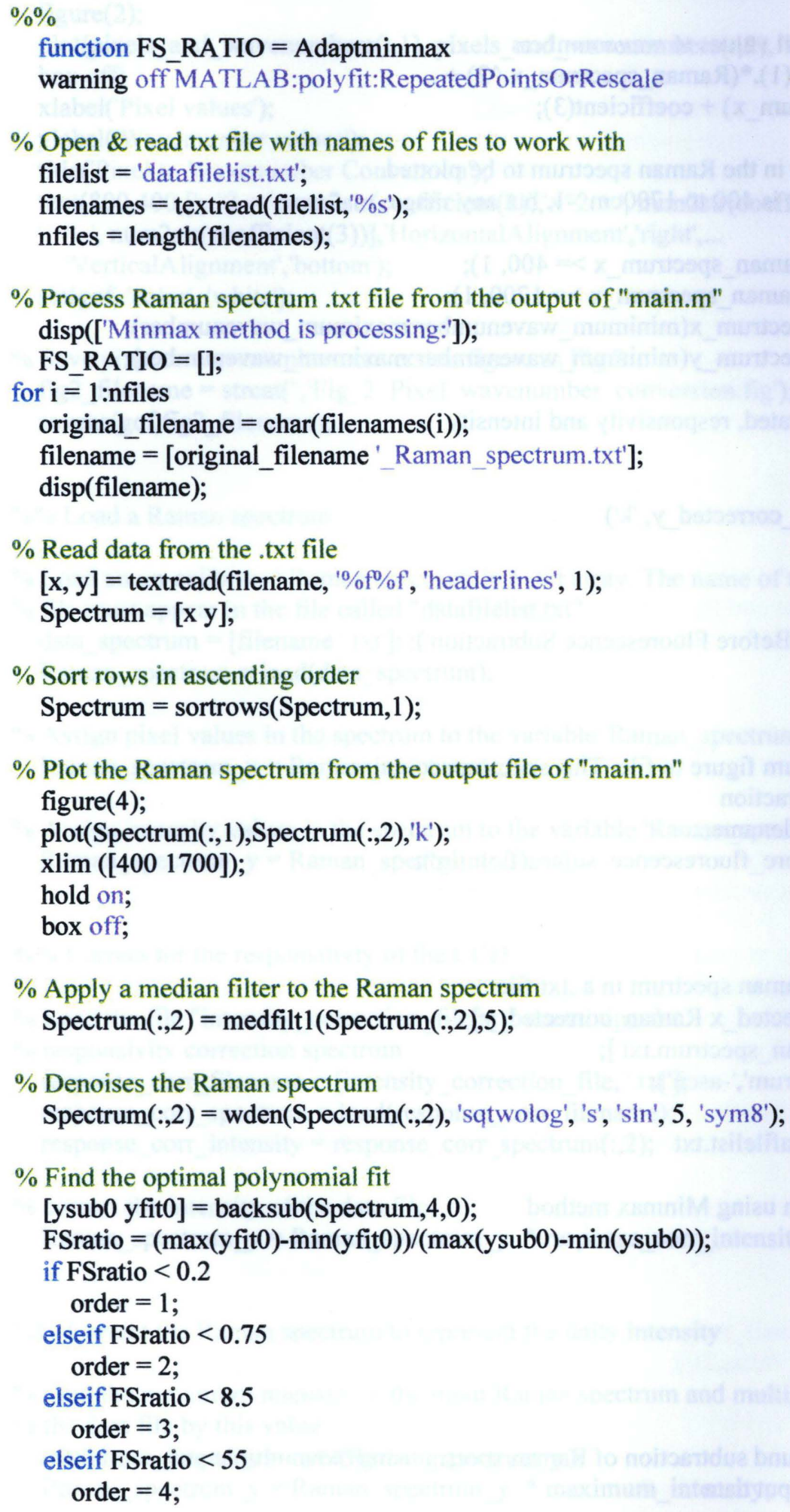




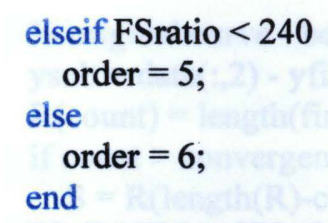

$\% \%$ Plot the optimal polynomial fit and the Raman spectrum

raman_wavenumbers = Poly_Fit_Spectrum(:,1);

raman_intensity $=$ Poly_Fit_Spectrum(:,2);

figure(4);

plot(raman_wavenumbers(:,1),yfit4,'r');

$x \lim \left(\left[\begin{array}{lll}400 & 1700])\end{array}\right.\right.$

xlabel('Raman Shift $\left.\left(\mathrm{cm}^{\wedge}\{-1\}\right)^{\prime}\right)$;

title('Raman Spectrum With Optimal Polynomial Fit');

ylabel('Raman Intensity (a.u.)');

set(gcf, 'color', 'white');

\% Save Raman spectrum and optimal polynomial fit as Fig 4

fig4_filename $=$ strcat('Fig_4 ',original_filename,...

saveas(gcf,fig4_filename);

'_Raman_spectrum_with_polynomial.fig');

$\% \%$ Plot the final fluorescence background subtracted Raman spectrum with band assignments

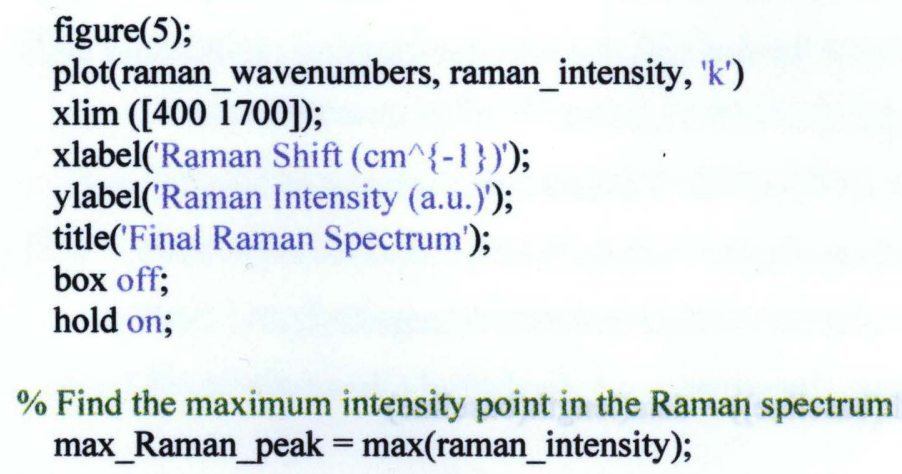

$\%$ Find the maximum intensity point in the Raman spectrum max_Raman_peak $=\max ($ raman_intensity); 


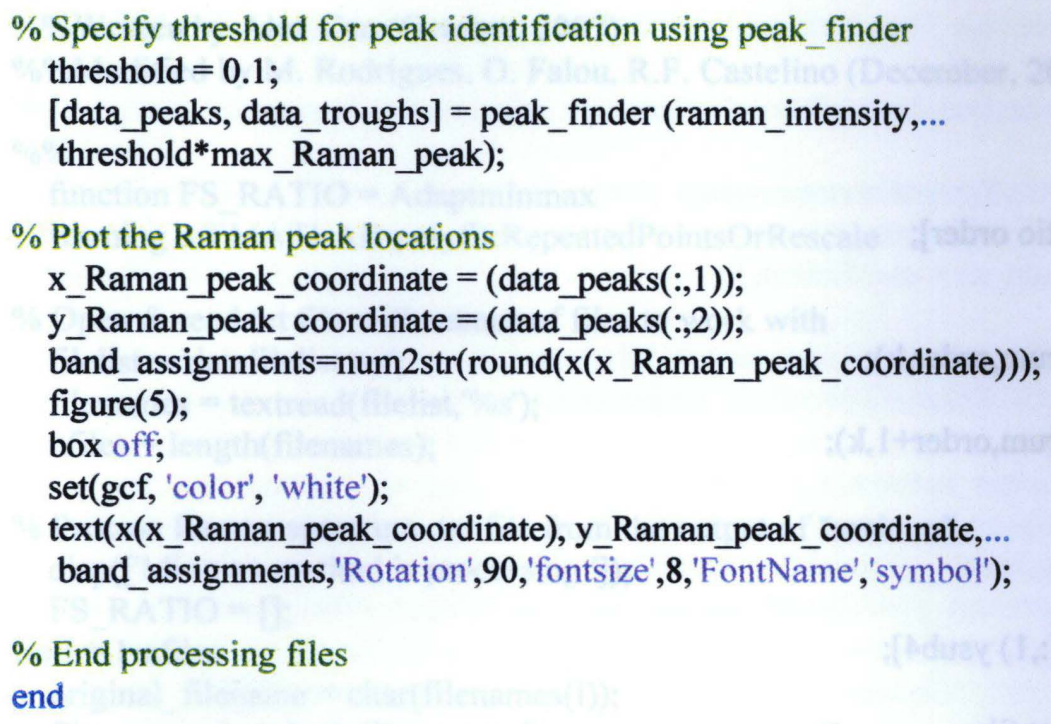




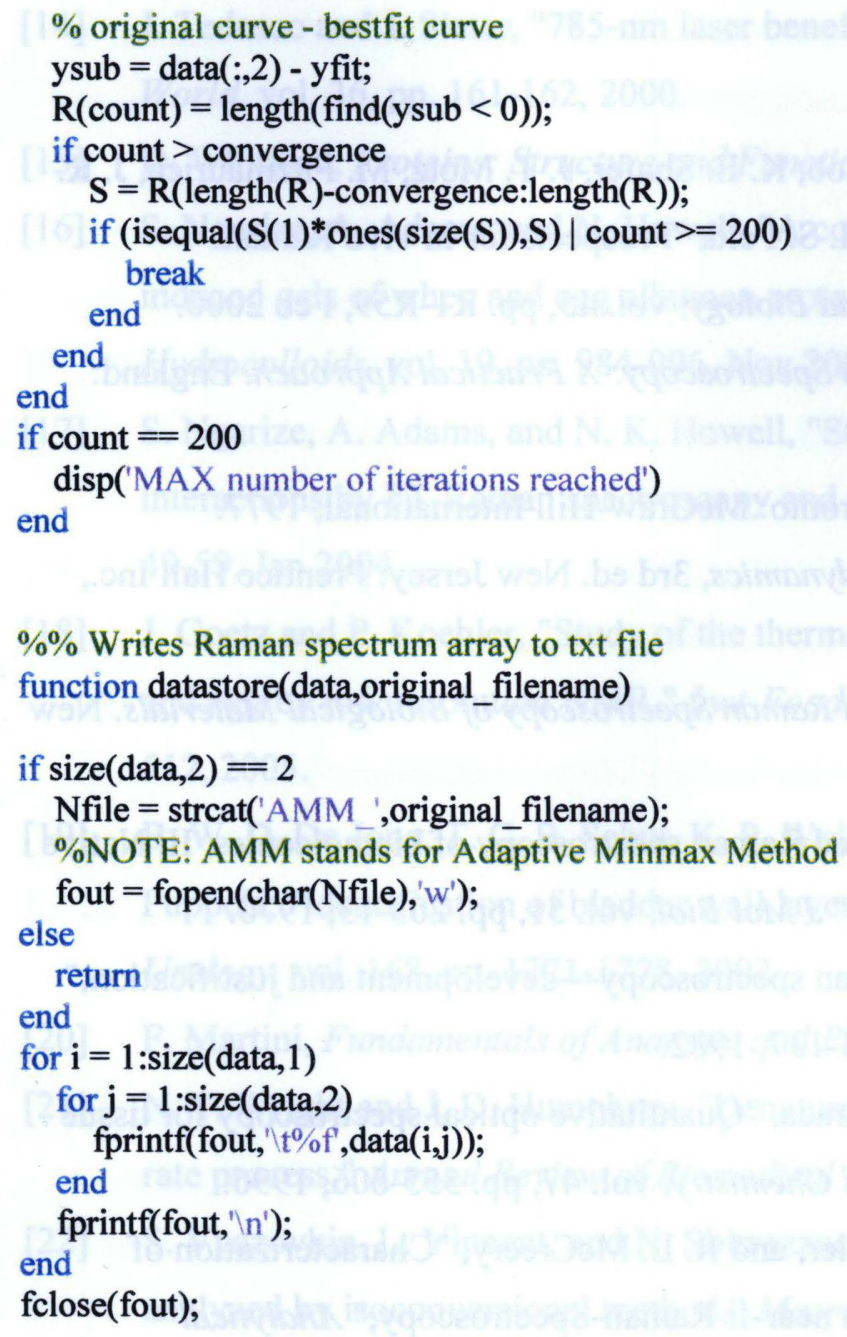




\section{6-References}

[1] E. B. Hanlon, R. Manoharan, T. W. Koo, K. E. Shafer, J. T. Motz, M. Fitzmaurice, J. R. Kramer, I. Itzkan, R. R. Dasari, and M. S. Feld, "Prospects for in vivo Raman spectroscopy," Physics in Medicine and Biology, vol. 45, pp. R1-R59, Feb 2000.

[2] E. Smith and G. Dent, Modern Raman Spectroscopy: A Practical Approach. England: John Wiley \& Sons, 2005.

[3] D. A. Long, Raman Spectroscopy. Toronto: McGraw-Hill International, 1977.

[4] D. J. Grifiths, Introduction to Electrodynamics, 3rd ed. New Jersey: Prentice Hall Inc., 1999.

[5] H. Gremlich and B. Yan, Infrared and Raman Spectroscopy of Biological Materials. New York: Marcel Dekker Inc., 2001.

[6] R. C. Lord and N. T. Yu, "Laser-excited Raman spectroscopy of biomolecules. II. Native ribonuclease and alpha-chymotrypsin," J Mol Biol, vol. 51, pp. 203-13, 1970.

[7] T. Hirschfeld and B. Chase, "FT-Raman spectroscopy-development and justification," Applied Spectroscopy, vol. 40, pp. 133-137, 1982.

[8] R. Richards-Kortum and E. SevickMuraca, "Quantitative optical spectroscopy for tissue diagnosis," Annual Review of Physical Chemistry, vol. 47, pp. 555-606, 1996.

[9] C. J. Frank, D. C. B. Redd, T. S. Gansler, and R. L. McCreery, "Characterization of Human Breast Biopsy Specimens with near-Ir Raman-Spectroscopy," Analytical Chemistry, vol. 66, pp. 319-326, 1994.

[10] M. G. Shim and B. C. Wilson, "Development of an in vivo Raman spectroscopic system for diagnostic applications," Journal of Raman Spectroscopy, vol. 28, pp. 131-142, 1997.

[11] P. Crow, A. Molckovsky, N. Stone, J. Uff, B. Wilson, and L. M. Wongkeesong, "Assessment of fiberoptic near-infrared Raman spectroscopy for diagnosis of bladder and prostate cancer," Urology, vol. 65, pp. 1126-1130, 2005.

[12] C. J. Frank, R. L. McCreery, and D. C. B. Redd, "Raman-Spectroscopy of Normal and Diseased Human Breast Tissues," Analytical Chemistry, vol. 67, pp. 777-783, 1995.

[13] Y. Wang and R. L. McCreery, "Evaluation of a Diode-Laser Charge Coupled Device Spectrometer for near-Infrared Raman-Spectroscopy," Analytical Chemistry, vol. 61, pp. $2647-2651,1989$. 
[14] J. Tedesco and J. Slater, "785-nm laser benefits Raman spectroscopy," Laser Focus World, vol. 36, pp. 161-162, 2000.

[15] D. Whitford, Proteins: Structure and Function: Wiley, 2005.

[16] S. Ngarize, A. Adams, and N. Howell, "A comparative study of heat and high pressure induced gels of whey and egg albumen proteins and their binary mixtures," Food Hydrocolloids, vol. 19, pp. 984-996, Nov 2005.

[17] S. Ngarize, A. Adams, and N. K. Howell, "Studies on egg albumen and whey protein interactions by FT-Raman spectroscopy and theology," Food Hydrocolloids, vol. 18, pp. 49-59, Jan 2004.

[18] J. Goetz and P. Koehler, "Study of the thermal denaturation of selected proteins of whey and egg by low resolution NMR," Lwt-Food Science and Technology, vol. 38, pp. 501$512,2005$.

[19] B. W. D. De Jong, T. C. B. Schut, K. P. Wolfenbuttel, J. M. Nijman, D. J. Kok, and G. J. Puppels, "Identification of bladder wall layers by Raman spectroscopy," Journal of Urology, vol. 168, pp. 1771-1778, 2002.

[20] F. Martini, Fundamentals of Anatomy and Physiology. New Jersey: Prentice Hall, 2001.

[21] N. T. Wright and J. D. Humphrey, "Denaturation of collagen via heating: An irreversible rate process," Annual Review of Biomedical Engineering, vol. 4, pp. 109-128, 2002.

[22] S. Vyazovkin, L. Vincent, and N. Sbirrazzuoli, "Thermal denaturation of collagen analyzed by isoconversional method," Macromolecular Bioscience, vol. 7, pp. 1181. $1186,2007$.

[23] R. X. Dong, X. L. Yan, X. F. Pang, and S. G. Liu, "Temperature-dependent Raman spectra of collagen and DNA," Spectrochimica Acta Part a-Molecular and Biomolecular Spectroscopy, vol. 60, pp. 557-561, 2004.

[24] J. Sebag, S. M. Nie, K. Reiser, M. A. Charles, and N. T. Yu, "Raman-Spectroscopy of Human Vitreous in Proliferative Diabetic-Retinopathy," Investigative Ophthalmology \& Visual Science, vol. 35, pp. 2976-2980, 1994.

[25] S. M. Nie, K. L. Bergbauer, J. F. Kuck, Jr., and N. T. Yu, "Near-infrared Fourier transform Raman spectroscopy in human lens research," Exp Eye Res, vol. 51, pp. 61923,1990 . 
[26] R. Manoharan, J. J. Baraga, M. S. Feld, and R. P. Rava, "Quantitative Histochemical Analysis of Human Artery Using Raman-Spectroscopy," Journal of Photochemistry and Photobiology B-Biology, vol. 16, pp. 211-233, 1992.

[27] J. J. Baraga, M. S. Feld, and R. P. Rava, "In situ Optical Histochemistry of Human Artery Using near-Infrared Fourier-Transform Raman-Spectroscopy," Proceedings of the National Academy of Sciences of the United States of America, vol. 89, pp. 3473-3477, 1992.

[28] R.P. Rava, J. J. Baraga, and M. S. Feld, "Near-Infrared Fourier-Transform RamanSpectroscopy of Human Artery," Spectrochimica Acta Part a-Molecular and Biomolecular Spectroscopy, vol. 47A, pp. 509-512, 1991.

[29] Y. N. Wang, C. Galiotis, and D. L. Bader, "Determination of molecular changes in soft tissues under strain using laser Raman microscopy," Joumal of Biomechanics, vol. 33, pp. 483-486, 2000 .

[30] I. Notingher, S. Verier, H. Romanska, A. E. Bishop, J. M. Polak, and L. L. Hench, "In situ characterisation of living cells by Raman spectroscopy," Spectroscopy-an International Joumal, vol. 16, pp.43-51, 2002.

[31] S. Keller, B. Schrader, A. Hoffmann, W. Schrader, K. Metz, A. Rehlaender, J. Pahnke, M. Ruwe, and W. Budach, "Application of near-Infrared Fourier-Transform Raman" Spectroscopy in Medical-Research," Journal of Raman Spectroscopy, vol. 25, pp. 663$671,1994$.

[32] A. C. Williams, B. W. Barry, H. G. M. Edwards, and D. W. Farwell, "A Critical Comparison of Some Raman-Spectroscopic Techniques for Studies of Human StratumComeum," Pharmaceutical Research, vol. 10, pp. 1642-1647, 1993.

[33] B. W. Barry, H. G. M. Edwards, and A. C. Williams, "Fourier-Transform Raman and Infrared Vibrational Study of Human Skin - Assignment of Spectral Bands," Journal of Raman Spectroscopy, vol. 23, pp. 641-645, 1992.

[34] S. Fendel and B. Schrader, "Investigation of skin and skin lesions by NIR-FT-Raman spectroscopy," Fresenius Journal of Analytical Chemistry, vol. 360, pp. 609-613, 1998.

[35] E. E. Lawson, A. N. C. Anigbogu, A. C. Williams, B. W. Barry, and H. G. M. Edwards, "Themally induced molecular disorder in human stratum comeum lipids compared with 
a model phospholipid system; FT-Raman spectroscopy," Spectrochimica Acta Part aMolecular and Biomolecular Spectroscopy, vol. 54, pp. 543-558, 1998.

[36] P. J. Caspers, G. W. Lucassen, R. Wolthuis, H. A. Bruining, and G. J. Puppels, "In vitro and in vivo Raman spectroscopy of human skin," Biospectroscopy, vol. 4, pp. S31-S39, 1998.

[37] M. Gniadecka, O. F. Nielsen, D. H. Christensen, and H. C. Wulf, "Structure of water, proteins, and lipids in intact human skin, hair, and nail," Journal of Investigative Dermatology, vol. 110, pp. 393-398, 1998.

[38] C. H. Liu, B. B. Das, W. L. S. Glassman, G. C. Tang, K. M. Yoo, H. R. Zhu, D. L. Akins, S. S. Lubicz, J. Cleary, R. Prudente, E. Celmer, A. Caron, and R. R. Alfano, "Raman, Fluorescence, and Time-Resolved Light-Scattering as Optical Diagnostic-Techniques to Separate Diseased and Normal Biomedical Media," Journal of Photochemistry and Photobiology B-Biology, vol. 16, pp. 187-209, 1992.

[39] A. S. Haka, K. E. Shafer-Peltier, M. Fitzmaurice, J. Crowe, R. R. Dasari, and M. S. Feld, "Diagnosing breast cancer by using Raman spectroscopy," Proceedings of the National Academy of Sciences of the United States of America, vol. 102, pp. 12371-12376, 2005.

[40] M. V. P. Chowdary, K. K. Kumar, J. Kurien, S. Mathew, and C. M. Krishna, "Discrimination of normal, benign, and malignant breast tissues by Raman spectroscopy," Biopolymers, vol. 83, pp. 556-569, 2006.

[41] J. S. Thakur, H. B. Dai, G. K. Serhatkulu, R. Naik, V. M. Naik, A. Cao, A. Pandya, G. W. Auner, R. Rabah, M. D. Klein, and C. Freeman, "Raman spectral signatures of mouse mammary tissue and associated lymph nodes: normal, tumor and mastitis," Journal of Raman Spectroscopy, vol. 38, pp. 127-134, 2007.

[42] R. A. Bitar, H. D. S. Martinho, C. J. Tierra-Criollo, L. N. Z. Ramalho, M. M. Netto, and A. A. Martin, "Biochemical analysis of human breast tissues using Fourier-transform Raman spectroscopy," Journal of Biomedical Optics, vol. 11, 2006.

[43] A. Mizuno, H. Kitajima, K. Kawauchi, S. Muraishi, and Y. Ozaki, "Near-Infrared Fourier-Transform Raman-Spectroscopic Study of Human Brain-Tissues and Tumors," Journal of Raman Spectroscopy, vol. 25, pp. 25-29, 1994. 
[44] S. Kaminaka, H. Yamazaki, T. Ito, E. Kohda, and H. O. Hamaguchi, "Near-infrared Raman spectroscopy of human lung tissues: possibility of molecular-level cancer diagnosis," Journal of Raman Spectroscopy, vol. 32, pp. 139-141, 2001.

[45] Z. W. Huang, A. McWilliams, H. Lui, D. I. McLean, S. Lam, and H. S. Zeng, "Nearinfrared Raman spectroscopy for optical diagnosis of lung cancer," International Journal of Cancer, vol. 107, pp. 1047-1052, 2003.

[46] M. G. Shim, L. Song, N. E. Marcon, and B. C. Willson, "In vivo near-infrared Raman spectroscopy: Demonstration of feasibility during clinical gastrointestinal endoscopy," Photochemistry and Photobiology, vol. 72, pp. 146-150, 2000.

[47] A. Molckovsky, L. Song, M. G. Shim, N. E. Marcon, and B. C. Wilson, "Diagnostic potential of near-infrared Raman spectroscopy in the colon: differentiating adenomatous from hyperplastic polyps," Gastrointestinal Endoscopy, vol. 57, pp. 396-402, 2003.

[48] A. S. Haka, Z. Volynskaya, J. A. Gardecki, J. Nazemi, J. Lyons, D. Hicks, M. Fitzmaurice, R. R. Dasari, J. P. Crowe, and M. S. Feld, "In vivo margin assessment during partial mastectomy breast surgery using Raman spectroscopy," Cancer Research, vol. 66, pp. 3317-3322, 2006.

[49] J. T. Motz, M. Fitzmaurice, A. Miller, S. J. Gandhi, A. S. Haka, L. H. Galindo, R. R. Dasari, J. R. Kramer, and M. S. Feld, "In vivo Raman spectral pathology of human atherosclerosis and vulnerable plaque," Journal of Biomedical Optics, vol. 11, 2006.

[50] A. M. K. Enejder, T. G. Scecina, J. Oh, M. Hunter, W. C. Shih, S. Sasic, G. L. Horowitz, and M. S. Feld, "Raman spectroscopy for noninvasive glucose measurements," Journal of Biomedical Optics, vol. 10, 2005.

[51] S. G. Bown, "Phototherapy of Tumours," World Journal of Surgery, vol. 7, pp. 700-709, 1983.

[52] Z. Amin, J. J. Donald, A. Masters, R. Kant, A. C. Steger, S. G. Bown, and W. R. Lees, "Hepatic Metastases - Interstitial Laser Photocoagulation with Real-Time US Monitoring and Dynamic CT Evaluation of Treatment," Radiology, vol. 187, pp. 339-347, 1993.

[53] J.L. Boulnois, "Photophysical processes in recent medical laser developments: a review," Lasers in Medical Science, vol. 1, pp. 47-66, 1986. 
[54] C. T. Germer, A. Roggan, J. P. Ritz, C. Isben, D. Albrecht, G. Muller, and H. J. Buhr, "Optical properties of native and coagulated human liver tissue and liver metastases in the near infrared range," Lasers in Surgery and Medicine, vol. 23, pp. 194-203, 1998.

[55] S. Thomsen, J. Schwartz, R. Joseph, J. A. Pearce, B. Rae, and T. McMurray, "Temperatures associated with thermally-induced red blood cell changes in tissues irradiated in vivo." SPIE Proceedings, vol. 2130, pp. 156-163, 1994.

[56] M. Castren-Persons, J. Lipasti, P. Puolakkainen, and T. Schroder, "Laser-Induced Hyperthermia - Comparison of 2 Different Methods," Lasers in Surgery and Medicine, vol. 12, pp. 665-668, 1992.

[57] N. Daikuzono, S. Suzuki, H. Tajiri, H. Tsunekawa, M. Ohyama, and S. N. Joffe, "Laserthermia - a New Computer-Controlled Contact Nd-Yag System for Interstitial Local Hyperthermia," Lasers in Surgery and Medicine, vol. 8, pp. 254-258, 1988.

[58] R. Matsumoto, A. M. Selig, V. M. Colucci, and F. A. Jolesz, "Interstitial Nd:YAG laser ablation in notrnal rabbit liver: Trial to maximize the size of laserinduced lesions," Lasers in Surgery and Medicine, vol. 12, pp. 650-658, 1992.

[59] A. H. Dachman, J. A. McGehee, T. E. Beam, J. A. Burris, and D. A. Powell, "Us-Guided Percutaneous Laser Ablation of Liver-Tissue in a Chronic Pig Model," Radiology, vol. 176, pp. 129-133, 1990.

[60] S. L. Jacques, S. Rastegar, M. Motamedi, S. L. Thomsen, J. Schwartz, J. Torres, and I. Mannonen, "Liver photocoagulation with diode laser (805 nm) vs ND:YAG laser (1064 nm)," SPIE Proceedings, vol. 1646, pp. 107-117, 1992.

[61] J. P. Ritz, A. Roggan, C. T. Germer, C. Isbert, G. Muller, and H. J. Buhr, "Continuous changes in the optical properties of liver tissue during laser-induced interstitial thermotherapy," Lasers in Surgery and Medicine, vol. 28, pp. 307-312, 2001.

[62] S. Thomsen, "Pathologic analysis of photothermal and photomechanical effects of lasertissue interactions," Photochemistry and Photobiology, vol. 53, pp. 825-835, 1991.

[63] M. M. Judy, J. L. Matthews, B. L. Aronoff, and D. F. Hults, "Soft Tissue Studies With $805 \mathrm{~nm}$ Diode Laser Radiation: Thermal Effects With Contact Tips and Comparison With Effects of 1064 nm Nd:YAG Laser Radiation," Lasers in Surgery and Medicine, vol. 13, pp. 528-536, 1993. 
[64] S. A. Sapareto and W. C. Dewey, "Thermal dose determination in cancer therapy," International Joumal of Radiation Oncology, Biology, Physics, vol. 10, pp. 787-800, 1984.

[65] T. G. Purdie, T.-Y. Lee, M. N. lizuka, and M. D. Sherar, "Dynamic contract enhanced CT measurement of blood flow during interstitial laser photocoagulation: Comparison with an arhenius damage model," Physics in Medicine and Biology, vol. 45, pp. 1115-1126, 2000.

[66] K. Matthewson, P. Coleridge-Smith, J. P. O'Sullivan, T. C. Northfield, and S. G. Bown, "Biological effects of intrahepatic neodymium:yttrium-aluminum-garnet laser photocoagulation in rats," Gastroenterology, vol. 93, pp. 550-557, 1987.

[67] R. A.Tracz, D. R. Wyman, P. B. Little, R. A. Towner, W. A. Steward, S. W. Schatz, P. W. Pennock, and B. C. Wilson, "Magnetic resonance imaging of interstitial laser photocoagulation in brain," Lasers in Surgery and Medicine, vol. 12, pp. 165-173, 1992.

[68] R. D. Peters, E. Chan, J. Trachtenberg, S. Jothy, L. Kapusta, W. Kucharczyk, and R. M. Henkelman, "Magnetic resonance thermometry for predicting thermal damage: An application of interstitial laser coagulation in an in vivo canine prostate model.," Magnetic Resonance in Medicine, vol. 44, pp.873-883, 2000.

[69] M. D. Sherar, J. A. Moriarty, M. C. Kolios, J. C. Chen, R. D. Peters, L. C. Ang, R. S. Hinks, R. M. Henkelman, M. J. Bronskill, and W. Kucharcyk, "Comparison of thermal damage calculated using magnetic resonance thermometry, with magnetic resonance imaging post-treatment and histology, after interstitial microwave thermal therapy of rabbit brain." Physics in Medicine and Biology, vol. 45, pp. 3563-3576, 2000.

[70] T. J. Vogl, M. G. Mack, P. Mueller, R. Straub, K. Eichler, F. Scheib, K. Engelmam, and R. Felix, "Percutaneous laser-induced thermotherapy of malignant liver tumors," Seminars in Interventional Radiology, vol. 16, pp. 3-12, 1999.

[71] D. E. Malone, L. Lesiuk, A. P. Brady, D. R. Wyman, and B. C. Wilson, "Hepatic Interstitial Laser Photocoagulation - Demonstration and Possible Clinical Importance of Intravascular Gas," Radiology, vol. 193, pp. 233-237, Oct 1994.

[72] D. E. Malone, D. R. Wyman, F. G. DeNardi, F. P. McGrath, C. J. DeGara, and B. C. Wilson, "Hepatic interstitial laser photocoagulation. An investigation of the relationship 
between acute thermal lesions and their sonographic images." Investigative Radiology, vol. 29 , pp. 915-921, 1994.

[73] R. van Hillegersberg, M. T. de Witte, W. J. Kort, and O. T. Terpstra, "Water-Jet-Cooled Nd:YAG Laser Coagulation of Experimental Liver Metastases: Correlation Between Ultrasonography and Histology," Lasers in Surgery and Medicine, vol. 13, pp. 332-343, 1993.

[74] D. R. Wyman, C. L. Swift, R. A. Siwek, and B. C. Wilson, "A Control Method for a Nonlinear Multivariable System - Application to Interstitial Laser Hyperthermia," leee Transactions on Biomedical Engineering, vol. 38, pp. 891-898, Sep 1991.

[75] D. R. Wyman, B. C. Wilson, and K. Adams, "Dependence of laser photocoagulation on interstitial delivery parameters," Lasers in Surgery and Medicine, vol. 14, pp. 59-64, 1994.

[76] K. Ivarsson, J. Olsrud, C. Sturesson, P. H. Moller, B. R. Persson, and K. G. Tranberg, "Feedback interstitial diode laser $(805 \mathrm{~nm})$ thermotherapy system: Ex vivo evaluation and mathematical modeling with one and four-fibers," Lasers in Surgery and Medicine, vol. 22, pp. 86-96, 1998.

[77] L. C. L. Chin, W. M. Whelan, M. D. Sherar, and I. A. Vitkin, "Changes in relative light fluence measured during laser heating: implications for optical monitoring and modelling of interstitial laser photocoagulation," Physics in Medicine and Biology, vol. 46, pp. 2407-2420, Sep 2001.

[78] L. C. L. Chin, W. M. Whelan, and I. A. Vitkin, "Models and measurements of light intensity changes during laser interstitial thermal therapy: implications for optical monitoring of the coagulation boundary location," Physics in Medicine and Biology, vol. 48, pp. 543-559, Feb 2003.

[79] W. M. Whelan, P. Chun, L. C. L. Chin, M. D. Sherar, and I. A. Vitkin, "Laser thermal therapy: utility of interstitial fluence monitoring for locating optical sensors, "Physics in Medicine and Biology, vol. 46, pp. N91-N96, Apr 2001.

[80] L. C. L. Chin, W. M. Whelan, and I. A. Vitkin, "Perturbative diffusion theory formalism for interpreting temporal light intensity changes during laser interstitial thermal therapy," Physics in Medicine and Biology, vol. 52, pp. 1659-1674, 2007. 
[81] K. Matthewson, H. Barr, C. Tralau, and S. G. Bown, "Low power interstitial Nd:YAG laser photocoagulation: studies in a transplantable fibrosarcoma." British Journal of Surgery, vol. 76, pp. 378-381, 1989.

[82] T. J. Vogl, R. Straub, K. Eichler, D. Woitaschek, and M. G. Mack, "Malignant liver tumors treated with MR imaging-guided laser-induced thermotherapy: Experience with complications in 899 patients (2,520 lesions), Radiology, vol. 225, pp. 367-377, Nov 2002.

[83] Z. Amin, S. G. Bown, and W. R. Lees, "Local Treatment of Colorectal Liver Metastases a Comparison of Interstitial Laser Photocoagulation (Ilp) and Percutaneous Alcohol Injection (Pai)," Clinical Radiology, vol. 48, pp. 166-171, Sep 1993.

[84] J. Hahl, R. Haapiainen, J. Ovaska, P. Puolakkainen, and T. Schoder, "Laser-induced hyperthermia in the treatment of liver tumours, "Lasers in Surgery and Medicine, vol. 10, pp. 319-321, 1990.

[85] C. M. Pacella, D. Valle, G. Bizzarri, S. Pacella, M. Brunetti, R. Maritati, J. Osbom, and R. Stasi, "Percutaneous laser ablation in patients with isolated unresectable liver metastases from colorectal cancer: Results of a phase II study," Acta Oncologica, vol. 45, pp. 77-83, Feb 2006.

[86] S. A. Harries, Z. Amin, M. E. F. Smith, W. R. Lees, J. Cooke, M. G. Cook, J. H. Schurr, M. W. Kissin, and S. G. Bown, "Interstitial laser photocoagulation as a treatment for breast cancer," British Joumal of Surgery, vol. 81, pp. 1617-1619, 1994.

[87] H. Mumtaz, M. A. HallCraggs, A. Wotherspoon, M. Paley, G. Buonaccorsi, Z. Amin, I. Wilkinson, M. W. Kissin, 1. Davidson, I. Taylor, and S. G. Bown, "Laser therapy for breast cancer: MR imaging and histopathologic correlation," Radiology, vol. 200, pp. $651 \% 658,1996$.

[88] C. Bremer, T. Allkemper, J. Menzel, U. Sulkowski, E. Rummeny, and P. Reimer, "Preliminary clinical experience with laser-induced interstitial thermotherapy in patients with hepatocellular carcinoma," Journal of Magnetic Resonance Imaging, vol. 8, pp. 235$239,1998$.

[89] H. Dossing, F. N. Bennedbaek, and L. Hegedus, "Beneficial effect of combined aspiration and interstitial laser therapy in patients with benign cystic thyroid nodules: a pilot study," British Joumal of Radiology, vol. 79, pp. 943-947, Dec 2006. 
[90] M. Landthaler and U. Hohenleutner, "Laser therapy of vascular lesions," Photodermatol Photoimmunol Photomed, vol. 22, pp. 324-332, 2006.

[91] R. P. Meijer, T. A. Boon, G. van Venrooij, and C. J. Wijburg, "Long-term follow-up after laser therapy for penile carcinoma," Urology, vol. 69, pp. 759-762, Apr 2007.

[92] M. B. Paiva, J. A. Sercarz, A. J. Pantuck, M. Polyakov, R. A. Figlin, R. F. Canalis, and D. J. Castro, "Combined cytoreductive laser therapy and immunotherapy for palliation of metastatic renal cell carcinoma to the head and neck," Lasers in Medical Science, vol. 22 , pp. 60-63, Mar 2007.

[93] H. Yamaguchi, M. Ueda, M. Kanemura, S. Izuma, K. Nishiyama, Y. Tanaka, and S. Noda, "Clinical efficacy of conservative laser therapy for early-stage cervical cancer," International Journal of Gynecological Cancer, vol. 17, pp. 455-459, Mar-Apr 2007.

[94] A. H. Chung, F. A. Jolesz, and K. Hynynen, "Thermal dosimetry of a focused ultrasound beam in vivo by magnetic resonance imaging.," Medical Physics, vol. 26, pp. 2017-2026, 1999.

[95] "COHERENT Laser Division. Operator's Manual, Verdi (TM) V-5 Diode-Pumped Laser. Coherent Inc (C)," 2002.

[96] "Titanium-Saphire 3900S brochure, Spectra-Physics Lasers Inc.," 2003.

[97] D. E. Battey, J. B. Slater, R. Wludyka, H. Owen, D. M. Pallister, and M. D. Morris, "Axial Transmissive F/1.8 Imaging Raman Spectrograph with Volume-Phase Holographic Filter and Grating," Applied Spectroscopy, vol. 47, pp. 1913-1919, Nov 1993.

[98] M. G. Shim, "Analysis of Biological Tissue with Ex Vivo and In Vivo Raman Spectroscopy," in Graduate Department of Medical Biophysics. vol. MSc Toronto: University of Toronto, 1996.

[99] G.F. Knoll, Radiation Detection and Measurement, 3rd ed. New Jersey: John Wiley \& Sons Inc., 2000.

[100] S. T. Wollman and P. W. Bohn, "Evaluation of Polynomial Fitting Functions for Use with CCD Arrays in Raman Spectroscopy," Applied Spectroscopy, vol. 47, p. 125, 1993.

[101] I. R. Lewis and H. G. M. Edwards, Handbook of Raman Spectroscopy: From the Research Laboratory to the Process Line. New York, NY: Marcel Dekker Inc., 2001. 
[102] J. Zhao and R. L. McCreery, "Multichannel FT-Raman Spectroscopy: Noise Analysis and Performance Assessment," Applied Spectroscopy, vol. 51, pp. 1687-1697, 1997.

[103] M. Gao, G. Lewis, G. M. Turner, A. Soubret, and V. Ntziachristos, "Effects of background fluorescence in fluorescence molecular tomography," Applied Optics, vol. 44, p. $5468,2005$.

[104] J. F. Brennan, Y. Wang, R. R. Dasari, and M. S. F. II, "Near Infrared Spectrometer Systems for Human Tissue Studies," Applied Spectroscopy, vol. 51, p. 201, 1997.

[105] Z. Huang, A. McWilliams, H. Lui, D. I. McLean, S. Lam, and H. Zeng, "Near-Infrared Raman Spectroscopy for the Optical Diagnosis of Lung Cancers," International Journal of Cancer, vol. 107, p. 1047, 2003.

[106] T.J. Vickers, R. E. Wambles, and C. K. Mann, "Curve fitting and linearity: data processing in Raman spectroscopy," Applied Spectroscopy, vol. 55, p. 389, 2001.

[107] K. W. Short, S. Carpenter, J. P. Freyer, and J. R. Mourant, "Raman Spectroscopy Detects Biochemical Changes Due to Proliferation in Mammalian Cell Cultures," Biophysical Journal, vol. 88, p. 4274, 2005.

[108] C. A. Lieber and A. Mahadevan-Jansen, "Automated Method for Subtraction of Fluorescence from Biological Raman Spectra," Applied Spectroscopy, vol. 57, p. 1363, 2003.

[109] A. Cao, A. K. Pandya, G. K. Serhatkulu, R. E. Weber, H. Dai, J. S. Thakur, V. M. Naik, R. Naik, G. W. Auner, R. Rabah, and D. C. Freeman, "A robust method for automated background subtraction of tissue fluorescence," Journal of Raman Spectroscopy, vol. 38, p. 1199, Sep 2007.

[110] J. D. Pasteris, J. J. Freeman, S. K. Goffredi, and K. R. Buck, "Raman spectroscopic and laser scanning confocal microscopic analysis of sulfur in living sulfur-precipitating marine bacteria," Chemical Geology, vol. 180, pp. 3-18, Oct 2001.

[111 R. L. McCreery, "McCreery Research Group. Raman Shift Frequency Standards," 2007.

[112] M. N. Iizuka, M. D. Sherar, and I. A. Vitkin, "Optical Phantom Materials for Near Infrared Laser Photocoagulation Studies," Lasers in Surgery and Medicine, vol. 25, pp. $159-169,1999$.

[113] J. J. Harris, R. K. Miller, J. W. Savell, H. R. Cross, and L. J. Ringer, "Evaluation of the Tenderness of Beef Top Sirloin Steaks," Journal of Food Science, vol. 57, pp. 6-\&, 1992. 
[114] M. Rodrigues, R. Weersink, and W. Whelan, "Raman Spectroscopy: Potential for Detecting Tissue Coagulation During Laser Therapy," Proceedings of the OSA (in press), 2008.

[115] M. H. Yip and M. Carvalho, "A Monte-Carlo maplet for the study of the optical properties of biological tissues," Computer Physics Communications, vol. 177, pp.965975, 2007.

[116] L. H. Wang, S. L. Jacques, and L. Q. Zheng, "Mcml - Monte-Carlo Modeling of Light Transport in Multilayered Tissues," Computer Methods and Programs in Biomedicine, vol. 47, pp. 131-146, 1995.

[117] R. F. Castelino, W. M. Whelan, and M. C. Kolios, "Photoacoustic Detection of Tissue Coagulation in Albumen-Based Phantoms," SPIE, In Press, 2008.

[118] W. C. Lin, C. Buttemere, and A. Mahadevan-Jansen, "Effect of thermal damage on the in vitro optical and fluorescence characteristics of liver tissue's," leee Journal of Selected Topics in Quantum Electronics, vol. 9, pp. 162-170, 2003.

[119] D. J. Parekh, L. W. Chiang, and S. D. Herrell, "In vivo assessment of radio frequency induced thermal damage of kidney using optical spectroscopy," Journal of Urology, vol. 176, pp. 1626-1630, 2006.

[120] R. Agah, A. H. Gandjbakhche, M. Motamedi, R. Nossal, and R. F. Bonner, "Dynamics of temperature dependent optical properties of tissue: Dependence on thermally induced alteration," Ieee Transactions on Biomedical Engineering, vol. 43, pp. 839-846, 1996.

[121] S. Thomsen, S. Jacques, and S. Flock, "Microscopic Correlates of Macroscopic Optical Property Changes During Thermal Coagulation of Myocardium," Proceedings of LaserTissue Interaction, vol. 1202, pp. 2-11, 1990.

[122] G. J. Derbyshire, D. K. Bogen, and M. Unger, "Thermally Induced Optical Property Changes in Myocardium at 1.06 Mu-M," Lasers in Surgery and Medicine, vol. 10, pp. 28-34, 1990.

[123] J. C. Cuq and J. C. Cheftel, "Tryptophan Degradation During Heat-Treatments .1. the Degradation of Free-Tryptophan," Food Chemistry, vol. 12, pp. 1-14, 1983.

[124] J. C. Cuq, M. Vie, and J. C. Cheftel, "Tryptophan Degradation During Heat-Treatments .2. Degradation of Protein-Bound Tryptophan," Food Chemistry, vol. 12, pp. 73-88, 1983. 
[125] W. C. Lin, C. Buttemere, and A. Mahadevan-Jansen, "Effect of thermal damage on the in vitro optical and fuorescence characteristics of liver tissues, "Ieee Journal of Selected Topics in Quantum Electronics, vol. 9, pp. 162-170, 2003. 